Portland State University

PDXScholar

Fall 11-14-2016

\title{
The Efficacy and Feasibility of a Context-Specific Autism Behavior Rating Tool with Real Time Data Collection Methods from the Perspectives of Clinicians, Educators, and Parents
}

Kathleen Marie Panaccione

Portland State University

Follow this and additional works at: https://pdxscholar.library.pdx.edu/open_access_etds

Part of the Special Education and Teaching Commons

Let us know how access to this document benefits you.

\section{Recommended Citation}

Panaccione, Kathleen Marie, "The Efficacy and Feasibility of a Context-Specific Autism Behavior Rating Tool with Real Time Data Collection Methods from the Perspectives of Clinicians, Educators, and Parents" (2016). Dissertations and Theses. Paper 3293.

https://doi.org/10.15760/etd.3284

This Dissertation is brought to you for free and open access. It has been accepted for inclusion in Dissertations and Theses by an authorized administrator of PDXScholar. Please contact us if we can make this document more accessible: pdxscholar@pdx.edu. 
The Efficacy and Feasibility of a Context-Specific Autism Behavior Rating Tool with Real Time Data Collection Methods from the Perspectives of

Clinicians, Educators, and Parents

by

Kathleen Marie Panaccione

A dissertation submitted in partial fulfillment of the requirements for the degree of

Doctor of Education

in

Educational Leadership: Special and Counselor Education

\author{
Dissertation Committee: \\ Micki M. Caskey, Chair \\ Dannelle D. Stevens \\ Ann Fullerton \\ Amy Donaldson
}

Portland State University

2016 
(C) 2016 Kathleen Marie Panaccione 


\begin{abstract}
The incidence of autism has increased tremendously over the past 20 years; however, the tools used for diagnosis and educational identification have largely remained the same. Diagnostic and educational decisions are based on observations and interactions to identify hallmark skill deficits associated with autism. Research demonstrates behaviors are affected by the environment, and real-time data collection is more accurate than reflective methods.

The problem is current autism diagnostic and educational identification tools lack essential features. The Autism Diagnostic Observation Schedule (ADOS), considered the gold standard, relies on contrived settings, and lacks an observational comparison to same aged peers. Autism behavior rating scales, rely on reflective data collection, and are not context specific.
\end{abstract}

The purpose of this study was to gain feedback from stakeholders (clinicians, educators, parents) about the perceived efficacy and feasibility of a context-specific autism behavior rating tool with real time data collection methods for diagnosis and educational planning. Results showed stakeholders confirmed the perceived efficacy of the context-specific tool for improved accuracy for diagnosis, more specific information for educational planning, and increased understanding for parents to support their child's learning needs.

Even though the tool was useful, stakeholder feedback also indicated the tool lacked feasibility for teacher use and may be better suited for administration by school psychologists or other trained professionals. The increased specificity and accuracy 
provided by a context-specific autism behavior rating tool has the potential to affect the future of autism evaluations and educational planning; thereby influencing the future life function of individuals with autism. 


\section{Dedication}

I dedicate this work to the men in my life, Ed, Joe, and Ryan. My desire to love you and make you proud exceeds all. I am grateful for your support and encouragement. 


\section{Acknowledgements}

I would like to express my appreciation and gratitude to my advisors, Micki

Caskey and Dannelle Stevens. Their knowledgeable guidance, patient support, and gentle manner offered me exactly what I needed to accomplish this goal. 
Table of Contents




Appendix H Real Time Data Collection Sheet ..................151

Appendix I Clinician Survey ...................................156

Appendix J Educator Survey ................................ 158

Appendix K Parent Survey .................................. 160 


\section{List of Tables}

Table 1 Contact and Responses by Stakeholder Groups......................... 72

Table 2 Clinicians Reported Use of Autism Behavior Rating Scales................ 73

Table 3 Educators Reported Use of Autism Behavior Rating Tools.................81 


\section{List of Figures}

Figure 1 Bandura's (1971) social cognitive theory of learning................... 24

Figure 2 Vested stakeholders' interest for autism evaluations................... 27

Figure 3 Clinician rating of their likelihood to use a context-specific autism behavior rating tool............................................. 74

Figure 4 Educator rating of the feasibility of the example context-specific autism behavior rating tool................................... 82

Figure 5 Themes identified from stakeholder feedback about a context-specific autism evaluation tool........................................... 92 


\section{Chapter One}

Brian was a handsome 13-year-old boy who was big for his age. He was obsessed with watching YouTube videos of baby porcupines; he liked watching the animals so much that when his parents or teachers tried to engage him in something else he hit them. His aggressiveness was not as much of a problem when he was smaller because he could be held tightly until he calmed down. At 13, he was too big to restrain.

His parents sat impassively in my office looking exhausted. Brian's father said, “The school won't teach him, and the tutor won't come to the house anymore because they're afraid of him. Frankly, so is his mother. He started to hit her too. I can't be home all the time." Brian was banging on the door crying, "I have my shoes on!" His mother said, "That is what he says when he is ready to go. He's saying that because he wants to go home." His father said, "This is hard, but the truth is we are at our wit's end and need help." Brian was being admitted to the hospital for safety reasons.

Tom was in seventh grade. He always had on big red earphones; he did not like loud noises. When other children tried to talk to him, he echoed back what they said. Sometimes he would recite a line from a movie. His accuracy was uncanny. Everyone laughed. He liked to make people laugh. Tom's mother said he wore the earphones since he was 2 years old. Since then she did not have any pictures of him without the red earphones on. He had been in school with the same children since kindergarten; yet they did not call him by his name. He was known as, "The kid with the red earphones."

Billy was in third grade when I met him. He was very bright and loved to talk about vacuum cleaners. He knew more about vacuum cleaners than the sales clerks at 
Sears. He had a notebook in which he kept pictures of Electrolux and Hoovers and wrote down the details of horsepower and cleaning features. He never failed to make adults smile. Billy could complete academic work without difficulty; however, he did not have any friends and argued with his classmates. He got very upset and refused to cooperate if the classroom routine changed in any way. His parents were worried because he just could not seem to get along with children his own age.

In my role as an autism specialist, I had the pleasure of working with Brian, Tom and Billy, as well as their families, teachers, and physicians. All of the boys had a diagnosis of autism spectrum disorder (ASD, autism). According to the Diagnostic and Statistical Manual of Mental Disorders (5 ${ }^{\text {th }}$ ed., DSM-5), the hallmark skill deficits associated with autism are: deficits in social-emotional reciprocity, deficits in non-verbal communicative behaviors used for social interaction, and deficits in developing, maintaining, and understanding relationships (American Psychiatric Association, [APA] 2013). Typically, children with autism have co-morbid disorders that further impact their ability to function in life (Simonoff et al., 2008).

In the past children like Brian, Tom, and Billy may have been locked in a psychiatric hospital for life. Because of the considerable body of research conducted since the days of institutionalization (Wolff, 2004), people's understanding about the treatment of the disorder has greatly improved (Stahmer, Schreibman, \& Cunningham, 2011). The methods and techniques used to identify and diagnose autism have likewise been a part of the progress in the field. 
Evaluating children for autism is not an exact science. Autism cannot be diagnosed through a medical test like a blood test or genetic testing. Instead, autism is determined by observations and behavioral data collected across time and environments. Parents and knowledgeable practitioners from a variety of disciplines contribute to the information collected for diagnosis (Autism Society of America, 2013; Landa, 2008; Volkmar et al., 2014).

One of the tools practitioners use for evaluating children to determine if they have autism are questionnaires generically called, autism behavior rating scales. Parents, caregivers, and educators fill out behavior rating scales to identify hallmark skill deficits associated with the disorder. Behavior rating scales can be used in both medical and educational settings for diagnosis as well as identifying the specific learning needs of a child requiring special education services (Rehabilitation Act, 1973).

After evaluating children for special education needs, teachers use the evaluative data to develop goals and objectives that direct instruction. Special education is individualized for a specific child's level of functioning. Autism behavior rating scales are intended to provide information about the child's current levels of functioning. The scales identify areas of need for remedial instruction.

However, problems exist with current behavior rating scales for teachers. Current scales do not describe behaviors typically seen in a school setting, nor do they collect data that offers present levels of performance. The possible consequence of these shortcomings is misdiagnosis, inappropriate educational programming, and a negative impact on future life function of individuals with autism. 
I turn my attention to the background of the problem from the historical and social perspectives to understand the importance of context-specific autism rating scales. Background information will assist in understanding how the current tools were developed and the impact they have on society.

\section{Background of the Problem}

To understand the impact of a new context-specific autism rating tool, I turn my attention to the background of the problem from the historical and social perspectives. I discuss the difference between a diagnosis of autism and an educational identification of autism. I also highlight the importance of accurate evaluative tools for diagnosis and educational identification. Last, I discuss the educational and economic impact of increasing rates of autism in the United States.

The history of autism evaluations helps people to understand how current evaluative techniques evolved. In the early 1940s, Leo Kanner (1943) was the first practitioner to recognize that the unusual set of behaviors represented a distinct condition, which he named autistic. Kanner had an extensive career studying autism and was the first physician to be certified by the American Psychiatric Association as a Pediatric Psychiatrist. He also served as the editor of the Journal of Autism and Developmental Disorders (Ganzler, 2014). In 1966, Rimland (1971) was the first to develop an autism evaluation to include a teacher questionnaire. In 1980, the American Psychiatric Association (APA) added autism to the Diagnostic and Statistical Manual of Mental Disorders (DSM). Since those early years, the diagnostic criteria of autism have changed many times. 
As the diagnostic criteria changed, evaluative methods were adapted to meet the new criteria. Autism evaluations were developed, standardized, and normed for use in the clinical and educational settings. Many evaluation tools include a questionnaire designed for parents and teachers that document skill deficits associated with the disorder (e.g., joint attention, theory of mind, stereotyped behaviors, executive functioning, and sensory issues). Current research demonstrates identifying skill deficits in a variety of settings to be the most accurate method of diagnosing individuals with autism spectrum disorder (Filipek et al., 2005; Volkmar, Cook, Pomeroy, Realmuto, \& Tanguay, 2014).

The Child Neurology Society and American Academy of Neurology (Volkmar et al., 1999) and 25 related organizations and institutions formed a panel to review more than 2,000 articles to develop specific practice parameters for evaluating individuals for ASD. The practice parameters of the original panel were recently updated with many of the same recommendations, including screening all children for developmental disorders. The panel recommends that full evaluations should be conducted with children whose screening elicit concerns among evaluators.

The panel recommended evaluations be conducted by a multi-disciplinary team including, clinicians, speech and language pathologists, educators, parents, and related service providers. Each member of the multi-disciplinary team targets evaluation based on areas of expertise. Physicians and licensed clinicians document medical history, developmental delays from birth, and ultimately diagnosis. Speech and language pathologists contribute expertise toward functional communication, expressive and receptive language skills, and pragmatics. Occupational therapists identify motoric and 
sensory difficulties. Educators evaluate for educational impact on learning related to skill deficits, and gather information on present levels of performance for educational planning and interventions. Parents evaluate their child's social skills in home and community settings and report on independence levels of self-care. The team considers the information collected from all the disciplines for a diagnosis and or an educational identification (Action, 1999; Prelock, Beatson, Bitner, Broder, \& Ducker, 2003).

A number of autism evaluation tools have substantiated psychometric properties. The gold standard for clinical settings is the Autism Diagnostic Observation Schedule $\left(2^{\text {nd }}\right.$ ed., ADOS-2) (Lord et al., 2012). The ADOS-2 is a structured and semi-structured set of questions and tasks designed to elicit expected responses. It is normed for people ages 15 months to 40 years, and it is reported to have high reliability, validity, and sensitivity (Lord et al., 2012). Drawbacks to using the ADOS-2 are the cost, time, and specialized training required to administer (Sikora, Hall, Hartley, Gerrard-Morris, \& Cagle, 2008). Lack of funding for both the materials and the training of the ADOS leads many clinicians and school districts to rely on autism behavior rating scales for the diagnosis and identification of ASD (Charman \& Gotham, 2013; Karim, Cook, \& O'Reilly, 2014; Matson, Rieske, \& Tureck, 2011).

The ADOS-2 differs from behavior rating scales by creating a contrived setting to collect data from observed behaviors. Behavior rating scales collect data based on reflection of behaviors observed within a specified time period. Some of the most widely used rating scales or questionnaires include the Childhood Autism Rating Scale $\left(2^{\text {nd }}\right.$ ed., Schopler, Van Bourgondien, Wellman, \& Love, 2010), Autism Spectrum Rating 
Scales (Goldstein \& Naglieri, 2009), Gilliam Autism Rating Scale (2 ${ }^{\text {nd }}$ ed., Gilliam, 2006), and the Autism Screening Instrument for Educational Planning ( $3^{\text {nd }}$ ed., Krug, Arick, \& Almond, 2008).

Neither the ADOS-2 nor any of the behavior rating tools are context-specific. The ADOS- 2 creates the context in a contrived setting. Behavior rating tools ask the same questions about a child's behaviors regardless of whether the behavior is in the home, community, or school setting; and they rely on reflective data collection methods.

For example, a question on the Autism Spectrum Rating Scales (ASRS) (Goldstein \& Naglieri, 2009) asked, "Does the child resist being touched or held?" The Gilliam Autism Rating Scale, (2 ${ }^{\text {nd }}$ ed., Gilliam, 2006), queried, "Is the child unaffectionate; does not give affectionate responses (e.g., hugs and kisses)?” While a parent may have insight into how a child responds to hugs and kisses, teachers are not as likely to observe a child's response to that particular behavior. In addition, the questions do not inform the evaluator that the skills being assessed are social and/or sensory deficits.

In a similar example from the Childhood Autism Rating Scale ( ${ }^{\text {nd }}$ ed.), Schopler et al. (2010) evaluated whether "The child shows the appropriate type and degree of emotional response, as indicated by a change in facial expression, posture, and manner." While the descriptor may apply to many settings, it does not offer a measure of present level of performance, or the skill needed as emotional regulation and social communication. A more descriptive example of an appropriate emotional response in the context of a classroom would be more helpful for teachers to understand how to respond. 
An important factor to consider when evaluating children for ASD is that behaviors can be dependent on characteristics of the environment (Ozonoff, GoodlinJones, \& Soloman, 2005). The DSM-5 (APA, 2013) diagnostic criteria for ASD require skill deficits to be present in multiple contexts for diagnosis. ASD may present differently in a home versus a school due to many factors. A child's functioning may be higher with the routine of school. Perhaps a child functions better at home because of fewer demands placed on him or her and familiarity with the setting. A child has different social expectations in a classroom than when gathered around a family dinner table.

Bronfenbrenner and Evans (2000) discussed the influence of the environment on behaviors as a proximal process. A proximal process is the interaction between the person and the immediate environment. Measuring behaviors that are not typical for the environment would yield data of questionable value. For accuracy and control, scientists should not make the mistake of integrating behavioral data across situations and environments.

Research that compares the accuracy of teacher-administered autism rating scales with parent scales has shown discrepancies that cannot be attributed to environmental differences (Reed \& Osborne, 2013). However, Reed and Osborne (2013) made an important point, "It must be remembered that teachers are observing the children in relation to other children, whereas, the parents may often be focusing on that child and the ASD only" (p. 475). While research exists to support the overall evaluation methods for autism (Fombonne, 2005; Shattuck, 2006), few studies have examined the accuracy 
and efficacy of current teacher-administered autism behavior rating scales (Matson et al., 2009; Reed \& Osborne, 2013).

Current autism rating scales ask teachers to reflect on how often the behaviors occur. Rather than collecting data in real time, educators are asked to think over the past months and record the approximate frequency or severity of behaviors. Reflective data collection methods are less accurate than real time data collection methods (Maxwell, 2012; Whittemore, Chase, \& Mandle, 2001).

Additionally, educators do not receive adequate training specifically for autism spectrum characteristics (Barnhill, Pollway, \& Sumutka, 2011). General education teachers have little understanding of the disorder (National Research Council, 2001); yet, they are tasked with evaluating students for very specific skill deficits that often present very subtly. Giving teachers rating scales that describe behaviors that are likely to be seen in a classroom will broaden their understanding of the disorder and how the skill deficits of ASD present in a learning environment.

The U.S. Government Accountability Offices' 2005 report highlighted the educational and economic impact of autism. The report stated, "Children identified with autism and receiving special education services increased $500 \%$ over the course of a decade" (p. 2). As a demonstration of the commitment to the issue, the U.S. Federal Government alone spent over 1.4 billion dollars for autism research and other autism related activities between the years of 2008 and 2012 (U.S. Government Accountability Office, 2014). Lavelle et al. (2014) estimated the cost of autism to society for the year 2011 alone at over \$11.5 billion. 
The sheer numbers of individuals diagnosed with the disorder is staggering. The educational, economic, and emotional impact of autism spectrum disorder affects us all. Clinicians and educators cannot continue to work with outdated and ineffective evaluative techniques for children suspected of having autism. Learning institutions need to meet the educational needs of these students. Accuracy in diagnosis and educational identification of autism is a way to address those needs.

Next, I turn my attention to defining the problem of inaccurate behavior descriptors and frame the issue within the theoretical constructs of behaviorism and social cognitive theory. With these two theoretical lenses, I consider the potential impact of using inaccurate behavior rating scales. 


\section{Statement of the Research Problem}

The problem is that current autism behavior rating scales for teachers are not context-specific. Teacher rating scales do not have accurate behavior descriptors based on an educational environment, nor do they offer accurate real time data collection for present level of functioning. The possible result of inaccurate behavior descriptors and reflective data collection is misdiagnosis, over- or under-diagnosis, inappropriate educational programming, and a negative impact on the future life function of individuals with autism.

The purpose of this study was to determine the efficacy and feasibility of a context-specific autism behavior rating tool with real time data collection methods for an educational environment from the perspectives of three major stakeholders: clinicians, educators, and parents. Reviewing the literature assisted in determining the salient features for stakeholders. By understanding the features most important to each, an example tool was developed to better identify the learning needs of children with autism. It was my goal to discover if the example of a context-specific tool could: (a) be useful enough to meet the diagnostic needs of clinicians; (b) be easy enough to administer to have feasibility for teachers; (c) contain instructional information needed for specific instruction; and (d) provide increased understanding for parents to aid in supporting their child's development.

The important data that can be gathered by teachers affects not only individuals with autism, but parents, clinicians, and educational teams making programming decisions for children identified with ASD. In the U.S., one in 68 children are identified 
as having autism (CDC, Center for Disease Control and Prevention, 2012). Society as a whole can benefit from addressing the needs of children with autism by ensuring they have been taught the skills needed for a full and functional life. Next, I outline the significance of the problem with current autism behavior rating scales in meeting the needs of these millions of individuals.

\section{Significance of the Research Problem}

In this section, I highlight the significance of a context-specific autism behavior rating tool for an educational environment. I look to the research to understand how current practice can be improved for clinicians, educators, and parents. I also address issues of equity for individuals affected by autism.

Improved teacher rating scales will offer clinicians increased information with which to base a medical diagnosis and will assist in differential diagnosis of often difficult to identify mental disorders. The medical community will have access to detailed observational data that represents the ways in which a child interacts with peers autonomously in a natural setting. The data gathered by teachers can offer insight that even the ADOS (i.e., Autism Diagnostic Schedule) cannot replicate. While the ADOS is considered the gold standard, it creates opportunity for behaviors instead of observing naturally occurring events. The ADOS attempts to replicate the data teachers have access to daily. Teachers have the advantage of observing students interacting with children of the same age, offering rich comparisons.

The more informed teachers are about autism, the more confident they will feel in meeting the needs of their students on the spectrum (Ingvarson, Meiers, \& Beavis, 2005). 
By offering an evaluation tool that describes the hallmark skill deficits of ASD in an educational environment, with clear and accurate measures of student performance, general education teachers will receive professional development while performing the duties of their job. The better informed teachers are about the skill deficits of their students, the better prepared they will be to support the unique instructional needs of students with autism.

Additionally, improved evaluation tools will allow a child's educational team to plan instruction and goals for the student's Individual Education Plan (IEP) with accurate data reflecting present levels of performance, and goals addressing appropriate skill deficits. Accurate educational programming and specific teaching will positively influence a child's skill set and future life function (Dawson \& Bernier, 2013).

Accurate school-based data can help parents have a better understanding of how their child learns and what skills need to be built upon. Parents can be better informed when making decisions that influence their child's educational outcomes. Parents can support their child's IEP goals if they fully understand the skill deficits associated with them. Parents can also gain insight into the ways their child's behaviors affect interactions with others.

Equity in education does not apply solely to race, ethnicity, or gender. Equity must also encompass those with special needs (Ainscow, Dyson, \& Weiner, 2013; Pazey \& Cole, 2013). We, members of society, need to work toward social justice for children with autism with as much dedication and rigor as we do for other communities that are marginalized. Understanding autism is the first step to rise above bias in education. 
Next, I briefly review the methods typically used for the autism evaluative process. I connect the research problem with the research purpose, and I outline the methods used to answer research questions about the efficacy and feasibility of a contextspecific tool.

\section{Presentation of Methods and Research Question}

In this section, I describe the methods used to answer questions relevant to the efficacy and feasibility of a context-specific autism behavior rating tool for an educational environment. I consider what questions might arise for parents, clinicians, and educators when considering a context-specific autism behavior rating tool. I position the stakeholders in the role of experts to determine what is most useful for them in understanding the child's learning profile.

For this study, I developed a brief example of a context-specific autism behavior rating tool and data collection method for an educational environment. After clinicians, teachers, and parents reviewed the example tool, they completed a survey which addressed the following research questions:

1. What did clinicians think about the efficacy and feasibility of a contextspecific autism behavior rating tool for assisting in diagnosis?

2. What did educators think about the efficacy and feasibility of a contextspecific autism behavior rating tool for educational planning?

3. What did parents think about the type of information gathered from a contextspecific autism behavior rating tool for understanding their child's learning needs? 
Pediatricians and educators are sometimes the first to notice when a child may not be developing in the same manner as their peers. New or inexperienced parents might not recognize their child is importantly different from others, or understand that their child has not reached key developmental milestones. The American Academy of Child and Adolescent Psychiatry recommended pediatricians screen every child for developmental delays (Volkmar et al., 2014). If delays are suspected, pediatricians refer parents to experienced clinicians for further assessment.

Because of their important role in assessment, I surveyed stakeholders who have a vested interest in the autism evaluative process to answer questions about a brief example of a context-specific autism behavior rating tool. I asked clinicians who diagnose mental disorders for feedback about the efficacy and feasibility of the tool for diagnosis and if they would find the information helpful in future practice.

I asked educators questions about the tool's ease of use and efficacy for educational identification and development of instructional goals. Last, I asked parents who have a child with a diagnosis, or eligibility for special education services under the identification of autism, if they feel a tool like the example would be helpful in understanding the IEP process and their child's learning needs.

I have worked for more than 10 years as a professional in the field of autism; I talked with experts in both clinical and educational practice. I also conducted an extensive literature review looking for a context-specific autism behavior rating tool. I did not find one. It was my hypothesis: stakeholders in the diagnostic and special education identification process for children with autism would affirm data collected 
from a context-specific autism behavior rating tool for an educational environment with real time data collection methods, would be useful and have feasibility for increase accuracy for diagnosis and educational programming decisions for children on the spectrum.

\section{Definitions of Key Concepts}

Autism spectrum disorder (autism, ASD, the spectrum). A developmental disorder characterized by deficits in social-emotional reciprocity, deficits in non-verbal communicative behaviors used for social interaction, and deficits in developing, maintaining, and understanding relationships; defined by the Diagnostic and Statistical Manual of Mental Disorders ( $5^{\text {th }}$ ed., APA, 2013).

Evaluation. A judgment applied against an agreed upon set of standards.

Autism behavior rating scale. One of the tools used in evaluating individuals for autism spectrum disorder. Parents, caregivers, and teachers' complete behavior-rating scales to contribute information toward a diagnosis or educational identification of ASD. I use behavior rating scale, autism rating scale, and teacher-rating scale interchangeably.

Context-specific autism behavior rating tool (context-specific tool, contextspecific behavior rating tool). A tool developed for this study to serve as an example for stakeholder feedback. The tool is designed to serve the same purpose as an autism behavior rating scale (diagnosis and educational planning), but attempts to increase accuracy by describing behaviors typical of a school setting.

Reflective data collection. Reflective data collection methods rely on the examiner to offer an opinion of the frequency of behaviors observed over a given time 
frame. Responses are typically on a severity scale. For example, over the past four weeks how often did the student have difficulty transitioning from one activity to the next? Never, seldom, occasionally, frequently, very frequently.

Real time data collection methods. Collecting observational data as the behaviors occur. Data collection sheets are part of the example context-specific behavior rating tool for this study. The data collection sheets offer an outline of observable behaviors with a frequency count.

Medical diagnosis of autism spectrum disorder. Diagnosis by a licensed clinician for an individual that meets the behavioral criteria for autism spectrum disorder as defined by the Diagnostic and Statistical Manual of Mental Disorders ( $5^{\text {th }}$ ed., APA, 2013)

Special education identification of autism spectrum disorder. The educational identification of a child needing educational intervention and individualized instruction under the category of autism spectrum disorder as defined by federal and state laws.

Efficacy and Feasibility. Efficacy refers to the helpfulness toward the purpose. The feasibility is the ease of use. While a context-specific tool may have efficacy in diagnosis and identification, it must also have feasibility for the teachers tasked with conducting the evaluation. 


\section{Chapter Two: Literature Review}

In the previous chapter, I discussed the importance of teacher-administered autism rating scales having accurate behavior descriptors for the environment and real time data collection methods. In this chapter, I report on an in-depth review of the literature. I identify the salient features of importance for vested stakeholders (clinicians, educators, parents) in the evaluative process.

The purpose of this study was to determine the efficacy and feasibility of a context-specific autism behavior rating tool for an educational environment from the perspectives of three major stakeholders: clinicians, educators, and parents. I treated the stakeholders as the experts in the evaluative process.

My hypothesis was that stakeholders in the diagnostic and special education identification process for children with autism would affirm data collected from a context-specific autism behavior rating tool with real time data collection methods, would be useful and have feasibility for increasing accuracy in diagnosis, educational identification, and educational programming for children on the spectrum.

Research regarding the importance of assessment for guiding instruction in education is plentiful. Research for scientifically based instruction methods for students with autism spectrum disorder (ASD) is abundant. Research as to the effectiveness of current autism evaluation tools in discriminating students with autism from typically developing children is also plentiful. As the field has expanded, independent researchers have examined the effectiveness of the current teacher rating scales as they relate to parent scales (Allen, Robbins \& Decker, 2008; Cunningham, 2012). However, from 
personal experience, conversation with experts in the field, and an extensive review of current research, information that considers the importance of context for autism behavior rating scales was missing. The list of recommended instruments for diagnostic evaluations did not include any evaluations that had unique parent and teacher questionnaires (National Professional Development Center on Autism Spectrum Disorder, 2011).

Without behavior descriptors tailored to educational environments, teachers can only guess about behaviors that might occur at home or in the community. Individual Education Plan (IEP) Teams are basing educational interventions and programming decisions on evaluative data that does not accurately identify skill deficits in the school setting. The importance of accurate data should not be minimized. The U.S. Government Code for Autism Education, Early Detection, and Intervention, (U.S.C. 280i-1, 2011) directs the use of valid and reliable tools to diagnose or rule out, and provide evidence based interventions:

To increase awareness, reduce barriers to screening and diagnosis, promote evidence-based interventions for individuals with autism spectrum disorder or other developmental disabilities, and train professionals to utilize valid and reliable screening tools to diagnose or rule out and provide evidencebased interventions for children with autism spectrum disorder and other developmental disabilities; and to conduct activities under this section with a focus on an interdisciplinary approach...(42 U.S.C. $280 \mathrm{i}-1)$

Special education teams look to evaluative data to determine if a student qualifies for individualized instruction under the identification of autism (Individuals with Disabilities Education Act, [IDEA], 2006). The evaluative data also offers information about a student's present levels of performance for the development of goals and 
objectives on the IEP. Current teacher-administered autism behavior rating scales offer information about the overall hallmark skill deficits associated with ASD, but they do not offer specific data for educational planning. Evaluative data that reflects how students interact with peers and receives instruction in a school setting is vital for determining educational interventions and required supports (Allen et al., 2008). To assist in understanding the problem, I present a review of the literature through lenses of behaviorism and social cognitive theory. Next, I review each theory and how it relates to the phenomena of autism evaluations.

\section{Theoretical Framework}

In this section, I examine the issue of context-specific teacher behavior rating tools from the perspectives of behaviorism and social cognitive theory. I explain how behavioral theory can frame the importance of accuracy in recording observational data in a naturalistic environment. Then, I describe how social cognitive theory can be used to demonstrate the impact of the environment, cognition, and observation on learning. Through these two theories, I demonstrate the importance of context for autism evaluations.

\section{Behaviorism}

Making data collection scientific and quantifiable is at the heart of assessments using a behavioral model (Skinner, 1953). Information that is gathered and quantified is what guides appropriate individualized instruction (Dunn, Airola, Lo, \& Garrison, 2013). At a conference on autism assessment given by renowned child and adolescent psychiatrist and pediatrician, Dr. L. Read Sulik (2013), dispensed what he called his best 
piece of advice, "If you are not sure about the size of something and there is a way to measure it; then measure it." In the case of a child with autism, behaviors need to be measured.

Behaviorism is the theoretical and philosophical framework that took the study of human behavior from the realm of subjective psychology into the realm of objective quantified science. John Watson (1924) expanded on earlier work by Thorndike to examine behaviors in a scientific way. Skinner (1945), also a behaviorist, noted, while one cannot look into the mind of a nonverbal child to determine why they behave the way they do, one can observe behaviors in an objective way. Skinner (1953) urged scientists to focus on objective observation to prevent distortions of data. Gathering data aids in our understanding of a child's skill deficits and gives accurate, relevant, information to direct educational programming.

When seeking accurate, unbiased data collection for the purpose of an evaluation, a behavioral approach offers the scientific methods for otherwise subjective interpretations of behaviors (Skinner, 1953). Bullock (1982) explained behaviorism as objectivism. He suggested observing behaviors in the environment because the environment has a significant influence on human behavior. Ozonoff, Goodlin-Jones, and Solomon (2005) supported Bullock in contending the environment influences behaviors associated with autism, thus influencing the data that directs instruction.

While behaviorism is a reasonable theory to frame the collection of data based on behaviors, it does not fully encompass how the environment influences behaviors and learning. Bronfenbrenner and Evans (2000) discussed the influence of the environment 
on behaviors as a proximal process. Proximal process is the interaction between the person and the immediate environment. Measuring behaviors that are not typical of the environment would eschew data. For accuracy and control, scientists should not make the mistake of integrating behavioral data across situations and environments.

Research demonstrating environmental effects on behavior support the need for accurate behavior descriptors on teacher-administered autism behavior rating scales (Belsky \& Hartman, 2014). It makes sense that behavior descriptors for a classroom would be different from those in a home or community setting. As evident from the earlier examples, current autism rating scales do not consider different environments when describing behaviors.

Behavioral implications. Behavioral theory applies to autism assessment in a very direct way. Teachers need to find a way to observe student behaviors in an objective rather than an emotional way. It is difficult to remove bias and report only on what observed. In my professional practice of coaching teachers to observe student behaviors, the most common mistake was insertion of intent. For example, a teacher reported the following: "The student looked up when his friend walked into the room and he was happy to see him." The observation implies the peer was a friend, and assumed an emotional state of happiness. Behavioral Theory clearly delineates between what observed and what is thought. A more accurate assessment of what the teacher observed might have been: "A peer entered the room and the student looked toward the peer and smiled while making eye contact." 
When using observation as an evaluative method, behaviorism is the best lens with which to frame the collection of data. Next, I reviewed the drawbacks to using a purely behavioral perspective to frame accurate behavior descriptors on teacheradministered autism behavior rating scales.

Critique of behaviorism. While behaviorism is an appropriate lens to view the process of collecting and analyzing observed behaviors, it does not fully explain how a child with ASD learns. Exploring educational programming and instructional practices with a purely behavioral perspective ignores the motivation that supports learning.

Behaviorists support learning as internally motivated, not externally motivated. Skinner (1945) contended learning occurs from positive and negative reinforcement. While reinforcement promotes learning, it does not fully explain why the behaviors were occurring in the first place. It is especially difficult to predict the internal motivation of a child with ASD as he or she often lacks the skills to verbalize their feelings or express their intentions.

Behaviorism does not address instructional practices in a way that is helpful to educators, parents, or the child's Individual Education Planning Team. To understand how to transform data into experiences that are meaningful motivation for learning, I explored social cognitive theory. Bandura's social cognitive theory (1971) illuminated motivation for learning has many influences.

\section{Social Cognitive Theory}

Social cognitive theory took shape with Dollard and Miller (1950) rejecting behavioral approaches that suggested learning is from internal drives alone. Bandura 
(1962) further expanded social cognitive theory when he considered learning occurring by observing others or viewing a model of the behaviors.

Social cognitive theory (Bandura, 1971) frames learning as occurring through continuous interaction of three factors. First, behavior is demonstrated or witnessed. Second, the environment influences behaviors. Last, personal factors such as cognition, affective, and biological events further influence learning (See Figure 1).

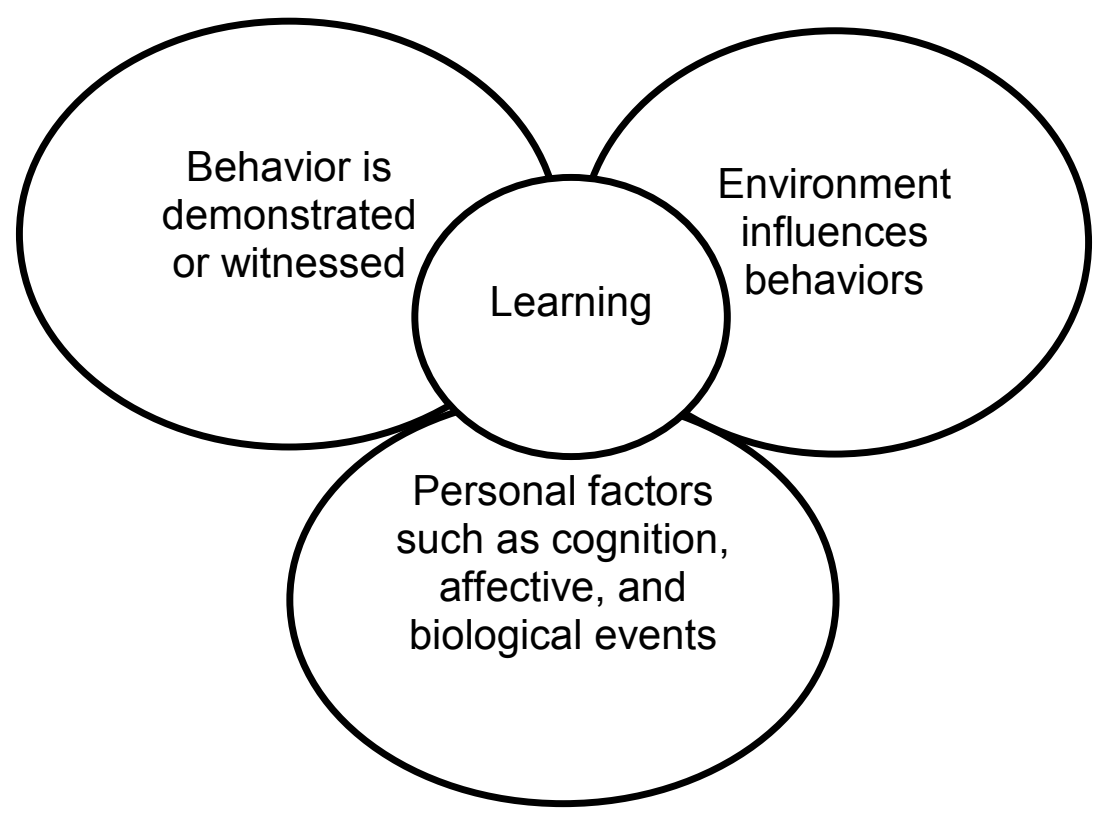

Figure 1. Bandura's (1971) social cognitive theory of learning

While social cognitive theory accounts for many of the influences that facilitate learning, how can it help a team of concerned individuals understand how a specific child learns? Viewing data through the lens of social cognitive theory can transform numbers into instructional practices that are effective for a child with ASD. For example, two methods of instruction that have proven efficacy for students with ASD are, peer 
modeling and video modeling. The techniques are effective for increasing skills through observation (Bellini \& Akullian, 2007; Charlop, Schreibman, \& Tryon, 1983).

Implications of social cognitive theory. Social cognitive theory can assist in understanding behavioral data as it relates to educational planning. Using behavioral observations identifies skills that are lacking. How behaviors present in differing environments helps the team to determine if a behavior is confined to a particular setting or travels across settings. For a diagnosis or educational identification of ASD behaviors must present across settings.

Student cognitive abilities and any health related issues should also be taken into account when identifying skill deficits. By viewing the issue of context-specific ASD behavior rating tools through the lens of social cognitive theory, stakeholders will be reminded of the many influences that may affect student learning that go beyond internal motivators. Next, I review the disadvantages to framing teacher-administered behavior rating scales for ASD solely through the lens of social cognitive theory.

Critique of social cognitive theory. No one educational learning theory offers all the insight needed to evaluate skills and develop educational programming for children with ASD. Only through accurate behavioral data collection in a child's learning environment and thoughtful consideration by the child's educational team can specific programming be developed.

While behaviorism lacks a full explanation of learning for children with ASD, social cognitive theory likewise does not offer a complete explanation of the evaluation itself. It is not enough to put a child with ASD in the environment and expect that they 
will learn from what is going on around them. One of the hallmark skill deficits of autism is social awareness; children with autism often need explicit instruction in social skills to improve functioning (APA, 2013).

Instruction for children with autism is often based on applied behavioral analysis. Applied behavior analysis, which the name implies, is based on behavioral learning theory. Applied behavior analysis has substantiated efficacy as a research-based method of instruction for children with autism. By positively reinforcing expected outcomes and behaviors, children with autism demonstrate increased occurrence of such outcomes (Leaf et al. 2016).

Combining specific teaching and reinforcement in a variety of environments employs both social cognitive theory and behavioral learning theory for students with autism. To exclude a learning theory without first considering the merits or drawbacks would be short sighted and could have a negative effect on a student's potential learning. Following Bandura's example of learning influenced by multiple factors, I review the literature from three perspectives to inform the practice of using teacher-administered behavior rating scales (see Figure 2). 


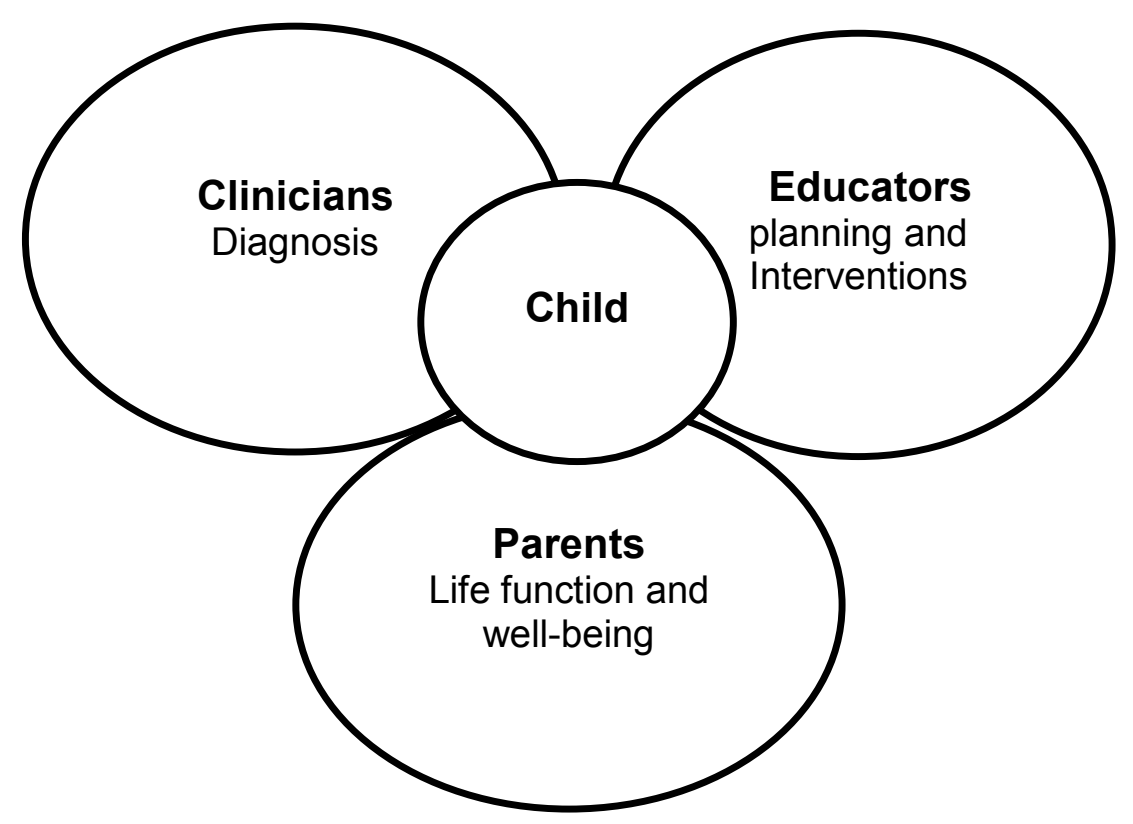

Figure 2. Vested stakeholders' interest for autism evaluations.

As stakeholders in the evaluative process, clinicians have an interest in diagnosis, educators have an interest in educational programming and interventions, and parents have an interest in the life function and well-being of a child with autism. In the next section, I report on my review the literature to describe the salient features of interest for each stakeholder group.

\section{Review of the Literature}

I looked to the literature for the importance of the accuracy of autism behavior rating scales from the perspectives of the three stakeholders (i.e., clinicians, educators, parents). It was my intention to gain an understanding of the impact evaluative data has on diagnosis and specific instructional practices.

In this section, I review the research for the importance of autism evaluations from a clinical or medical perspective to answers to the following questions: What are the 
recommendations for a comprehensive ASD evaluation? What are the most recent autism evaluation practice parameters? Last, what tools do clinicians use most commonly when making a diagnosis of autism?

Next, I explore research on teacher efficacy in understanding the hallmark skill deficits of students with autism. I look to the research to answer the following questions: What are the professional development and higher education opportunities regarding autism for general and special education teachers? This is important because general education teachers are often the ones who complete behavior rating scales for ASD. What does teacher efficacy toward ASD, and instructional practices for special and general education teachers reveal about instructional practices? In addition, how reasonable is it to assume an untrained teacher or one with insufficient understanding of autism can effectively assess a child's ASD concerns? Also, in what ways are IEP goals and objectives linked to autism evaluative data?

Finally, I examine the research regarding parent understanding of the autism evaluative process. What is parent understanding of how their child's learning differences make them unique from other children? What do parents understand about the how evaluative data connects to IEP goals and instruction? What are parent attitudes about the special education programming their child receives?

By examining the research literature from the three stakeholders' perspectives, I sought information about the effectiveness of current evaluative tools. By considering the stakeholders the experts, I identified shortcomings in the current evaluative tools. 
I also gained an understanding of autism evaluations from the vantage point of those most vested in the outcome. In the next section, I consider the medical perspective.

\section{Medical Perspective}

The purpose of my study was to determine the efficacy of a context-specific autism behavior rating tool for an educational environment from the perspectives of major stakeholders. It was my goal to determine if clinicians would find behavioral data specific to educational settings useful in making a medical diagnosis. In this section, I review the literature to determine the components of an autism diagnosis, as distinct from an educational identification that qualifies a child for special education services.

Components of a diagnosis. In the United States, clinicians make a diagnosis for autism spectrum disorder through a comprehensive examination using the criteria set forth in the DSM-5 (APA, 2013). A brief summary of the criteria includes persistent deficits in (a) social emotional reciprocity; (b) nonverbal communicative behaviors used for social interaction; and (c) developing, maintaining, and understand relationships . (see the DSM-5 for full diagnostic criteria and severity levels).

Commonly used diagnostic tools. Evidence-based assessment tools for autism have demonstrated psychometric qualities (Bolte \& Diehl, 2013; Falkmer, Anderson, Falkmer, \& Horlin, 2013). As noted previously, the gold standard in the medical community is the Autism Diagnostic Observation Schedule (ADOS) (Lord \& Jones, 2012). However, the use of the ADOS is often limited due to the expense of the tool itself and extensive training needed to conduct the assessment (Allen et al., 2008; Cunningham, 2012; Liu, Zhou, \& Lackaff, 2013). The medical community most often 
employs the ADOS not only for its psychometric properties, but also to allow clinicians an opportunity to observe and interact with their patients to garner information about skill deficits for diagnosis. Teachers have extended periods of time to observe students with peers, whereas physicians are limited to appointment times.

Medical diagnosis remains subjective, as children with autism do not have a biological marker that identifies the disorder. To compound the difficulty of diagnosis children with autism present a wide variety of developmental difficulties (Goldstein \& DeVries, 2013). Kulage, Smaldone, and Cohn, (2014) stressed accurate diagnosis as being the first step in obtaining appropriate medical, educational and community based services.

Practice parameters and interventions. No single assessment tool can fully explore the complexities involved is assessing an individual with autism (Vokmar et al., 2014). The Child Neurology Society and the American Academy of Neurology originally published practice parameters for autism evaluations in 1999 with further consensus from other professional societies (Action 1999; Filipek et.al., 1999). The American Academy of Child and Adolescent Psychiatry (Volkmar et al., 2014) published updated practice parameters related to diagnosing children with ASD:

1. A developmental assessment conducted by clinicians and caregivers.

2. A standard psychiatric assessment including child and family interview, record reviews. The history should include past and current educational and behavioral interventions. Observations of the child should focus on the broad areas of social interactions and repetitive behaviors.

3. Coordination of an appropriate multi-disciplinary assessment. Physical examination, genetic testing including chromosomal microarray, cognitive and adaptive skills should be measured to assist in intervention planning, communication assessment including expressive, receptive and pragmatic skills. 
4. Physicians should assist the family in finding structured evidence-based educational and behavioral interventions. Educational interventions include: Planned, intensive, individualized intervention with an experienced, interdisciplinary team of providers, and family involvement to ensure generalization of skills. The description of services should be explicit providing goals, objectives, and procedures for monitoring effectiveness.

5. Pharmacotherapy to target specific co-morbid conditions.

6. Maintenance of long-term treatment with clinician and community support providers.

7. Inquiry and discussion of risks associated with alternative treatment methods.

The medical community identified structured educational interventions showing better outcomes for children with ASD. The development of an appropriate individualized educational plan is central in providing effective services to the child and their family (Kurth \& Mastergeorge, 2010; Ruble \& McGrew, 2013). While a clinician diagnoses a child with autism, the family and school offer the interventions to teach the child the skills needed to function in life.

Volkmar et al. (2014) recommended clinicians follow up with interventional practices. Educators are included in the practice parameters for good reason. Pettygrove et al. (2013) demonstrated the importance of multiple sources reporting the identification of ASD. Analyzing 1,919 individuals identified as autistic, the Center for Disease Control (CDC) Developmental Disorder Monitoring Network, determined prevalence estimates for ASD from a single data source (i.e., medical diagnosis versus educational identification) under-identifies the actual number of individuals with autism. Pettygrove et al. expanded on an earlier study by the CDC that demonstrated a discrepancy in prevalence with only one source. Pettygrove et al. determined a minimum of $38 \%$ of autism cases would have been missed without access to educational information. 
In conclusion, while a medical diagnosis is very important for the identification and treatment of autism, it is not the only information needed, nor does a diagnosis offer intervention. Information from the educational community is a vital part of the diagnosis and treatment of ASD. The medical and educational communities working together have the best outcome for meeting the needs of children with autism.

Next, I turn my attention to educational research to explore autism assessments for educational identification and measures for specific instructional practice. I look to the literature to determine how teacher efficacy, as well as professional development opportunities for educators, effect autism evaluations.

\section{Educational Perspective}

As stated previously, the purpose of my study was to determine the efficacy of a context-specific autism behavior rating tool for teachers from the perspectives of major stakeholders. The current teacher-administered autism rating scales have the same questions and behavior descriptors as the parent scales, regardless of the difference in demands and behaviors the educational setting poses. It is of the utmost importance to understand the perspective of educators, as they are most often the first ones to identify skill deficits.

I look to the literature to gain an understanding of the professional development opportunities and educator preparation programs for teaching students with autism. I examine the literature for teachers' feelings about their effectiveness in understanding the unique learning needs of students with ASD. Last, I explore teacher understanding of the relationship between evaluations and individual education plan goals and objectives. 
The importance of teacher input. Educational identification of students with autism differs from a medical diagnosis. While clinicians diagnose mental disorders, educators identify areas of educational need for instruction. The United States has enacted and revised many laws to protect and serve children with disabilities. The Individuals with Disabilities Education Act (IDEA, 2006) defined autism as "a developmental disability significantly affecting verbal and nonverbal communication and social interaction, generally evident before age three, which adversely affects a child's educational performance" (300.8 Child with a disability).

Educational identification for special education services differs from a medical diagnosis in requiring adverse effect on a child's educational performance. This requirement sometimes excludes children from special education services even when they have a medical diagnosis of autism. States differ in the laws and requirements for special education identification. Some states mandate a medical diagnosis for autism, others like Oregon, have an educational identification that does not require a medical diagnosis. Educational identification requires evaluations that support a medical diagnosis and demonstrate educational impact.

It is important to understand that educational impact may not be academic. Children with autism often have difficulty working in groups or may have severe social issues that affect behaviors (Ozonoff et al., 2005). Children with autism may have above average cognitive skills and still struggle in school because of behavioral concerns.

Teachers are often the first ones to recognize the impact of ASD on a child's learning and development. The average age of diagnosis for children that have higher 
cognitive/functioning abilities is between 7 and 9 years of age, despite parent concern for development being reported as 19.6 months (Center for Disease Control and Prevention, 2012; Rosenberg, Landa, Law, Stuart, \& Law, 2011). While no single cause for such a late age of diagnosis has been identified (Rosenberg et al., 2011), one plausible factor is the child's skill level does not exceed social demands until school age, hence the importance of teacher input.

Parsons et al. (2013) wrote an important commentary in the journal, Autism. They suggested that educators and researchers team together to improve evaluation and interventions in schools. Pairing researchers with educators results in greater fidelity and research specific toward the everyday issues teachers face. Parsons et al. also made the important point that research methods must be applicable to a variety of educational settings - mainstream as well as special education. A teacher-administered autism rating tool that is specific to a school setting would offer general and special education teachers the ability to participate in evaluations in a meaningful way.

Among the benefits of pairing educators and autism researchers in school settings is the availability of large numbers of students on the autism spectrum, allowing for cross-sectional research design as well as longitudinal studies. Teachers have the ability to collect valuable data in real time as opposed to reflectively. Taber-Doughty and Jasper (2012) demonstrated data collected immediately following behaviors is the most accurate and reliable. 
Ozonoff et al. (2005) further highlighted the need for teacher's input and observations about functioning in the less structured aspects of the school setting as part of an evaluation.

... high-functioning children may present as charming, precocious, and highly intelligent when provided with on-on-one attention and conversational scaffolding from well-meaning adult professionals. The same child may look much more symptomatic with peers on a playground or in a distracting classroom, than in an evaluation room without familiar, well-practiced routines. A child may present more symptomatic with peers on a playground or in a distracting classroom situation where individual adult attention isn't available. (p. 525)

Ozonoff et al. (2005) noted that children may present differently as teenagers than when younger, making skill deficits more evident at one time or another in the child's development. For example, a child that does not make eye contact or social overtures when younger may have learned the needed skills or be more adept at social interaction as a teenager.

Reed and Osborne (2013) conducted a study to determine the role of parental stress on the discrepancy between parent and teacher behavior rating scales for children with ASD. They attempted to remove the variable of environmental influence by educators observing behaviors in the home. Reed and Osborne found that while the overall mean for parent and teacher-rating scales did not differ significantly, there was poor correspondence between individual student ratings. In other words, the evaluations were good at identifying the lacking skills of ASD overall, but the parent and teacher questionnaires had little agreement for the individual child's functioning. The lack of agreement could have great impact when designing instruction and interventions for individual students. 
Reed and Osborne (2013) suggested one possible difference that is not attributed to observational environment is the teacher's knowledge, training, and ability to compare children to more typically developing peers. They called for more study into the differences between teacher and parent rating scale responses. Next, I turn my attention to teacher education programs and professional development opportunities.

Educator training and professional development. In this section, I look to the literature to understand the impact of teacher training programs on autism evaluations in schools. Special education laws in the U.S. have changed dramatically. The requirements under federal statute for highly qualified special education teachers have left colleges and universities scrambling to develop adequate programs to deliver trained professionals (Smith, Robb, West, \& Tyler, 2010). The U.S. Department of Education (2014) has reported shortages of special education teachers in almost every school district in the nation for the last 20 years.

Further compounding the issue is the increased need for general educators to have specialized training to serve students with disabilities in general education classrooms. In $2014,94.8 \%$ of students receiving special education were educated in general education classrooms for at least some portion of the school day (U.S. Department of Education, 2014). General education teachers are often the ones that complete behavior-rating scales for autism evaluations.

Severe shortages of qualified special education teachers have led states to adopt emergency licensure procedures that have led to less qualified teachers in classrooms. The lack of training trickles down to teachers in both general and special education being 
less qualified to meet the demands of educating children with autism (Feng \& Sass, 2013). A significant increase in litigation against school districts has arisen from lack of highly qualified personnel. One factor that contributes to increased litigation is that most states lack competencies outlining requirements of highly qualified educators to teach students with ASD (Barnhill et al., 2011).

Simpson, Mundschenk, and Heflin (2011) defined a highly qualified teacher of students with autism as,

...familiar with a wide repertoire of evidence-based practices that are suitable for a diverse array of students on the autism spectrum. They have received intensive training in designing and implementing individualized supports and services, providing systematic instruction, implementing specialized curricula that addresses global areas of concern such as communication and social competence, structuring a supportive learning environment, addressing problem behaviors with functional approaches, and working with families. (p. 4)

Many recommendations in the literature described how to train educators effectively to meet the learning needs of children with autism. However, the supply has not kept up with the demand. Barnhill et al. (2011) surveyed teacher-training programs in 87 colleges and universities in 34 states. They reported an increase in teacher training programs in ASD; however, there was large variation in the scope and depth of those programs. Universities are working with governing bodies to develop guidelines for teacher preparation programs and licensure requirements for highly qualified teachers of students with autism (Barnhill et al., 2011).

No Child Left Behind (NCLB, 2001) legislation required school districts use evidence based practices when designing programming for students needing special education services. The National Professional Development Center on Autism, The 
National Standards Project, and The National Autism Center reviewed studies with randomized experimental group design to develop a set of evidence-based practices for instructing students with autism (Wong et al., 2013). The groups compiled the practices and ways to implement them effectively in school districts.

While legislation and best practice requires trained personnel to evaluate and design programming for students with ASD, colleges and universities have not had the time, resources or staffing to make comprehensive programs available. General education teachers are at more of a disadvantage in terms of lacking knowledge of specific disorders like autism (Simpson, Mundschenk, \& Heflin, 2011).

The research is plentiful and clear in highlighting the need for more training opportunities for educators working with children with ASD. The lack of understanding and training opportunities leads to inappropriate goals and objectives for students identified with autism. Next, I turn my attention to teacher self-efficacy as it relates to teaching students with autism and the impact on student performance.

Teacher efficacy. Many published studies investigated the correlation between teacher self-efficacy and improved performance for students with autism. Shelton (2013) interviewed 34 junior and senior students enrolled in special education teacherpreparation programs to determine self-efficacy of preservice educators in meeting the needs of students with ASD. Shelton found preservice educators had moderately high levels of self-efficacy in instructional practices, student engagement, and classroom management. However, their goals, resources, and strategies for students lacked specificity for students with ASD. The interviewees recognized their lack of 
preparedness to serve students with ASD and expressed plans to pursue ASD-specific professional development. Presumably, the training was not offered as part of their special education training.

In another study, Biasotti (2013) supported the findings of Shelton (2013). The difference with Biasotti's study was questioning general education teachers that had taught students with autism. Biasotti found the more experience teachers had instructing students with ASD and the level of professional development they had led to greater selfefficacy and a positive impact on student achievement.

Similarly, Humphrey and Symes (2013) demonstrated special educators reported greater self-efficacy in teaching students with ASD and coping with behaviors associated with ASD than did general education teachers. The results of their study supported the need for professional development that is specific for all teachers who work with pupils that have ASD.

In the next section, I look to the published research about the development of goals and objectives from evaluative data. The goals and objectives are important because they outline what the student is taught, how the student is taught, and how to measure student learning (Pretti-Fontczak \& Bricker, 2000).

Development of IEP goals and objectives. Individual education plans contain a set of goals and objectives designed to target the skill deficits of individual students. The goals and objectives are developed using data collected from evaluations. (Drasgow, Yell, \& Robinson, 2001). A plethora of research spanning decades called for more professional development for teachers so they understand the process of evaluation and 
individualized educational programming (Boavida, Aguiar, \& McWilliam, 2014;

Drasgow et al., 2001; Joy, 2008; More \& Hart Barnett, 2014).

Lack of professional development is not the only difficulty that teachers face when attempting to link evaluations and educational programming. A study done by Lebeer et al. (2012) organized and interviewed focus groups of medical and educational professionals, psychologists, and parents in seven countries to understand the current assessment practice of children with special education needs. They found that all participants were unhappy with the negative outlook of the reports. Lebeer et al. identify the heart of the problem being psychometric evaluations that focused on deficiencies, which caused lower expectations and often the exclusion of children with special education. Lebeer et al. stated:

When the purpose of evaluation is design for therapeutic intervention plans or to assign a child to special education it becomes very important to highlight a child's potential. This is the aspect most lacking in psychometric tests according to all parents and a majority of teachers. Psychometric tests may be valid in determining dysfunction, but they are hardly valid in determining educational needs. In order to design intervention, plan inclusion, or make recommendations to teachers and parents on how to facilitate children's learning and enable their participation in diverse groups, one needs to understand children's learning-in-context and look at what children may be able to do under certain conditions. (p. 85)

Lebeer et al. (2012) supported the need for context-specific evaluations for special education. They demonstrated the desire for teachers and parents to have access to information that is useful for educational planning; contending contextually based evaluation goes beyond diagnostics to be educationally informative. 
Ruble, McGrew, Dalrymple, and Jung (2010) measured IEP quality using eight indicators outlined by IDEA and the National Research Council (NRC) for educating children with autism. The results indicated $88 \%$ of IEPs were inadequate in describing how to assist the child toward progress and involvement in the general curriculum. Also, confirming research finding parents were not satisfied with educational decisions made on behalf of their children (Fish, 2008; Fisher \& Meyer, 2002), Ruble et al. reported parent input was only included in about half of the IEPs.

Only 39\% had behavioral objectives that were adequately described or provided conditions under which the behavior should occur. Other areas that were significantly weak were adequate descriptions of goal measurement (2\%), descriptions of specially designed instruction $(3 \%)$, or clearly stated criteria and timelines specifically written for the objective (0\%). (p. 1464)

Ruble et al. (2010) found $20 \%$ of reviewed IEPs had no social goals and $15 \%$ had no communication goals. Social and communication skill deficits are among the most obvious and impactful deficits for children with autism. All ASD evaluations measure social and communication domains. Without a measurable deficit in those areas children do not meet the diagnostic criteria or educational identification of autism.

Ruble et al. (2010) concluded overall IEP quality to be poor and recommended more training and support on how to (a) collect, (b) interpret, and (c) link data to educational practices. They also made a call for educators to encourage parental participation, because children with autism have difficulty generalizing skills and need to be taught and supported across settings.

Parental involvement is the last area reviewed of the evaluative process. Parents are part of their child's educational team and as such have input into the decisions made 
for their children. I look to the research to explore parent perspectives of evaluations and educational programming for children with autism.

\section{Parent Perspective}

Parents are likely the most vested stakeholders in the autism evaluative process. To gain a better understanding of parent perspective I review the literature to answer the following questions: What do parents think about the autism evaluative and special education process? Second, what do parents understand about the IEP and specially designed instruction for supporting their child's learning needs?

Understanding parent perspective is important because support of a child's learning needs can improve long term prognosis (Dawson \& Bernier, 2013; Landa, Gross, Stuart, \& Faherty, 2013; Matson et al., 2011) and reduce economic burden. In 2011 the average cost for families with a child that has autism was 17,000 dollars more than for a typically developing child (Lavelle et al., 2014).

Parental attitudes. During my work as an autism specialist, one mother told me that every report she had ever read about her son was negative. She said, “I just don't want any more evaluations done that are going to tell me what my son can't do. I want to know what he can do!" Her comment mirrored many parents' feelings reported in the literature.

Ho, Yi, Griffiths, Chan, and Murray (2013) did a study of the relationship between parents and professionals for evaluation and diagnosis of autism. Ho et al. defined three stages to the evaluative process: (a) pre-diagnosis, the time 'unexpected behavior' is noticed until referral for evaluation for autism; (b) diagnosis, the time of 
appointment for evaluation through the results and diagnosis phase; and (c) post diagnosis, begins with referral for services and continues throughout life.

Ho et al. (2013) suggested the diagnostic phase of the evaluative process is vitally important for parents, as it is 'the key' to unlocking further services. All of the parents interviewed by Ho et al. expressed feeling uncertain and lost during the process. The authors claim fostering a positive relationship with parents will contribute to enhanced treatment outcomes and empowerment for parents during the course of their child's treatment.

In the Ho et al. (2013) study, one parent said, "We went to two or three family doctors...I could not accept a doctor telling me that nothing was wrong” ( $p$ 843). Parents in the Ho et al. study also noted a frustration with the delay between when their child was first referred for evaluation and when they actually received a diagnosis. In Oregon, it is not unusual for wait times of a year or longer for an appointment with the developmental disorders clinics at local hospitals.

Parents reported confusion throughout the diagnostic process, but an apex being when the results were interpreted. They reported confusion with the terms used and did not feel their questions were answered. Parents also reported feeling they did not know what questions to ask or did not want to challenge the professionals that conducted the evaluation (Ho et al., 2013). A recommendation of the study was for professionals to not only give adequate time for questions, but also to facilitate by asking the parents what their concerns and questions might be. 
In another research study, Lebeer et al. (2012) interviewed medical and educational professionals, psychologists, and parents to understand the current assessment practice of children with special education needs in Europe. They found that all participants were unhappy with the negative outlook of the reports. They identified the heart of the problem being evaluations that focus on deficiencies cause lower expectations and often exclusion from general education for children with special needs.

Research suggests parents do not feel they have a clear understanding of the diagnostic and identification procedures for children with autism. A context-specific rating tool defining behaviors seen when the child is independent of parents, and uses non-judgmental language, may remove some of the mystery about diagnosis. This leads to the question of parents understanding about the IEP process and specially designed instructional goals, as well as parent satisfaction with educational programming.

\section{Understanding the IEP process.}

Leeber et al. (2012) reported teachers and parents wanting access to information that is useful for educational planning. By measuring what a child can do in a school setting, educators can base programming decisions on a child's current abilities. Parents can understand the skills their child has, which can be built upon to further skill development.

Litigation around appropriate instruction for autism has soared. One factor in the increased litigation is parent satisfaction with their child's educational programming. Drasgow, Yell, and Robinson (2001) reviewed 45 published due process hearings for students with autism in special education. They reported a primary violation was IEP 
development. IEPs were reported to lack adequate goals and objectives based on evaluative data. School districts that did not produce IEPs with adequate goals and objectives used precious resources in litigation rather than instruction. If parents and teachers better understood evaluative data and the link to student outcomes, perhaps the rate of litigation would drop.

In a study of a family support group for parents of children with autism, Fish (2008) found parents did not feel they were treated equally with the educators at IEP meetings. Parents felt their input was not valued or welcomed. Additionally, parents reported feeling that teachers treated the IEP process as a formality and teachers did not properly implement or adhere to the goals and objectives developed in the IEP. Last, Fish reported parents did not feel that school districts did enough to educate them about the IEP process. Due to the lack of understanding, parents had to educate themselves about the IEP process.

Another study involving 96 parents and 67 diagnostic professionals in Ireland regarding satisfaction with the autism diagnostic process by Keenan, Dillenburger, Doherty, Byrne, and Gallagher (2010) found that parents reported the entire process from diagnosis to educational programming extremely stressful. In the study, $49 \%$ of parents reported feeling the information was not presented clearly and they did not understand the process. Furthermore, half of professionals reporting noticing signs of parental distress.

Zeitlin and Curcic (2014) published an article, “Oh, IEP tomorrow? Rum tonight!" While the title may be tongue-in-cheek, many parents share the intended 
sentiment. Zeltin and Cucic reported parents used expressions such as frustrated, dissatisfied, overwhelmed, sad, and dejected to describe their emotions during the IEP process. Twenty parents shared their recommendations on how to make the process and product of IEP meetings more meaningful. Some of the suggestions were: Make the process more child focused, make reports more human-focused and caring with stories describing how their children perform in the classroom, and keep the process focused on the positive and what their children can do rather than what they cannot.

Lebeer et al. (2012) demonstrated the desire for teachers and parents to have access to information that was useful for educational planning. Neither school districts nor families' benefited from having to pursue litigation to achieve appropriate educational programming. By measuring what a child can do in a school setting, educators can base programming decisions on a child's current abilities in the educational context. Parents could be offered concrete examples of their child's skills in a classroom. Clear understanding of a child's performance on a context-specific rating tool may offer both teachers and parents' evaluative data that translates directly to goals and objectives, increasing understanding for all involved.

This concludes the review of the research for the stakeholders in autism evaluations. Next, I provide a synthesis of the literature review to examine the state of current autism evaluations and the impact they have on the stakeholders. I note unifying themes and gaps in the current knowledge. 


\section{Synthesis of the Research}

After reviewing the current literature for the salient features of autism evaluations from three stakeholders' perspectives, I found evidence of a need for a context-specific tool to address the gaps in knowledge for each of the vested parties. Research has shown the environment influences behaviors. Allen et al. (2008) determined data reflecting student interaction in a classroom is vital in determining appropriate educational interventions. Yet, autism behavior rating scales are not specific to the school setting.

Clinicians follow practice parameters in diagnosing ASD by examining behaviors across multiple contexts, yet the current scales ask the same questions regardless of context. The American Academy of Child and Adolescent Psychiatry (Volkmar et al., 2014) noted one assessment tool does not fully explore the complexities involved in assessing an individual with autism. Why then are we using the same tool for the home, community and school environs?

Research has also shown parent and teacher rating scales have poor correspondence between individual students (Reed \& Osborne, 2013). Teachers are reporting different behaviors in the school setting than parents are reporting in the home setting. Could it be the scale is flawed in behavior descriptors? Would the parent and teacher scales have more agreement if the skill deficits were described in terms of the setting where the behaviors occur?

Professional development opportunities are another area for which research supported improvements. The National Research Council (2001) contended educating teachers and school personnel was the primary way to ensure evidence-based teaching 
strategies are used when working with students on the spectrum. If teachers were given a list of behavioral descriptors - ones they would see in a classroom and that highlight the hallmark skill deficits of autism - they would gain a better understanding of how to develop programming for their students.

Parents reported disdain for the evaluative and IEP process for their children. It is a highly emotionally charged time for families. Ho et al. (2013) described parental understanding of the evaluative process as vital to understanding what services their children needed. Parents felt evaluative reports tell them what their children cannot do instead of what they can do. A context-specific rating tool might help parents understand how their child is performing in a classroom setting.

It is evident from the research that there is a need for further exploration of a context-specific behavior rating tool for teachers from the perspectives of all stakeholders. The literature confirmed the research questions address the salient features for each stakeholder group in the autism evaluative process. Next, I turn my attention to the gap in knowledge concerning a context-specific tool.

\section{Critique of Previous Research}

As demonstrated from the literature review, there is a gap in the research concerning a context-specific rating tool. While many authors highlighted the need for further research (Goldstein \& DuVries, 2013; Wilson et al., 2013; Wolff, 2004), the follow-through of that research is stymied by many factors. One factor is the changing diagnostic criteria. Since autism was first included in the DSM in 1980, the diagnostic 
criteria have changed four times (Ganzler, 2014). By the time one tool is developed the criteria has once again changed.

A second compounding factor that delays the development of more accurate autism evaluation is the cost and time involved in developing a standardized, normed evaluative tool (Cicchetti, 1994). The wheels of change sometimes move slowly.

In my practice, I have had the opportunity to work with educators on a daily basis involving autism evaluations. The over-riding feeling amongst my colleagues was one of confusion. Teachers were not sure when to refer a student for an evaluation. They were not sure if what they saw in the classroom was a skill deficit associated with autism. Finally, clinical and school personnel often lack the training needed to administer the highly specialized ADOS (Sikora et al., 2008). The literature demonstrated a shortage of information on how to meet the needs of all stakeholders in the evaluative process. One point made in the research was the need for more accurate and user-friendly evaluative tools. A context-specific behavior rating tool for teachers might meet that need.

In my review of the literature, I examined questions that related to the efficacy of a context-specific behavior rating tool for autism from the perspectives of the major stakeholders. I highlighted areas of importance for clinicians, educators, and parents in understanding and using the data collected as part of autism evaluations. Next, I turn my attention to the methodological research literature. Questioning the stakeholders directly for their perspectives of the efficacy of a context-specific autism behavior-rating tool for an educational environment can help shape the future of autism evaluations. 


\section{Review of Methodological Literature}

In this section, I review the methods best suited for investigating the efficacy and feasibility of a context-specific autism behavior rating tool for an educational environment. By treating the stakeholders as experts, I gained insight from those most vested in the process. Autism evaluations hold data that is important to stakeholders for different reasons. I searched the literature for methodologies that best support the understanding, viewpoints, and feelings of each of the stakeholders.

Due to the nature of my inquiry, I used a qualitative approach to data collection. Creswell (2012) defined qualitative research as addressing the meaning individuals or groups ascribe to a social or human problem. Data collection is sensitive to the people and places under study and is both inductive and deductive in establishing patterns or themes. Considering the efficacy of a context-specific rating tool required sensitivity to the needs of the stakeholders.

Maxwell (2012) described intellectual goals for which qualitative studies are especially suited, first on the list was, understanding the perspectives of participants. He defined this understanding as the key difference between qualitative and quantitative research. Maxwell identified three advantages of qualitative data collection methods:

1. Generating results...that are understandable and experientially credible, both to the people you are studying and to others. 2 . Conducting research that is intended to improve existing practices, programs, or policies... 3. Engaging in action... its focus on particular contexts and their meaning for participants in these contexts. (p. 31-32)

The three advantages outlined by Maxwell were useful for my study because they aligned with gaining understanding from the stakeholders of autism assessments. 
Research gives direction on ways to improve current educational practices. Those with vested interest in the outcomes were the ones who offered rich insight into changes that can be made to current practice. Next, I turn my attention to surveys as a data collection method.

\section{Surveys}

Fowler (2009) identified some of the advantages of surveys as being low cost, having the potential for a high speed of return, being self-administered, and providing time for thoughtful answers. Vogt, Gardner, and Haeffele (2012) outlined the following as important criteria for using surveys as an effective research design:

1. The data are best obtained directly from the respondents;

2. Your data can be obtained by brief answers to structured questions;

3. You can expect respondents to give you reliable information;

4. You know how you will use the answers;

5. You can expect an adequate response rate. (p. 16)

All of the criteria outlined by Vogt et al. (2012) matched the needs of my study. Considering my research was qualitative in nature it was important to ask people about their feelings.

The study I conducted was qualitative in nature. As Fowler (2009), stated, "The main way of collecting information is by asking people questions; their answers constitute the data to be analyzed" (p.1). The purpose of my survey was to produce useful feedback from stakeholders in the autism evaluative process. Fowler (2009) continued to note the data collected from surveys offers a sample of the population rather than the entire population. It would not be possible to question every stakeholder in the evaluative process. 
Bolster (1983) argued quantitative research did not understand the perspective of teachers or consider their particular setting. He suggested a qualitative approach to educational research offered a chance to connect with teachers' everyday experiences in the classroom. "If researchers are to generate knowledge that is likely to affect classroom practice, they must construe their inquiries in ways that are much more compatible with teachers' perspectives" (p. 295). It was my intent to offer teachers a forum in which they could respond without fear of reprisal.

Critique of surveys. While surveys may offer a quick and inexpensive way to contact participants, they also have many drawbacks. One major drawback noted by Fowler (2009), and experienced in my study, was finding participants willing to offer information and return surveys. Another drawback noted by Fowler (2009), was the inability of the surveyor to be available for questions, clarifications, or information. By using anonymous surveys, the responses could not be further elaborated upon.

Error and bias in surveys. Surveys attempt to take the responses of a sample population and infer the larger population would respond in a similar way. Fowler (2009) defined two types of inference error: bias and variability. I attempted to mitigate bias by ensuring the responses were anonymous, and by not recruiting participants with which I had a personal or professional relationship. To address variability, I set a minimum response rate of 10 per stakeholder group. I selected this response rate based on prior research experience with the demographic population as well as limited resources and time. While a response rate of 10 by no means represented the entire population, I was able to determine if a relationship existed between the responses, which 
demonstrated the efficacy and feasibility of a context-specific tool from stakeholder perspectives.

Another source of variability was responder choice. All the survey responders chose to participate, so it could be assumed they may have had an interest in the topic. Because I was studying the viewpoint of stakeholders and treating them as the experts, variability of participants was less of an issue for my study than sample size. However, because of my recruitment methods, I might have overlooked an entire population that has a different viewpoint. On the other hand, perhaps teachers surveyed at the end of a difficult day might have responded differently than those that had just participated in professional development; introducing a bias over which I had no control.

This is by no means an exhaustive list of the types of error and bias involved in survey methods. My samples were convenience samples. I did not look to find a randomized sample of educators from school districts across the state or nation. The questions I asked and the order in which they were asked may introduce some form of bias. Undoubtedly, bias existed in areas that I had not considered. This study was an attempt to gain understanding for future investigation for a context-specific autism behavior rating tool.

Next, I summarize the findings of my literature review. Each stakeholder has a unique perspective and requirements for the evaluative process. While ultimately the child is the center of importance, each team member offers insight and information toward accurate diagnosis and educational identification using a context-specific tool. 


\section{Summary of the Literature Review}

In this chapter, I reviewed the literature to determine the salient features of autism behavior rating scales from the perspectives of major stakeholders. The research clearly indicated a need for more effective and accurate evaluative measures for students with autism. Clinicians, educators, and parents have a stake in the outcome of accurate evaluative data. Educational programming that affects the future life function of millions of individuals depends on the data collected as part of the evaluative process.

Research demonstrated identifying skill deficits in a variety of settings to be the most accurate method of diagnosing autism spectrum disorder (Filipek et al., 1999; Volkmar et al., 2014). Research demonstrated the environment in which behaviors occur impacts the behaviors (Belsky \& Hartman, 2014; Bronfenbrenner \& Evans, 2000; Bullock, 1982; Orznoff et al., 2005). In addition, reflective data collection lacks the accuracy that real time data collection methods produce (Maxwell, 2012; Whittemore et al., 2001). There was a call for new behavior rating scales that are more effective and have behavior descriptors that match diagnostic criteria (Allen et al., 2008; Goldstien \& DeVries, 2013; Wilson et al., 2013). The research indicated that the current method of evaluating children for autism spectrum disorder is flawed and needs improvement.

Prior research has highlighted areas of importance to each stakeholder. In the next chapter, I review the methods of inquiry to determine the efficacy and feasibility of a context-specific autism behavior rating tool for teachers, with real time data collection methods, from the perspectives of major stakeholders. 


\section{Chapter Three: Methods}

In Chapter Three, I review the problem of practice, the purpose of the study, the research questions, and the methods used to answer the questions. I provide details about the participants, instruments, procedures, and any perceived bias that may have be involved on the part of the researcher or participants. Finally, I conclude this chapter with detailed steps of data analysis and how the results related to the research questions. I start with re-stating the problem and the purpose of my research.

The problem is that current autism behavior rating scales for teachers are not context-specific. Teacher rating scales do not have accurate behavior descriptors based on an educational environment, nor do they offer accurate real time data collection for

present level of functioning. The possible result of inaccurate behavior descriptors and reflective data collection is misdiagnosis, over- or under-diagnosis, inappropriate educational programming, and a negative impact on the future life function of individuals with autism. Addressing the problem is important to society as a whole; however, stakeholders are those with a special interest in the outcome.

The purpose of this study was to determine the efficacy and feasibility of a context-specific autism behavior rating tool for an educational environment from the perspectives of three major stakeholders: clinicians, educators, and parents. My hypothesis was diagnostic and special education identification and instructional programming decisions for children with autism can be positively affected by data collected from a context-specific autism behavior rating tool with real time data collection methods. 
The feedback of three major stakeholders in ASD evaluations offered valuable insight to the efficacy and feasibility of such a tool to guide future practice of autism evaluation. The following research questions were developed to address the problem.

Given an example of a context-specific autism behavior rating tool for an educational environment and an observation method for real time data collection:

1. What did clinicians think about the efficacy and feasibility of a contextspecific autism behavior rating tool for diagnosis?

2. What did educators think about the efficacy and feasibility of a contextspecific autism behavior rating tool for educational identification and planning?

3. What did parents think about the type of information gathered from a contextspecific autism behavior rating tool for understanding their child's learning needs?

To determine the efficacy and feasibility of the tool, I surveyed stakeholders to learn their thoughts, feelings, and opinions. In the next section, I explain the methods used for this research.

\section{Research Methods}

In this section, I review the qualitative nature of my research. According to Plano, Clark, and Creswell (2010), the two types of research problems are "problems that call for explanation and those that call for exploration" (p.85). Problems that call for exploration are qualitative in nature. In my study, I explored the feedback of stakeholders in the evaluative process, so it was qualitative in nature. 
Using an anonymous online survey, I questioned stakeholders for detailed feedback about the efficacy and feasibility of an example context-specific autism evaluation tool and observation method (further details in the Instruments section). The stakeholders were the experts in this case. My desired outcome, as described by Krathwohl (2009) was "a holistic picture of the phenomena" (p. 238). Understanding the view of each stakeholder revealed the efficacy and feasibility of a context-specific autism behavior rating tool for teachers.

Stakeholders have a vested interest in the evaluative process of autism for different reasons. "To be genuinely qualitative research, a study must take account of the theories and perspectives of those studied, rather than relying entirely on established theoretical views or the researcher's perspective" (Maxwell, 2012, p. 28). My study had a very practical purpose: to have an effect on the practice of diagnosis and educational identification and programming for children with autism. While quantitative data collection methods were available, those methods could possibly have missed the very details the stakeholders viewed as most important.

Glaser and Strauss (1967) described social research as the process of systematically gathering data for the purpose of (a) predicting and explaining behavior, (b) to be useful in theoretical advancement, (c) usable in practical applications, (d) provide perspective on behavior, and (e) to guide research on particular areas of behavior. Throughout my research, I used Glaser and Strauss' purposes as a guide. Next, I turn my attention to the participants. These individuals offered their insights and expertise into 
the evaluative process. I consider the stakeholders in the evaluative process as the experts.

\section{Participants}

In this section, I define each stakeholder group. As noted, I selected participants as the expert stakeholders in the autism evaluative process. I describe the participants by stakeholder group and offer a definition of whom the group might have included.

\section{Clinicians}

I defined clinicians as individuals who were licensed by the state of Oregon to medically diagnose individuals with mental disorders. Some examples of clinicians that were recruited to be part of this study were pediatricians, psychiatrists, psychologists, and neurologists. While more individuals may be part of the team offering information toward diagnosis, clinicians are the only individuals that are licensed by governing bodies to diagnose psychiatric disorders using the criteria in the DSM-5 (APA, 2013).

The sample of clinicians was a non-probability convenience sample (Krathwohl, 2009) chosen from a Google search of licensed clinicians in the state of Oregon identified by specialty. For clinicians with a public email address, I emailed them information about the study and how to participate. For clinicians who did not have an email account available with the Google search, I called their offices and briefly explained my purpose and requested the email address for the office staff. The office staff, in turn, agreed to forward the research information to clinicians (see Appendix A). 


\section{Educators}

Educators were defined as teaching professionals who were licensed by the state of Oregon to teach general education or special education in grades kindergarten through transition.

To recruit educator participants, I specific educational organizations and posted information on regional program web site, and the Autism Society of Oregon's web page. I also printed a flyer that contained study information and left it with educational institutions to distribute to those they thought might be interested in participating (see Appendix B)

\section{Parents}

Parent participants were defined as having a child that had a medical diagnosis or educational identification of autism spectrum disorder. However, no confirming documentation was requested or required.

To recruit parents, I used multiple approaches including recruitment flyers posted with agencies that serve the autism community (i.e., clinician's offices, advocacy centers, care providers, behavioral consultants, pediatric dentist offices) (see Appendix C) and online advertisements on web sites that serve parents of children with autism in the state of Oregon. I also recruited parents at an annual autism walk who agreed to participate and shared their email addresses. I do not know if any of the parents who shared their email addresses participated in the study. Next I discuss the procedures. 


\section{Procedures}

In this section I describe the procedures used to conduct the study including recruitment, informed consent, and maintenance of data. I begin with recruitment.

\section{Recruitment}

I recruited participants using judgment sampling, a type of non-probability sampling, which relies on the researcher's experience and wisdom in selecting a population (Krathwohl, 2009).

Clinicians were contacted by email list generated from an Internet search. I sent clinicians that had a published email address information about the study with a link to the survey. Flyers with study information were posted with educational agencies and organizations that serve individuals with autism. Information was posted on web sites that serve the autism community. Parents were recruited at a local autism walk by asking if they would share their email address to be sent information about the study.

Flyers and emails contained information for accessing the study site. Participants could either follow an internet link to the study site or scan a QR (Quick Response) code into a mobile device. The link or code opened the Qualtrics survey site and participants were shown a copy of informed consent. Participants could access the survey for one week after the initial consent to participate. They could start the survey and return to complete it by clicking the link. Participants could complete it anytime within the oneweek time frame. Incomplete survey information was not considered for this study. To prevent participants from taking the survey multiple times, Qualtrics identified the computer IP address and only allows access to one survey per computer IP address. 
I have no way of knowing how participants learned of the study. I also have no way of knowing which participants I emailed may have chosen to participate. Next, I review the informed consent.

\section{Informed consent}

When participants followed the link to Qualtrics survey site, they were presented with a copy of the informed consent document (see Appendices D, E, F) which introduced the study, outlined risks, benefits, confidentiality, compensation, voluntary participation, and rights of participant. The informed consent also included the university and my contact information if the participant had any questions or concerns.

If the participant wished to participate in the study, he or she clicked on the, "agree" link; if they did not wish to participate, he or she could either click the "do not agree" link, or close the browser window. If they agreed to participate, the survey opened.

\section{Maintenance of Data}

All survey data have been stored electronically on a password protected personal computer and the university server; only I have access to the information. The data are to be stored for a period of three years, at which time I will permanently delete the data from my personal computer and the university server. The participants can request a copy of the study results by emailing me from an address included with the study information. Next, I describe the instrument used to collect the study data. 


\section{Survey Instrument}

In this section, I offer the rational and benefits for developing the survey. I discuss the drawbacks and limitations with the data collection method, and I discuss the development of the survey. To assist the stakeholders in answering the questions on the survey, they were all shown the same brief example of a context-specific autism behavior rating tool for an educational environment with real time data collection methods (see Appendices G, H).

\section{Rational and Benefits}

Fowler (2009) identified three benefits for using surveys for research; (a) standardizing the measurement, (b) reducing bias, and (c) tailoring the instrument to the researcher's needs. An anonymous online survey fit the purposes of this study. To increase participation and response rate, Fowler (2009) recommended keeping survey questions concise and to a minimum to gather the information needed. I settled upon 10 questions or less for an approximate survey completion time of 20 minutes.

Survey design helps ensure consistency of the questions asked. Each stakeholder group was asked the same questions in exactly the same way reducing any bias that might be introduced by questioning through interviews. The online format meant participants could answer the questions at a time and place of their convenience and responses could remain anonymous to encourage participants to respond without fear of reprisal or influence. To further reduce bias, I did not recruit participants with whom I had a personal or professional relationship. 
Surveys with open-ended responses work best in smaller populations (Fowler, 2009). My goal was to gather information from at least 10 participants for each stakeholder group. While a larger number might have been beneficial, my experience and discussions with other area autism researchers (L. Pacheco May 2014; K. Sherman, Jan. 2014, personal communication) led me to conclude that finding participants would be challenging. It was my intent to gain a sufficient number of participants to have a variety of responses, offering insight into the efficacy and feasibility of a context-specific autism evaluation tool.

To generate the survey, I used Qualtrics software, Version [59780 0.999s] of the Qualtrics Research Suite (2013). Qualtrics software allowed for blind responses, meaning the receiver does not have access to the email account or identifying information of the sender. The software was available free for students enrolled in graduate studies at Portland State University adding to the benefit of cost effectiveness.

\section{Drawbacks and Limitations}

Surveys have a number of drawbacks. First, the survey design did not allow me to probe participant's responses. I was not able to ask participants to elaborate on their feedback or gather more information. Interviews offer more flexibility for clarification and probing for expansion of responses. Despite extensive recruitment efforts, response rate may be low. Difficulty with response rate is common with survey research (Fowler, 2009; Krathwohl, 2009). Undoubtedly, I did not think of every relevant question to ask of participants. However, despite the drawbacks I felt the advantages of a self-administered survey outweighed the disadvantages. 


\section{Survey Development}

No existing surveys offered the information needed to address my research problem. Using the literature as a basis for item development, I designed the survey to address the research questions. The survey started with questions about background information of the stakeholders to ensure the participants had some experience with the autism evaluative process.

In the clinician survey, clinicians were asked about their area of practice, how often they conducted autism evaluations, if they requested educational information as part of diagnostic decisions, and which evaluative tools they had used and felt comfortable administering. In the educator survey, educators were asked if they taught general or special education, how many years of experience they had, if they had any prior professional development or coursework in autism, if they had ever completed an autism behavior rating scale, and if and how often they attend IEP meetings for students with autism. In the parent survey, parents were asked if they had a child that had a medical diagnosis or educational eligibility of autism, if their child received special education services, and how old their child was when first diagnosed or identified.

The survey included open-ended questions to give stakeholders the opportunity to give feedback about the efficacy and feasibility of the example tool in their own words. Clinicians were asked if they felt the example tool might be useful for diagnostic purposes, and if so how? Educators were asked their opinion on how the example tool might be helpful for understanding the hallmark deficits of autism and if the tool could offer insight into educational planning? Parents were asked if the example tool might 
help them understand their child's learning needs and IEP process? Each stakeholder group was asked questions particular to their interests (see Appendices I, J, K). Included in the survey was an opportunity to offer any additional thoughts or comments they had that might not have been included.

I reviewed the survey questions with a colleague who is a Professor of Special Education with many years of experience in the field of autism. After discussion, I added a scale (from 0-100) to the clinician and educator surveys to gain feedback about the likelihood of using the example tool for diagnosis, or educational identification and programming. Next, I review my role as the researcher.

\section{Role of the Researcher}

I am an educator as well as a researcher. I have worked in the field of education for more than 20 years. For the past 10 years, my focus has been with students on the autism spectrum and the education staff that serves them. Witnessing the struggles of educators in understanding the complex learning profiles of children with autism propelled me to engage in research that will have an impact on a field of practice.

I live and work in the state where the research was conducted. To avoid any potential bias on the part of study participants, I only actively recruited participants with whom I did not have a personal or professional relationship. The surveys were anonymous to facilitate honest and open responses without fear of any unforeseen repercussions to the participants.

As a researcher, I was responsible for the analysis of the survey data. It was my role to remain transparent and offer clear and concise information with examples when 
interpreting the results. It was my responsibility to conduct the research as designed and approved by the Internal Review Board of Portland State University. In the next section, I review the methods used in analyzing the data.

\section{Data Collection and Analysis}

Next, I turn my attention to describing the survey data collection and analysis. As mentioned earlier, the survey responses were anonymous. However, the stakeholder title was included in the survey design. For example, the clinician, educator, and parent survey were labeled clinician survey, educator survey, and parent survey. This allowed me to compare surveys not only to others in the same stakeholder group, but also across the whole of the stakeholders. To begin, I downloaded the data from Qualtrics (2014) software. Qualtrics offered a qualitative data analysis function I used to assist with tabulating, analyzing, and reporting.

The first type of analysis was descriptive information of the participants to assure experience with the autism evaluative process. For analyzing the open-ended questions, I used constant comparative analysis using Cognitive Map Coding (Myles \& Huberman 1994), based in Grounded Theory (Glaser \& Strauss, 1967) to ensure traceability and verification. In essence, I compared bits of information, or data, from each of the responses to identify themes. I constructed an overall understanding of the responses by stakeholder group to determine how they were similar, and how they differed to answer the question of the efficacy and feasibility of a context-specific autism observation schedule for an educational environment. 
Lincoln and Guba (1985) outlined four stages of understanding qualitative data through constant comparative analysis: (a) comparing incidents applicable to each category; (b) integrating categories and their properties; (c) delimiting the theory; and (d) writing the theory (p. 339). Using Lincoln and Guba's four steps, I developed an understanding the combined responses of stakeholders. I completed the four steps with each stakeholder group (i.e., clinician, educator, parent), and then, for all of the participants as a whole.

Qualtrics software allowed answers to be displayed in a table format (e.g., all answers to question one listed together, all answers to question two listed together, and so on) to assist in reviewing responses and offered a word cloud to represent words that were common across different participants. After reviewing the survey responses multiple times, I compared repeated incidences from the responses and identified categories. For example, if more than one parent participant identified confusion with their child's IEP goals, I identified IEP goals as a category.

I defined the characteristics of each category to clarify inclusion of responses and used direct quotes. I color-coded each quote with the category on the response sheet to avoid inadvertently assigning the quote to more than one category. I reviewed the responses to ensure information was accurately assigned for the category and that it did not need to be broken down further.

The next step was to delimit categories and their properties to more general themes. Lincoln and Guba (1985) described delimiting the theory as sorting data into categories, reviewing the categories for overlap, and then looking for relationships among 
the categories. Reflecting on the original research questions, I identified themes that fully captured the intent of my research questions for each stakeholder group. Dey (1993) described making sense of the patterns as "bound up on the one hand with the bits of data to which it is assigned, and on the other hand with the ideas it expresses" (p. 102). I delimited the information for concise reflection of the research questions.

According to Lincoln and Guba (1985), the last step in analyzing data is writing the theory. This step entails more than the summary of the results. I offer a conceptualization of responses by stakeholder group, and then all groups as a whole, about the efficacy and feasibility of a context-specific autism behavior rating tool for teachers. These results helped me to understand stakeholders' perspectives and consider the next steps for research in the field of autism assessments.

Last, I summarized the analysis of the data scrutinizing my methods, unexpected results, and any unforeseen shortfalls in my research. It was my intent for this study to offer important information about improvements that could be made to current evaluative methods. Ultimately, the goal of my qualitative research was to have an impact on a problem of practice and give direction toward possible solutions.

In the next chapter, I report the results of my study. I link the interpretations of the findings with the purpose of the study and the research questions. I also discuss the limitations of the study. 


\section{Chapter Four: Results}

In Chapter Four, I restate the research problem, questions, and I review the analysis of the surveys completed by stakeholders in the autism evaluation process (i.e., clinicians, educators, and parents). I base the analysis in Glaser and Strauss' Grounded Theory (1967), who argued; theory and analysis happen simultaneously by constantly and systematically comparing the data. I present the results and interpret the findings for how they related to the research questions. Finally, I reflect on the study limitations and discuss unforeseen obstacles to the original study design.

The problem is current autism behavior rating scales for teachers are not contextspecific, they do not accurately describe behaviors associated with autism spectrum disorder (ASD) in an educational environment, nor do they offer a real time data collection method for identifying present levels of functioning. The possible result is misdiagnosis, inappropriate educational programming, and a negative impact on future life function of individuals with autism. Addressing the problem is important to society as a whole; however, stakeholders are those with a special interest in the outcome.

The purpose of this study was to determine the efficacy and feasibility of a context-specific autism behavior rating tool for an educational environment with real time data collection methods from the perspectives of three major stakeholders: clinicians, educators, and parents. It was my hypothesis that diagnostic and special education identification and instructional programming decisions for children with autism could be positively impacted with data collected from a context-specific autism behavior rating tool. 
The feedback of three major stakeholders in ASD evaluations was valuable to determine the efficacy and feasibility of such a tool and guide future practice of autism evaluation. I developed the following research questions to address the problem.

To guide the stakeholders' responses, I provided an example of a context-specific autism behavior rating tool for an educational environment with a real time data collection sheet. The research questions were:

1. What did clinicians think about the efficacy and feasibility of a contextspecific autism behavior rating tool for diagnosis?

2. What did educators think about the efficacy and feasibility of a contextspecific autism behavior rating tool for educational identification and programming?

3. What did parents think about the type of information gathered from a contextspecific autism behavior rating tool for understanding their child's learning needs?

I surveyed each stakeholder group (i.e., clinicians, educators, parents) to address the research questions. The surveys and related materials are included in the Appendices section. I turn my attention to the analysis of the data.

\section{Analysis of Data}

The descriptive information collected from stakeholders came directly from participant responses. The information gave a background and helped to ensure that stakeholders had experience with the evaluative process. Due to the qualitative nature of the open-ended questions, my analysis served the following purposes (Maxwell, 2012): 
(a) generate results that were understandable, (b) inform the problem of practice, and (c) use stakeholders' feedback to guide future study of a context-specific autism behavior rating tool. With these purposes in mind, I used a constant comparison method of analysis based in Grounded Theory (Glaser \& Strauss, 1967) to gain an understanding of the participants' perspectives.

To aid in visualizing the data, I created a Cognitive Map (Myles \& Huberman 1994), by posting my research questions and the responses. I used Lincoln and Guba's four steps of analysis to build the map. First, I compared incidents applicable to each category; I organized the data by using a large corkboard to visually display all the data in one place. Then, I printed out the responses and cut them into strips to cluster them to identify shared themes. I color-coded responses to avoid inadvertently using them more than once. Second, I integrated categories and their properties; I reduced the data by combining like themes. After much review and consideration, I developed a final set of themes for each stakeholder group. Third, I delimited the theory; I defined each theme for the information it included. Fourth, I wrote the theory; I ensured the themes and related participant comments answered the research questions to understand the feedback about the efficacy and feasibility of a context-specific autism behavior rating tool. I review the last step, writing the theory, in Chapter Five.

\section{Presentation of the Results}

The results of this study included feedback from 10 clinicians, 10 educators, and six parents. Table 1 displays the contact made with each stakeholder group and the respective response rate. 
CONTEXT-SPECIFIC AUTISM BEHAVIOR RATING TOOL

Table 1 Contact and responses by stakeholder groups

\begin{tabular}{lccc}
\hline Stakeholders & $\begin{array}{c}\text { Emails } \\
\text { sent/organizations } \\
\text { contacted }\end{array}$ & Surveys viewed & Completed surveys \\
\hline Clinicians & 64 & 19 & 10 \\
Educators & 35 & 16 & 10 \\
Parents & 73 & 12 & 6 \\
\hline
\end{tabular}

Next, I organized the results by stakeholder group. I reported the descriptive information to provide a background of expertise and experience of the participants, and then I reported on the open-ended questions using the constant comparative method to build a cognitive map (Miles \& Huberman, 1994).

I present the results in the following manner: (a) identification of stakeholder group, (b) restatement of the research question associated with the stakeholder group, (c) descriptive information of participants, (d) identification of each theme with representative quotes, and (e) analysis of all stakeholder groups about the efficacy and feasibility of a context-specific autism behavior rating tool for an educational environment. I begin with clinician responses.

\section{Clinician Responses}

The clinician research question (Research Question 1) was what did clinicians think about the efficacy and feasibility of a context-specific autism behavior rating tool for diagnosis?

Descriptive information. Of the 10 participants, nine identified themselves as psychologists and one identified as a clinical psychologist. In the comment section, two of the 10 participants identified as school psychologists with clinical licensure. Seven of 
the psychologists currently diagnose children with autism. Three clinicians have made diagnosis in the past but are not currently offering diagnostic services for autism. This information lends assurance the practitioners feedback is informed and relevant to the problem.

When asked with which tools they had familiarity and felt comfortable administering, half of the clinicians identified the ADOS-2, and the other half relies on autism behavior rating scales or other instruments for diagnostic information. Table 2 summarizes the clinician responses.

Table 2 Clinicians Reported Use of Autism Behavior Rating Scales

\begin{tabular}{lc}
\hline Tool & Response \\
\hline & 5 \\
Childhood Autism Rating Scale-2 (CARS-2) & 1 \\
Autism Diagnostic Interview Revised (ADI-R) & 5 \\
Autism Diagnostic Observation Schedule - 2 (ADOS-2) & 6 \\
Autism Rating Scale-2 (GARS-2) & 0 \\
Autism Screening Instrument for Educational Planning-3 (ASIEP-3) & 4 \\
Autism Spectrum Rating Scale & 6 \\
Other & 6 \\
\hline
\end{tabular}

When asked to indicate the likelihood (on a scale of 0 as unlikely to 100 as likely) of requesting teachers to complete a tool like the example to assist in diagnostic decisions, eight clinicians responded they would be likely to use the tool and two responded they would be unlikely to use the tool. The responses on the scale of 0 (unlikely) to100 (likely) were: $0,15,68,74,80,83,86,97,100$. See Figure 3 for a visual representation of responses. 
Not likely

$0 \quad 15$
Very Likely

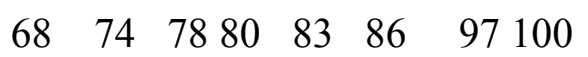

Figure 3. Clinician rating of their likelihood to use a context-specific autism behavior rating tool.

The clinician that replied zero likelihood provided negative feedback for every question. It is important to note, this clinician spent 3 minutes, 45 seconds reviewing the materials and answering the questions. Whereas, the average time clinicians spent on the survey was 34 minutes. The brevity of the time spent on the survey led me to consider the thoroughness with which he or she might have reviewed the materials. That said, the results might also relate to preference this clinician has toward other diagnostic methods.

The final descriptive question asked clinicians, "How frequently do you request educational information/records to support diagnostic information for autism?" The participants were given three choices: never, once a year, once a month, or once a week. Eight of the 10 clinicians responded to the question. They reported requesting information with varying frequency: (a) once a year $(n=1),(b)$ once a month $(n=2)$, (c) once a week or more $(n=5)$. Next, I offer an analysis of the open-ended responses.

Open-ended responses. I identified three themes from clinician feedback:

1. Value and efficacy for diagnosis - the value of the data collected and how it could/could not be used for diagnosis.

2. Specificity (accuracy) and objectivity of data collected the type of data collected, if it was considered accurate and specific for educational planning, interventions, and diagnosis.

3. Feasibility of the example context-specific tool for teacher administration. 
In the next section, I support the development of these themes using clinicians' responses to the survey items.

Value and efficacy for diagnosis. Overall, the clinicians offered positive feedback toward the efficacy of the example tool for diagnosis of children with autism. Nine of the 10 clinician's comments expressed value in the instrument in assisting in diagnostic decisions. The following were representative comments from clinicians:

"This idea is excellent. How kids interact in real life situations will give far better info than the contrived situations of standardized settings."

I have used the ADOS, but it is meant to be administered in an environment that is unfamiliar for the child and it does not allow one to see what the child is like on a daily basis in their natural environment.

The considerable advantage of using real time data in a school setting which INCLUDES same aged peers is the opportunity to make IMMEDIATE COMPARISONS of the specific behavior. The same aged peers are, in effect, the comparison group. The direct comparison process improves the identification of atypical, unusual behaviors.

"If the information obtained by context-specific teacher scales is very different from information obtained from other sources, the evaluator will need to reconcile the difference, and this could lead to a more accurate evaluation."

Clinicians' comments reflected efficacy of the tool for offering more accurate information than the current behavior rating scales. Clinicians' identified the importance of a natural setting with same aged peers as a comparison group, and highlighting discrepancies in information from other sources.

The following comments address the specificity of the behavior descriptors and the severity levels of the new diagnostic criteria:

"I like the continuum of severity levels." 
“...gives specific information about what a student can do or cannot do, leading to more accurate diagnosis."

The clinicians' commented on the continuum of traits on the example scale offering more information for the levels of severity listed in the DSM-5, and offering positive information for reporting. Current rating scales do not offer information on severity levels.

In contrast, one clinician offered negative feedback, "I don't care for this. I think it is far too loose of an indicator. Better measures like the SRS already exist." This clinician was referring to the Social Responsiveness Scale (Constantino \& Gruber, 2005). The Social Responsiveness Scale measures one domain of the hallmark skill deficits of autism and may be used as part of the autism battery. Autism behavior rating scales typically measure four or more domains. The Social Responsiveness Scale is typically used more often in research applications rather than clinical environments as a diagnostic tool (Center for Autism Research, 2014). The clinician added, “...open ended questions are useful." The next theme I identified was specificity (accuracy) and objectivity.

Specificity (accuracy) and objectivity of data collected. Again, there was overall agreement among clinicians as to the benefit of information that is context-specific aiding in diagnosis and educational programming. Comments from clinicians included:

Information specific to the context of recess during which the child's ability to cope with lack of structure coupled with high opportunity to initiate/respond to others, as well as ability to sustain focus/cope with academic challenges in class (including organizational/sensory, challenges of transitions) certainly would provide 'real life' information.

It allows one to assess how they communicate their needs and wants, how they respond to unexpected events, and whether they have any sensory needs or engage in repetitive behaviors. Watching children in a familiar 
setting like a school is much more relevant to observing them in an unfamiliar setting like a clinic or hospital.

"Undoubtedly, the subject's social/emotional behaviors will be different given context, to some extent. On many levels, the ability for an individual to be successful at school has greater implications for real-world adjustment than behaviors observed in the clinic."

Clinicians' comments reflected the value of context-specific information of the evaluative tool. They identified academic challenges, social/emotional behaviors, and communication methods to be influenced by the environment.

Feedback from clinicians that support the practice parameters for diagnosing autism (Volkmar et al., 2014) and physicians assisting the family in finding structured evidence-based educational and behavioral interventions included:

"More easily identify which behaviors need to be specific for improvement and have a baseline for measuring improvement."

"Provides better tracking data."

"Helpful to form interventions and accommodations needed in the school setting that rightfully may differ from those in the home setting."

"It gives information re: instructional direction."

The feedback from clinicians confirmed the efficacy of the information for educational planning and interventions, beyond efficacy for diagnostic purposes. Some important concerns were also raised. Inter-rater reliability and the frequency of observed behaviors were noted as valid concerns.

Historically I place stronger weight in global/general observations (Vanderbilt ADHD) made by an educator than the quantifiable data gathering (e.g. IEP data collection). As hard as it is to admit. Although the latter could be very informative, my experience has been inter-rater reliability in taking such measurements can be fairly weak. This may be 
controlled for better with a more concrete operational definition of behavior to measure.

"Depending on what activity is being observed, it may lend itself to seeing certain behaviors more or less often."

Inter-rater reliability is a concern for any evaluative tool. For a tool to be effective it must measure what it set out to measure, regardless of who is doing the measuring. As one clinician noted, "This may be controlled for better with a more concrete operational definition of behavior to measure." Ensuring the individual is using the tool has a thorough understanding of the behaviors being measured is one way to increase interrater reliability. The final theme I developed from the clinician responses was the feasibility of the example context-specific tool.

Feasibility of the example context-specific tool. Clinician feedback in this area raised concern about the ability of teachers to complete the tool. Some of the clinicians' comments were:

It is way too demanding to expect a teacher with many students to focus exclusively enough on one student to complete this type of instrument 'online'. By contrast a visiting school psychologist or counselor might conceivably rate the student's behaviors across limited periods of time.

“...a teacher has to monitor 30 or so children at a time. If an evaluator was doing a formal evaluation, then the evaluator could tally behaviors during a specified period of time."

"If such a tool was available, I worry that it would be too difficult for the classroom teacher to collect the information because they are responsible for many other students and they may miss some more subtle interactions/behaviors."

Overall, clinicians did not feel the tool would have feasibility (ease of use) for classroom teachers. They identified large class size, ability to focus on one student for an extended 
period of time, and missing subtle behaviors as barriers to feasibility. The suggestion made by clinicians of having school psychologist complete the evaluation is certainly one that has merit and deserves further investigation. Two clinicians gave feedback that supported the feasibility for teachers:

"A context-specific autism behavior rating scale allows the teacher reacts to the types of behaviors with which $\mathrm{s} / \mathrm{he}$ is familiar. The teacher is also familiar with the setting, and so the ratings will likely feel more natural to her/him."

Often teacher(s) just circle the rating number with few comments.

Sometimes they fill out the questionnaires while in a meeting and their answers are inconsistent. This measure would ensure they are actually putting in the effort to contribute quality data to the evaluation.

The comments supporting teacher feasibility of the tool identified the familiarity the teacher has with the child and the quality of the responses typical on the current behavior rating scales.

In summary, clinician feedback was supportive of the value of information collected from a context-specific autism evaluative tool for diagnosis and for educational programming and intervention. The majority of the clinicians reported they would be likely to use a context-specific tool if available. However, overall clinicians had concerns over teachers being able to complete such an in-depth evaluation during the course of the regular school day. Clinicians suggested that school psychologists or counselors might be better equipped to meet the evaluative demands of a context-specific autism tool. Next, I turn my attention to the stakeholder feedback of educators. 


\section{Educator Responses}

The educator research question (Research Question 2) was what did educators think about the efficacy and feasibility of a context-specific autism behavior rating tool for educational identification and programming. I defined educators as teaching professionals who are licensed by the state of Oregon to teach general education or special education in grades kindergarten through transition. First, I review the descriptive information of the stakeholder group.

Descriptive information. Six of the educators identified being licensed to teach general education, one identified special education only, two as general and special education licensure, and one as early intervention/early childhood education. The length of service included three educators with zero to five years of experience, two with 10 to 15 years, two with 15 to 20 years, and three with over 20 years of experience. The licensure and work experience information helped to ensure that the participants had knowledge of educational practice in the state of Oregon. The feedback comes from both special education and general education teachers.

Educators were asked if they ever had any professional development or continuing education in autism spectrum disorders. All had some type of training. Three responded as having school based professional development, while seven had coursework at a college or university. Educators had experience using a variety of the identified autism behavior rating tools. The results are outlined in Table 3 . 
CONTEXT-SPECIFIC AUTISM BEHAVIOR RATING TOOL

Table 3 Educators Reported Use of Autism Behavior Rating Tools

\begin{tabular}{lc} 
Tool & Response \\
\hline Childhood Autism Rating Scale-2 (CARS-2) & 9 \\
Autism Rating Scale-2 (GARS-2) & 7 \\
Autism Behavioral Checklist from the Autism Screening & 6 \\
$\quad$ Instrument for Educational Planning-3 (ASIEP-3) & 6 \\
Autism Spectrum Rating Scale & 7 \\
Other & \\
I have completed an autism behavior rating scale, but I & 0 \\
$\quad$ am not sure which one & 0
\end{tabular}

All of the identified behavior rating scales include both teacher and parent scales with the same questions regardless of the environment. There were not any educators that identified never having completed an autism behavior rating scale. The results demonstrate the educator participants have experience with completing behavior rating tools and have some understanding of the information they contain.

When asked how often the educators estimated to be involved with an IEP meeting for a child with autism they reported with varying frequency: (a) once a year $(n=$ $0),(b)$ once a month $(n=4)$ and, (c) once a week $(n=6)$. The responses indicated all of the participants have been members of an Individual Education Planning Team to create educational interventions for children with autism spectrum disorder. None of the participants replied as never participating in an IEP for a child with autism.

The next question focused on feasibility of the tool. The question was, considering data collection could happen over the course of three days (they do not need to be consecutive) and could be completed by teachers, aides, lunch and recess monitors, 
etc., and a full-length tool might contain twelve behavior descriptors, how feasible would it be to complete this type of tool during the regular school day? The responses on the scale of 0 (easy) to100 (difficult) were: 51, 63, 64, 75, 79, 90, 90, 95, 100. See Figure 4 for a visual representation of responses.

\begin{tabular}{llllllll} 
Easy & & \multicolumn{3}{c}{ Difficult } \\
\hline \hline & 51 & 6364 & 75 & 79 & 90 & 95 & 100 \\
& & & & 90 &
\end{tabular}

Figure 4. Educator rating of the feasibility of the example context-specific autism behavior rating tool for teacher administration

Educators reported perceived difficulty completing the example tool during the regular school day. One educator did not respond, the other nine reported notable difficulties. It is clear from the feedback the tool as designed has little feasibility for teachers, which warrants consideration for future design. One of the suggestions from clinicians was to have a school psychologist or counselor administer the tool. Next, I turn my attention to the open-ended responses.

Open-ended responses. I identified three themes from educator feedback:

1. Relevant information for educational planning - efficacy of information for educational planning

2. Increased accuracy of data collected specific to school setting over a generic tool

3. Training tool for educators - information related to serving as training tool for educational staff

The following are educator quotes supporting evidence for each theme.

Relevant information for educational planning. Educator feedback about the efficacy of the data was positive. Responses from special and general educators indicated 
nine out of 10 educators viewed the information contained in the example contextspecific behavior rating tool as relevant for educational planning. Educators and researchers should agree about what is useful and relevant to be applicable to the educational setting (Parsons et al., 2013). The feedback from both special and general education teachers noted the applicability of the tool. The following comments represented educator feedback:

We're trying to define educational impact and I think your rating scale comes closer to doing this by 1) relying on direct observation and data points 2) measuring behaviors within the context of a school setting. I think this process is especially valuable for social communication impact at school. This process provides a good link between data driven present levels and SDI (student direct instruction).

These results would be much more informative, both in describing a child's struggles in an IEP meeting, as well as designing specific and specific interventions to address areas of highest concerns (which may or may not be the behaviors with the greatest frequency).

"I think this would be very helpful when writing a current/reflective PLOP (present level of performance) and meaningful IEP."

This type of scale would be beneficial in providing data for a general education teacher in regards to social interactions and in classroom interactions for the IEP. It may drive the conversation to providing additional supports for the student within the classroom.

While nine of the 10 educators responded positively about the tool providing relevant information for educational planning, one educator responded, "I don't think it would be helpful to my knowledge." It is not clear if the response meant it would not be helpful for him or her personally, or for educators as a whole.

Improved accuracy. Educator feedback about the accuracy of the data collected in the educational environment directly effects student instruction and interventions. A 
representative sample of comments by educators included:

"I appreciate that this is specific to school settings, since after all, we are looking for educational impact."

A rating scale that identifies specific school environments and school behaviors/interactions/compliance demands would really help me (the teacher), and the parents and others in the IEP team really get a descriptive picture of where a child struggles, and where a child excels.

Students impacted with autism look very different in the home setting as the demands, expectations and comfort level are very different. Personally, I would love something more relevant to the school setting, specifically general education setting for those students who mainstream a lot.

"Unless you've spent a lot of time with ASD students, you may not appreciate what to look for during the observation. Often behavioral targets to observed are based on our preconceived notions based on limited experience."

Again, the feedback was overwhelming positive toward the benefits of increased

accuracy when the context of a school setting is added to behavior rating scales. Some of the comments focused on the increased accuracy of the real time data collection method.

Comments about real time data collection included:

"Having a greater time frame is helpful (over the snapshot of the ADOS). This allows for observations in a variety of settings."

"A very clear description of particular behavior, with frequency count of actual occurrences and intensity levels, would be much more informative than the typical scales that just ask (always, sometimes, never)."

“...there are three observational opportunities noted... In fact, many rating scales are generic and capture 'impressions' versus focusing on specific recollections based on observations."

This would force educators to do complete observations, and provide specific detail. It would force the person that is taking the data to get to know the student and there is very little question as to what the data is seeking. 
One educator did not see the value in the tool and commented, "No clear benefit at this time." There was no further elaboration. Next, I reviewed the comments made toward the last identified theme for educators.

Training tool for educators. The following were some of the illustrative comments from educators about the efficacy of the tool to serve as training information or professional development:

"For a regular education teacher, this may provide a bit of insight in how the student reacts to different situations during the day."

"It would be helpful when I work with general education teachers who do not understand autism and how it looks in different settings."

"For an inexperienced observer or a teacher who has her/his first student with autism in the class, this gives a lot of direction."

Educators noted the information that was contained in the context-specific tool could be helpful for inexperienced teachers to recognize the presentation of characteristic skill deficits in the classroom. The following comments support training opportunities of the context-specific tool for instructional support staff:

"The survey tool may be an effective training tool for me with new EAs (educational assistants)."

"You could use this rating scale with actual video as a training tool to A) learn how to observe well, B) as a training tool to become a better observer of common traits in students with ASD."

I would be happy to use this scale as part of a training exercise for my educational assistants. It would be beneficial for them to see how this data can be taken and applied to modifying individual goals on a consistent basis.

Educators expressed many ways the tool itself could be useful for the purpose of professional development for staff. 
However, there was also concern raised about the training needs for the administration of the evaluative tool itself, "This measurement would have training needs for an inexperienced person to use." The educator's comment made an important point about the time commitment to learning how to administer the tool. Most evaluative tools come with lengthily manuals that offer detail for administration and often require some level of training and experience to administer.

In summary, educator feedback was positive for the value of the information in terms of efficacy for IEP planning and development, the specificity to an educational setting, and increasing educator understanding of the disorder. However, there were drawbacks to the tool as the example was designed. The following educator response summarized the concerns voiced by educators and clinicians,

"The domains and levels appear to indicate valuable behavioral information. However, it is incredibly wordy. I am not sure I'd have time to complete this full scale with all of my other assigned duties."

Teacher and clinician feedback agreed that time to complete the tool is a barrier. For the tool to be effectively used in an educational setting would require modifications to the design or changing the personnel who complete it. Next, I turned my attention to the parent feedback in the evaluative process.

Parent Responses. The parent research question (Research Question 3) was what did parents think about the type of information gathered from a context-specific autism behavior rating tool for understanding the learning needs of their child?

Descriptive information: Six parents responded to the survey. Five parents reported their child has a medical diagnosis of autism, and all six reported their child had 
received special educational services under the identification of autism. This information helped to ensure the parents that responded to the survey had experience with special education, the IEP process, and most also had experience with medical diagnosis for their children.

Parents were asked the age of diagnosis/identification of their children. Parent responses were; between birth and five years old $(n=4)$, between six and 12 years old ( $n$ $=1)$ and, 12 years or older $(n=1)$. The parent responses of age of diagnosis/identification offered a variety of experiences and age levels of impacted children.

Open-ended responses. The following are the themes that I identified from parent feedback data:

1. Comparison to peers/context of school - the value of information afforded by the school setting and comparison to same age peers.

2. Mutual understanding child's behaviors - parent concerns for shared understanding of his/her child's behaviors.

3. Information relevant to IEP - the efficacy of information collected to inform the IEP process parent understanding of their child's IEP.

Comparison to peers/context of school. Parents commented about the value of data specific to a school setting with same age peers. Their typical comments included:

I think seeing the full range of possibilities as laid out in the attached context-based scale was very informative. It allowed me to really see where in the spectrum my son lies, to get a sense of what behaviors would need to change/improve to move up the spectrum, and to get a better sense of 'normal'.

"My child is an only child, so the information about how my child interacts with peers would be very useful to me." 
"It would be nice to have detailed information about how my child behaves in school. As a parent I can only guess what he acts like and responds like to teachers and his classmates..."

'I would be able to ask myself, 'Is she like that?' And then be able to make value judgements about whether she is lower or higher functioning than her peers."

"Parents can't observe the child at high school, the descriptors might fill in gaps about the parent's knowledge of the child's interactions with others. My kid's teachers often describe diligence and regulation of behaviors we rarely see at home."

All of the parent participants reported value in the information collected specific to the school setting with same aged peers. Parents' identified the benefit of understanding the development of same age peers offering increased understanding of their child's unique learning needs. In turn, parents may be better prepared to support their child in areas where development may be lagging. Parents expressed a desire to have information about how their child functions outside family supports. The next identified theme was concern for school staff understanding the child's behaviors.

Mutual understanding child's behaviors. The parent responses seemed quite emotional when commenting on other's understanding of their child's behaviors. Parents reflected concern for understanding their children in the following comments:

Often, evaluation tools used with kids with disabilities, especially I think with Asperger's, are a litany of bad behaviors and failures. Your kid can't do this. He doesn't do that. His peers are skilled at this thing, and your child is not. These types of tools do not describe my child's incredible gifts: his sense of humor, his amazing intellect, the incredible range and depth of his interests. Just the bad things. I am looking forward to behavior scales that might be more descriptive of what he actually does, measured at the time of the observation, rather than a teacher sitting down at the end of a long day of work and answering the question: Tell us how much this kid annoys you. 
"This would offer real, descriptive, non-jargon language that does not judge but only describes."

We are perhaps more accommodating of his 'quirks' at home and have learned to recognize behaviors that mean he is building to a meltdown and then we back off and suggest he may need a break. I don't think that happens often at school...I think my presence changes how he deals with difficult situations, even when I don't intervene. It is like my being there is a safety blanket or a mental checklist of alternatives to exploding is invisibly pinned to my forehead.

Sometimes teachers will speak to me about his behavior at school, and that behavior is very different than what I see at home. But the descriptions are also colored by the teacher's judgement of his motivation, and often attributed to rudeness or disrespect. Having an impartial person observe behaviors leading up to an action of concern would help me, and all members of the IEP team, recognize that his motivations are often very different than their assumptions. Then we can plan goals that address the antecedent behaviors as well as the explosion, or avoidance, or shut-down behaviors.

Parents' seemed to have a strong emotional response to educators understanding their child's behavioral challenges. Parents' comments reflected a desire to have his or her child understood by educators and the benefit of having a common language to do so.

The last theme tied the information together to identify relevant information for the IEP.

Information relevant to IEP. Parents reported the efficacy of behavior rating scale information for the development of their child's IEP. The representative parent feedback about information for educational planning included:

"This scale would more fully explain the reasoning behind some of the supports suggested by my child's case manager."

"The scale would present a possible list of specific behaviors that might be addressed by the IEP. Right now he has two behaviors on his daily (behavior) tracker that aren't even addressed in his IEP." 
"Knowing how he interacts at school would be immensely useful in developing IEP goals."

"This would set clear boundaries and keep everyone on the same page."

Parent feedback expressed a desire to understand more fully the IEP meetings and the goals contained on IEPs. The following comments reflected parent concern about not understanding the process of IEP development and its relationship to evaluative data:

My experience with IEP 'decision making' has always been along the lines of 'And this is what we think would be the best option for your son, do you agree?' To which we usually say yes. Having behavior descriptors would fill in the picture better.

As long as the information was provided well in advance of the IEP meeting, I think it would likely influence me to see things the way the school personnel see them. And if we were not in complete agreement, I could provide my counter-arguments in a prepared and logical manner.

Parents' comments demonstrated their current confusion about the process and the need for more open communication between educators and parents for the IEP process. Fish (2008) reported parents did not feel that school districts did enough to educate them about the IEP process.

Due to the lack of understanding, parents had to instead educate themselves about the IEP process. Their comments speak to this issue:

IEP meetings are so full of 'school' language. I find sometimes I am just trying to keep up with what they are talking about because all of the wording is so specific to the school setting. It would be nice to have something like this, in plain language that I could understand without having to try and figure out what the acronyms stand for!

My child's medical diagnosis was thoroughly understandable because I was the one pushing for it after reading about autism. I wish I could say the educational identification was so clear. The first 1-3 IEP meetings should be explained at a meta level to parents. Why do we have these meetings? How often? When? What can a parent do at them? Are parents 
allowed to influence the outcome? And so on. I attended five annual IEP meetings before anyone did more than hand me the Parent Rights Handbook, which of course reads like a legal text and is not very helpful. Having the process and test results presented in plain language could help.

Again, comments from these parents about the efficacy of the information for IEP planning, and understanding their child's developmental level were positive. The parent responses mirrored concerns noted earlier in the literature review.

In summary, parent feedback spoke to the efficacy of data collected from a context-specific autism behavior rating tool for offering increased understanding of educational programming, and to aid in supporting their child's development. Parent comments included an increased understanding of how their child functions in an environment without family supports. Feedback also suggested an increased understanding of children's learning needs and how they relate to the IEP process. Parents gave poignant feedback about their experiences in working with educators toward mutual understanding their children's behaviors and learning challenges.

Next, I next offer an interpretation of the findings from all stakeholder groups to describe the efficacy and feasibility of a context-specific behavior rating tool with real time data collection methods.

\section{Interpretation of Findings}

The majority of the stakeholders expressed efficacy of a context specific autism behavior rating tool with real time data collection methods. Figure 5 illustrates the dynamics of the stakeholder feedback and how it relates to the evaluative process. 


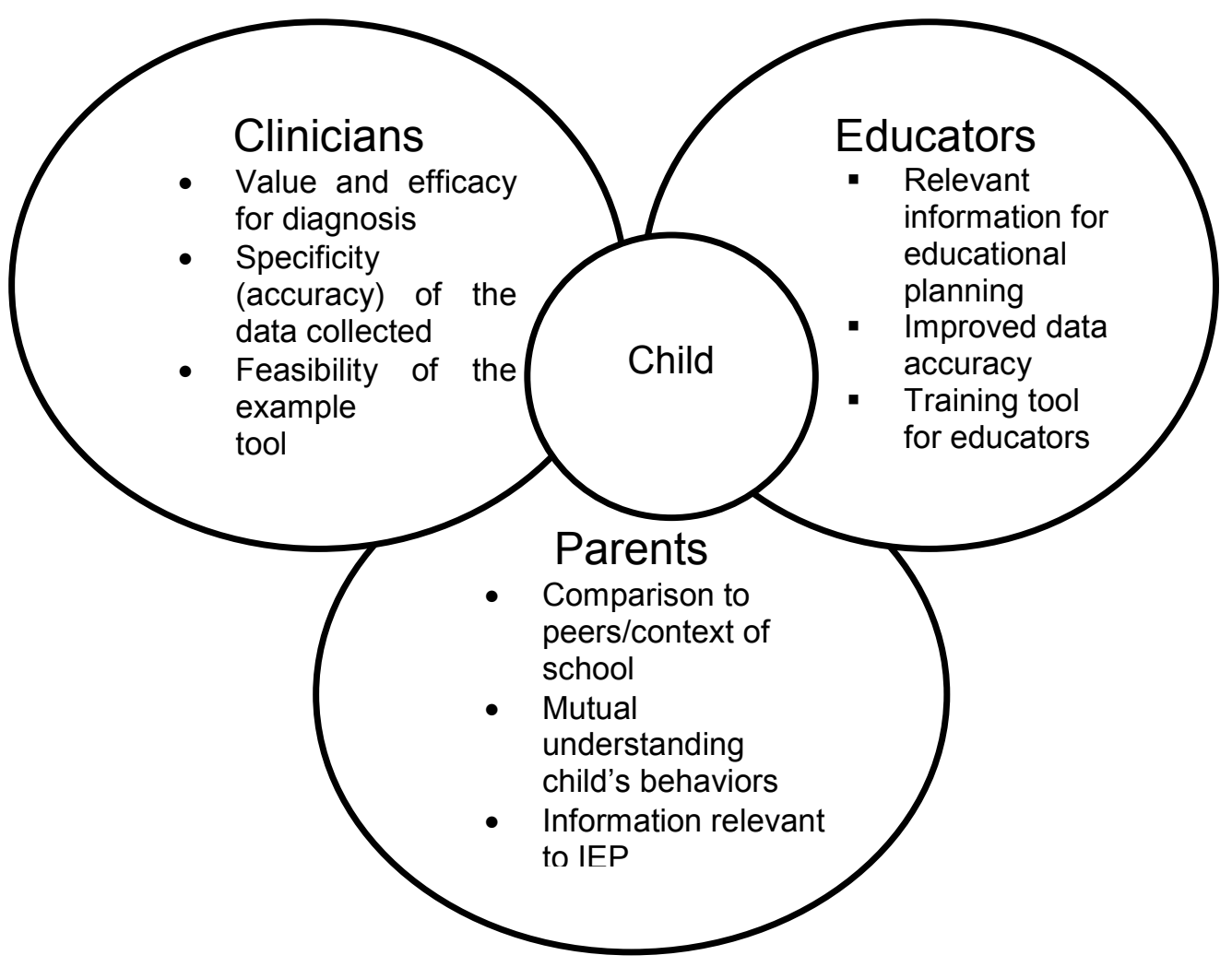

Figure 5. Themes identified from stakeholder feedback about a context-specific autism evaluation tool

I identified the three themes from clinicians' feedback: (a) the value and efficacy for diagnosis, (b) specificity (accuracy) and objectivity of the data collected, and (c) the feasibility of the example context-specific tool for teachers use. The themes from educators' feedback were: (a) improved relevancy of information for educational planning, (b) improved accuracy of the data collected, and (c) the benefit as a training tool for educators. For parents' the themes were how the tool could allow for (a) comparison to peers in the context of school, (b) mutual understanding with school staff of their child's behaviors; and (c) information that was relevant to the IEP, educational planning, and their child's development. 
The purpose of this study was to determine the efficacy and feasibility of a context-specific autism behavior rating tool for an educational environment from the perspectives of stakeholders. I learned that stakeholders indeed found the information useful for their individual interests in the evaluative process. Another important piece of information from this study was the clinician and educator agreement that the contextspecific autism behavior rating tool did not have feasibility for teachers to administer. Clinician and educator feedback both expressed a perceived difficulty for a teacher to administer the tool during the course of a regular school day. One suggestion made by multiple participants was administration by a school psychologist or counselor.

Confirmation of the feedback could come from further study demonstrating the psychometric properties of the tool in diagnosis and educational identification of children with autism. Next, I describe the limitations and drawbacks to the design and execution of this research.

\section{Limitations}

Previously, I outlined the general drawbacks associated with survey data collection methods; I experienced some of these drawbacks. For example, I did not have the ability to answer clarifying questions for participants. One clinician commented, "I am not sure what you mean by peers." This difficulty could have been mitigated with a clearer definition of the term. However, due to the anonymous, online survey format, I was unable to respond or clarify the meaning. There were also instances when I would have liked to probe participants for elaboration or clarification of the responses, but I was 
unable to do so. I attempted to control for bias when interpreting responses by using the participants' actual words.

My choice of wording for the survey questions could also be a limitation. It is possible the wording of survey questions could have influenced participants' responses. For example, by asking clinicians if they felt a tool like the one presented would offer increased accuracy, then clinicians responded directly to the accuracy. The tool was also an example and was not actually administered. The purpose of this study was to determine if a tool like the example held value for the stakeholders. Actual testing of the tool will take place in a future study.

One of the more obvious limitations of my study was the lack of the desired 10 parent participants. I received responses from six. While the number of parent groups contacted, flyers posted, and information distributed to recruit parent participants was the highest, it is the group with the least number of participants. In making the decision to either continue recruitment efforts, or use the responses of the six parent participants, I considered the feedback collected from the six. The amount parent feedback seemed sufficient to develop themes. Considering this study will serve as springboard for future research into the psychometric properties of a context-specific autism behavior rating tool, I decided to analyze the available data and report the results.

During my recruitment efforts, I contacted other individuals involved in autism research in the state of Oregon. I learned the difficulty of recruiting parent participants was not unique to my study. At any given time, numerous studies are vying for participation from the same population. Researchers at organizations with significantly 
more resources, also reported difficulty in recruiting parents to participate in their studies (L. Pacheco, personal communication, May 2014).

A limitation of any study with a small sample size is the variability of the responses. Even using the same population, with a larger sample size, results would likely have offered insights that were not gleaned from the feedback of my study. Another limitation of this study was the wording of the question for clinicians about requesting educational information. The way in which I worded the questions could lead to misunderstanding. The intention of the question was to discover if clinicians requested educational information as part of the autism battery. For example, asking how often the clinician requested education information did not give evidence of how often they requested this information when conducting an autism evaluation. The results indicated that every clinician has requested educational information, but did not offer information about how often they did so.

Replicability is one way to check the validity of results for research. This study is replicable in terms of stakeholder groups and survey methods. If replicated, participants from a different demographic area may offer disparate responses. Nevertheless, lending to the validity of the results was stakeholder feedback that reflected and aligned with the research literature.

Despite the limitations of this study, I suggest the feedback of the stakeholders was adequate to address the research questions and warrant further investigation into a contextually based autism behavior rating tool. In the next chapter, I synthesize the findings of my study as situated in the larger context of autism diagnosis and educational 
identification. I conclude with a discussion of the implications for further study and practice. 


\section{Chapter Five: Discussion}

In Chapter Five, I restate the research problem and questions. I give a brief and concise discussion of the major findings and outcomes, and offer conclusions. I relate the results to the research questions to the literature review. For mutual reference and understanding, I frame the results within the theoretical constructs of behaviorism and social cognitive theory. I also offer suggestions and recommendations for further research. Finally, I discuss implications for future policy and practice of the autism evaluative process.

The problem is current autism behavior rating scales for teachers are not contextspecific, they do not accurately describe behaviors associated with autism spectrum disorder (ASD) in an educational environment, nor do they offer a real time data collection method of identifying present levels of functioning. The possible result is misdiagnosis, inappropriate educational programming, and a negative impact on future life function of individuals with autism. Addressing the problem is important to society as a whole; however, stakeholders are those with a special interest in the outcome.

The purpose of this study was to determine the efficacy and feasibility of a context-specific autism behavior rating tool for an educational environment from the perspectives of three major stakeholders: clinicians, educators, and parents. It was my hypotheses that, the stakeholders in the evaluative process would provide positive feedback of the efficacy and feasibility of data collected from a context-specific autism behavior rating tool for an educational environment with real time data collection methods. 
To guide the stakeholders' survey responses, I provided a brief example of a context-specific autism behavior rating tool for an educational environment and an observation method for real time data collection. The following were the research questions:

1. What did clinicians think about the efficacy and feasibility of a contextspecific autism behavior rating tool for diagnosis?

2. What did educators think about the efficacy and feasibility of a contextspecific autism behavior rating tool for educational identification and planning?

3. What did parents think about the type of information gathered from a contextspecific autism behavior rating tool for understanding their child's learning needs?

I surveyed each stakeholder group (clinicians, educators, and parents) to answer the research questions. I analyzed the data using a constant comparative method based in Grounded Theory (Glaser \& Strauss, 1967). Next, I provide a synthesis the findings derived from stakeholder feedback.

\section{Synthesis of Findings}

Stakeholder feedback indicated the information from a context specific autism behavior rating tool is useful. It was my hypotheses that stakeholders in the diagnostic and special education identification process for children with autism would affirm data collected from a context specific autism behavior rating tool with real time data collection methods, to be useful and have feasibility for increase accuracy in diagnosis 
and educational identification and programming for children on the spectrum. Only part of my hypotheses was confirmed. Stakeholders agreed to the efficacy of the tool; however, their feedback did not confirm feasibility. Stakeholders' responses indicated the tool as designed was too cumbersome and time consuming to be administered by classroom teachers.

Descriptive information for each stakeholder group helped to ensure that all stakeholders were qualified to be considered experts for their particular interest. All participants had experience with the evaluative process for children with ASD, and their feedback indicated an understanding of educational interventions and the IEP process. To assist in understanding responses, I review each stakeholder group, restate the research question and themes, and offer a synthesis of the feedback.

\section{Clinicians}

1. The research question for clinicians (Research Question 1) asked, what did clinicians think about the efficacy and feasibility of a context-specific autism behavior rating tool for diagnosis?

The descriptive information revealed all of the clinicians were experienced with administering autism evaluations. The themes identified from responses to the open ended questions were: (a) the value and efficacy for diagnosis (b) the specificity (accuracy) and objectivity of the data collected, and (c) the feasibility of the example context specific tool for teachers use.

Feedback from nine of 10 clinicians indicated the information from a contextspecific behavior rating tool would be useful for diagnosis of individuals with autism. I 
suspect the one clinician who consistently gave negative feedback did not review the example scale before completing the survey, and therefore may not have been able to offer informed responses to the questions.

Clinicians' noted that the data from the example context-specific autism rating tool is unique and different from other evaluative techniques. They considered the information from the example context-specific tool to be useful for diagnosis, supplemental information to other evaluative tools, and a reliability measure to use in conjunction with other data sources.

When clinicians were asked the likelihood of using a context-specific tool eight out of 10 responded a strong likelihood. Half of these clinicians surveyed did not feel comfortable administering the ADOS-2, supporting findings in the literature review of autism behavior rating scales being used for diagnostic purposes (Charman \& Gotham, 2013; Karim et al., 2014; Matson et al., 2011).

Clinicians feedback suggested the example context-specific tool would offer better baseline data, and improved measures over existing tools. One clinician commented, "On many levels, the ability for an individual to be successful at school has greater implications for real-world adjustment than behaviors observed in the clinic." This comment reflected the importance of the context in offering a more accurate reflection of functioning abilities.

Clinicians identified another advantage of the context-specific tool as having the potential for increasing diagnostic accuracy through the use of a comparison group of same age peers. One clinician commented, "The same aged 
peers are, in effect, the comparison group. The direct comparison process improves the identification of atypical, unusual behaviors." The information in a context-specific tool could offer clinicians inexperienced with children and youth with autism a better understanding of typical development.

Eight of 10 clinicians expressed concern for the feasibility of the contextspecific tool for teacher administration. Clinician feedback identified concerns about teachers being able to complete such an in-depth evaluation during the course of the regular school day. They made the suggestion that a school psychologist or counselor might be better equipped to meet the evaluative demands of a context-specific tool. School psychologists are uniquely qualified to evaluate and assist educators in meeting the mental health needs of students (National Association of School Psychologists, 2015). Next, I turned my attention to educator results.

\section{Educators}

The research question for educators (Research Question 2) asked, what did educators think about the efficacy of a context-specific autism behavior rating tool? The themes identified from educator feedback were: (a) improved relevancy of information for educational planning, (b) improved accuracy of the data collected, and (c) the benefit as a training tool for educators.

The descriptive information assured educators had experience and understanding of the evaluative process for educational identification of children with autism. Participants included both general and special education teachers, offering a broader 
understanding of the educator perspective. The feedback demonstrated overwhelming support for the efficacy of the context-specific tool. Educators expressed the tool's efficacy for clearly documenting deficit areas, directing IEP goals, data for more specific instruction, assistance with scaffolding instruction, highlighting possible gaps in current instructional methods, and acting as a template for how to approach interventions. One educator's comment encompassed the importance of a tool designed for a school setting, "I appreciate that this is specific to school settings, after all, we are looking for educational impact." The educator addressed the main difference between diagnosis and educational identification for special education services.

Educators also commented on the perceived increase in accuracy of the data collected from a context-specific tool over current evaluative methods. Included in accuracy comments were clearly defined behaviors, more accurate measurement standards, and the number of opportunities for data collection. One educator commented, "A very clear description of particular behavior, with frequency count of actual occurrences and the intensity levels, would be much more informative than the typical scales that just ask (always, sometimes, never)." The details are what assist teachers with defining the expected growth and measures for IEP development.

Educators also commented about the ease of translating the evaluative results to goals for instruction, "This process provides a good link between data driven present levels and SDI (student direct instruction)." Current scales do not offer behaviors descriptors typically observed in the classroom setting, so educators are tasked with 
translating the skill deficit to experiences that can be measured in a classroom environment (Leeber et al., 2012).

Educators also reported the efficacy of the tool for professional development and training opportunities for both licensed professionals and instructional support staff. The complex behavior presentation of students on the spectrum can be difficult to understand for staff that lacks training specific to autism (Barnhill et al., 2011). Educators identified inexperienced teachers, general education teachers, and support staff would benefit from the information contained in the context-specific tool.

Like clinicians, the educators reported that the tool does not have feasibility as currently designed. Drawbacks for feasibility included time to complete the tool, and the detail and amount of reading required. For the tool to be used effectively in an educational setting there would need to be modifications to the design or the personnel who completed it. Next, I review the results of the parent feedback.

\section{Parents}

The research question for parents, (Research Question 3) asked, what did parents think about the type of information gathered from a context-specific autism behavior rating tool for understanding their child's learning needs? The themes identified for parent feedback were: (a) allowed for comparison to peers in the context of school, (b) mutual understanding with school staff of their child's behaviors, and (c) improved information that was understandably relevant to IEP and educational planning and their child's development. 
The parent responses were quite emotional. Parents reported on feelings and understanding, more than psychometric qualities for instruction or diagnosis. Comments were made about the value of having comparison of peers to understand their children's skill deficits. One parent expressed the comparison as, getting a better sense of "normal." Children with autism having higher cognitive function may not be diagnosed or identified until school age. Research suggests the skill deficits become more apparent with the social challenges of the school setting (APA, 2013). Having same-age peers as a comparison group highlights the subtler learning differences (Center for Disease Control and Prevention, 2012; Rosenberg et al., 2011).

The topic with the most feedback from parents was mutual understanding of their child's behaviors and needs. Most of the parents voiced concern about teachers and school staff misunderstanding their child. Parents expressed the context-specific tool offered a way of describing behaviors in non-judgmental terms, and the possible motivation for the behaviors, which was not available to them in the past. One parent described feeling like past evaluative tools asked a teacher to sit down at the end of a long day and report how much the child annoyed them. One parent said, “...it (contextspecific tool) would help me and all members of the IEP team, recognize that his motivations are often very different than their assumptions." Parent feedback indicated an appreciation of the descriptive, non-judgmental language the context-specific tool offered.

The last theme identified by parents' feedback was the efficacy of the information collected to inform the IEP process. Parents reported not having a clear understanding of 
how the current goals related to their child, or, a poor relationship between goals and skill deficits. One parent reported his or her child having behaviors that were tracked daily by school staff, but were not part of the child's IEP goals and objectives. Another parent's comments reflected an apparent disagreement at past IEP meetings at his or her child's school, “....if we were not in complete agreement, I could provide my counter-arguments in a prepared and logical manner." These parents indicated feeling more equipped to discuss his or her child's goals in an IEP meeting.

All stakeholders vested in the autism evaluative process expressed the efficacy of a context-specific autism rating tool with real time data collection methods. Clinician's that request the information for diagnosis, and the teachers that would complete the context-specific tool, both agree that it does not have feasibility as it is designed. Parents were not queried about the feasibility of the context-specific autism behavior rating scale, as they do not have the same interest in feasibility as clinicians and teachers. Next, I discuss the findings in relation to the literature review, framing the findings in the context of behaviorism and social cognitive theory.

\section{The Larger Context}

Gathering expert feedback is not evidence of need for a context-specific autism behavior rating tool. Without a research base to support the need, the information would be speculative. In this section, I relate the feedback of stakeholders to the salient features identified in the literature. In this way, feedback builds on prior study to inform future practice. First, I review the theoretical frameworks used to offer increased understanding of the phenomena of autism evaluative tools. 


\section{Theoretical Framework}

Behaviorism is the theoretical and philosophical framework that took the study of human behavior from the realm of subjective psychology into the realm of objective quantified science (Skinner, 1953, Watson, 1924). Behaviors turned into quantifiable

data are what guide appropriate individualized instruction (Dunn, Airola, Lo, \& Garrison, 2013).

Behaviorist research has also demonstrated how behaviors are influenced by the environment (Bullock, 1982; Ozonoff et al., 2005). Bronfenbrenner and Evans (2000) called the influence of the environment on learning as proximal process, and contend measuring behaviors that are not typical of the environment would eschew data.

Behavioral theory is reflected in the results of this study by support for a contextspecific behavior rating tool increasing accuracy in diagnosis and educational planning. Clinician comments reflected the increased accuracy of the behavior descriptors as improving information for diagnosis. Educator feedback commented on the accuracy of the behavioral information for identifying present levels of performance for IEP goal development. Parents identified non-judgmental language and common language for understanding as benefits of clearly defined behaviors in understanding their child's learning needs.

Social cognitive theory frames the act of learning. Bandura (1971) described learning as occurring through continuous interaction of three factors: First, behavior is demonstrated or witnessed. Second, the environment influences the ways in which 
behaviors occur. Last, personal factors such as cognition, affective, and biological events further influence learning.

Social cognitive theory was reflected in the stakeholder feedback. Clinician comments addressed the importance of considering the comparison of same aged peers for improving diagnosis. Part of the diagnostic process includes medical history and cognitive function. Educators expressed the importance of understanding how the demands placed on children during the school day impacts learning. They identified using a context-specific tool as a training opportunity for inexperienced school personnel so they too might understand the factors that influence learning for a child on the spectrum. Parents commented on the helpfulness of understanding how their child is different from other children. They also expressed a desire to have their children's motivation for behaviors understood by educators.

Understanding the feedback of stakeholders by using the lens of behaviorism for clearly defined behaviors and observations, and social cognitive theory for a deeper understanding of the learning profile of a child with autism, gives a more holistic view of the child's developmental needs. Next, I give a brief summary of findings in the literature review that are reflected in the stakeholder feedback.

\section{Research Literature}

The following section outlines the responses by stakeholder group as they relate to the literature. Feedback from the stakeholders' links to prior research as verification of the results offering additional knowledge for the field. 
Clinicians. Research demonstrated identifying skill deficits in a variety of settings to be the most accurate method of diagnosing of individuals with autism spectrum disorder (Filipek et al., 2005; Volkmar et al., 2014). Without access to educational records and educational input, a minimum of $38 \%$ of autism cases would have been missed (CDC, 2012; Pettygrove et al., 2013). Clinician feedback supported the useful information gleaned from the context-specific tool for improving diagnostic information over current behavior rating scales.

While the ADOS-2 (Lord et al., 2012) is considered the gold standard in autism assessments and most commonly used by clinicians, research identified drawbacks of using the ADOS-2: costly, time consuming, and requiring specialized training to administer (Sikora et al., 2008). These drawbacks could attribute to clinicians and school districts often relying on behavior rating scales for diagnosis and educational identification (Charman \& Gotham, 2013; Karim et al., 2014; Matson et al., 2011). My findings align with the research that indicates that $50 \%$ of the clinicians using behavior rating scales for diagnosis and reported not feeling comfortable administering the ADOS2 (Charman \& Gotham, 2013; Karim, Cook, \& O'Reilly, 2014; Matson, Rieske, \& Tureck, 2011). While my study did not probe participants for reasons, there feedback might be attributed to the identified drawbacks.

Research supported the need for accurate behavior descriptors on teacheradministered autism behavior rating tools (Belsky \& Hartman, 2014). In my study, clinician feedback confirmed the importance of accurate behavior descriptors in the context of the school for aiding diagnostic decisions. The literature review revealed poor 
reliability between parent and teacher scales as they currently exist. Reed and Osborne (2013) found the parent and teacher questionnaires had little agreement for the individual child. Clinician feedback in my study suggests the context-specific tool has the potential to increase the inter-rater reliability between parent and teacher responses.

In addition to diagnostic concerns, the medical community identified structured educational interventions showing better outcomes for children with ASD (Kulage, Smaldone, \& Cohn, 2014). The development of an appropriate individualized educational plan is central in providing effective service to children and their families (Kurth \& Mastergeorge, 2010; Ruble \& McGrew, 2013). In my study, clinicians identified the context-specific tool as offering better baseline data and improved measurement over existing tools for educational planning. Next, I review the research for the educator stakeholders.

Educators. Parsons et al. (2013) contended pairing researchers with educators that used the methods and interventions resulted in greater fidelity and information useful for the everyday issues teachers faced. Parsons et al. also made the important point that research methods must be applicable to a variety of educational settings, mainstream (general), and special education. The feedback from teachers in my study was from general and special education teachers and supported the efficacy of the information for educational planning. Including educators in this study gave them a forum to contribute their concerns to the problem of practice.

Leeber et al., (2012) revealed poor IEP goal development from evaluative data. 
Leeber et al. recommended evaluating a child's learning in context to offer more accurate results and instructional goals. The stakeholder feedback in my study supported Leeber et al.'s recommendations. Educators expressed confusion for creating IEP goals from current scales, and identified an increased understanding in the link between the evaluative data, educational goals, and instructional methods with the context-specific tool.

A number of researchers identified measuring behaviors not typical of the environment eschews data. For accuracy and control, scientists should not make the mistake of integrating behavioral data across settings because the environment has a significant influence on human behavior (Bronfenbrenner \& Evans, 2000; Bullock, 1982; Ozonoff et al., 2005). In addition to context of behaviors, research identified reflective data collection methods to be less accurate than real time data collection methods (Maxwell, 2012; Taber-Doughty \& Jasper, 2012; Whittemore et al., 2001). In my study, educators expressed agreement that a context-specific autism behavior rating tool with real time data collection methods offered more accurate and useful information than the current evaluative tools for educational planning and understanding the learning profile of children with autism.

Educator responses indicated the efficacy of the context-specific tool for professional development and training. Barnhill et al. (2001) found educators do not receive adequate training specifically for autism spectrum characteristics. In addition, general educators need specialized training to serve students with disabilities in general education classrooms (Humphrey \& Symes, 2013; U.S. Department of Education, 2008). 
Biasotti (2013) found the more experience teachers had instructing students with ASD, and increased levels of professional development, led to greater self-efficacy and a positive impact on student achievement. The results of my study supported use of the tool for professional development specific toward all educators who work with children that have ASD. Educator stakeholders identified the tool as useful for training both teachers and educational support staff in meeting the needs of children on the spectrum.

Parents. In my study, parents identified the advantage of having a comparison of peers, in the context of school, for better understanding of their child's learning needs. Allen et al. (2008) identified evaluative data that reflected how students interacted with peers and received instruction in a classroom as vital for the determination of educational interventions and supports. Leeber et al. (2012) spoke to the importance of data in context for parent understanding, "In order to design interventions, plan inclusion, or make recommendations to teachers and parents on how to facilitate children's learning and enable their participation in diverse groups, one needs to understand children's learning-in-context and look what children may be able to do under certain conditions" (p. 85). Parent feedback about understanding their children in comparison to other children the same age supported Leeber et al.'s claims.

Keenan et al. (2010) and Zeitlin and Curcic (2014) found parents reported the entire process from diagnosis of ASD to educational programming extremely stressful. The emotion was evident in the parent responses in my study and might have been a contributing factor to the low response rate for that stakeholder group. Perhaps when faced with the choice of yet another emotional charged experience parents are reluctant to 
engage. Some of the suggestions to make the process less stressful for parents included: make the process more child focused; make reports more human-focused and caring with stories describing how their children performed in the classroom; and keep the process focused on the positive and what their children can do rather than what they cannot (Ho et al., 2013).

Parent feedback from my study reported an appreciation for a context-specific tool having a common language to describe and understand their child's learning needs. Parents echoed prior research documenting frustration toward educators understanding their children's behaviors. Parents also identified an appreciation for the language on the context-specific too being non-judgmental.

The comments from parents seemed to express relief for having the skill deficits clearly defined in terms of behaviors in school. One parent commented, “...his behaviors are colored by the teacher's judgement of his motivation, and often attributed to rudeness or disrespect." Another commented, "a teacher sitting down at the end of a long day of work and answering the question: Tell us how much this kid annoys you." It seemed important to parents that teachers not view their children as "rude" or "bad" but recognize their child's behaviors were the result of a disability.

The research about connecting evaluative results to IEP goals was not encouraging. Ruble et al. (2010) determined overall IEP development is poor and parent input was only included in about half of the IEPs. The responses from parent participants in my study reflected the same concerns identified by Ruble et al. Parents expressed the an increased understanding in the relationship between the evaluative results and 
educational programming with the context-specific tool. They also identified feeling more equipped to participate constructively in IEP meetings using the data from the context-specific tool.

Despite the small sample size, and other limitations of the study, the overall

feedback from all stakeholder groups was supported by prior research. The connection to prior research offered validity to the results. In the next section, I discussed the implications for future practice.

\section{Implications}

The results of my research contributed to the body of knowledge concerning autism evaluative practices. Beyond the relevancy of the efficacy of the tool for stakeholder purposes, I also learned that clinicians and educators perceived the tool to be too cumbersome or time consuming for use by classroom teachers.

It was my goal to discover if the example of a context-specific tool could: (a) be useful enough to meet the diagnostic needs of clinicians; (b) be easy enough to administer to have feasibility for teachers; (c) contain instructional information needed for specific instruction; and (d) provide increased understanding for parents to aid in supporting their child's development. The stakeholders in my study helped me to realize this initial goal.

Nevertheless, I am concerned about completely removing classroom teachers from the administration of a context-specific autism behavior rating tool. Teachers commented on the benefit of the tool for understanding what the skill deficits of autism present like in a classroom environment. Parent feedback indicated how common language would allow them to participate more meaningfully in their child's IEP 
meetings. To completely remove teachers might also remove the reported benefits. It will be important to consider the feedback of parents and educators in future design.

Simply answering the questions of efficacy and feasibility from stakeholder perspectives does not mean the tool will have validity or reliability for identifying hallmark skill deficits of autism. For the tool to have proven psychometric qualities, it needs to be tested with a large population. My personal interest in conducting this study was twofold: (a) to investigate the likelihood of a tool, like the example in this study, being used by practitioners in the medical and educational communities, (b) to gather evidence in support of funding, for the investigation of the psychometric properties of a context-specific tool for an educational environment.

The Continuum of Autism Spectrum Traits (C.O.A.S.T.) is the parent version of the tool that compliments the context-specific version in this study. The preliminary validity study of the C.O.A.S.T. is currently under way with Dr. Eric Fombonne, Director of Autism Research at Oregon Health and Sciences University (Fombonne, Sherman, \& Ganzler, 2015). It is my hope funding organizations will recognize the value of supporting further research of the C.O.A.S.T. Teacher Edition, which is a contextspecific autism behavior rating scale with real time data collection methods.

The importance of context can no longer be ignored when evaluating children for autism. We, as clinicians, educators, parents, and society, have a responsibility to heed the research results. The possibility of improving the life function of individuals with autism is simply too important to ignore. 


\section{References}

Action, A. O. (1999). Practice parameters for the assessment and treatment of children, adolescents, and adults with autism and other pervasive developmental disorders. Journal of the American Academy of Child and Adolescent Psychiatry, $38(12), 32 \mathrm{~S}-54 \mathrm{~S}$.

Ainscow, M., Dyson, A., \& Weiner, S. (2013). From exclusion to inclusion: a review of international literature on ways of responding to students with special educational needs in schools. En-clave pedagógica: Revista Internacional de Investigación e Innovación Educativa, 13, 13-30.

Allen, R. L., Robbins, D. L., \& Decker, S. L. (2008). Autism spectrum disorders: Neurobiology and current assessment practices. Psychology in the Schools, 45(10), 905-917.

American Psychiatric Association. (2013). Diagnostic and statistical manual of mental disorders ( $5^{\text {th }}$ ed.). Arlington, VA: Author. Retrieved from http://www.dsm5.org/Documents/Autism\%20Spectrum\%20Disorder\%20Fact\%20 Sheet.pdf

Autism Society of America. (2013). Medical diagnosis [Data file]. Retrieved from http://www.Autism-society.org/about-Autism/diagnosis/medical-diagnosis.html

Bandura, A. (1962). Social learning through imitation. In M. R. Jones (Ed.), Nebraska symposium on motivation (pp.189-282). Lincoln, NB: University of Nebraska Press.

Bandura, A. (1971). Social learning theory. New York, NY: General Learning Press. 
Barnhill, G. P., Polloway, E. A., \& Sumutka, B. M. (2011). A survey of personnel practices in autism spectrum disorders. Focus on Autism and Other Developmental Disabilities, 26(2), 75-86.

Barth, P., Dillon, N., Hull, J., \& Higgins, B. H. (2016). Fixing the holes in the teacher pipeline [White paper]. Retrieved from Center for Public Education website: http://www.centerforpubliceducation.org/Main-Menu/Staffingstudents/AnOverview-of-Teacher-Shortages-At-a-Glance/Overview-of-Teacher-ShortagesFull-Report-PDF.pdf

Bellini, S., \& Akullian, J. (2007). A meta-analysis of video modeling and video selfmodeling interventions for children and adolescents with autism spectrum disorders. Exceptional Children, 73(3), 264-287.

Belsky, J., \& Hartman, S. (2014). Gene-environment interaction in evolutionary perspective: Differential susceptibility to environmental influences. World Psychiatry, 13(1), 87-89.

Biasotti, N. A. (2013). The impact of professional development training in autism and experience on teachers' self-efficacy (Dissertation). Available from ProQuest Digital Dissertations Database. (AAT 3602382).

Boavida T., Aguiar, C., \& McWilliam, R. A. (2014). A training program to improve IFSP/IEP goals and objectives through the routines-based interview. Topics in Early Childhood Special Education, 33(4), 200-211.

Bolster, A. (1983). Toward a more effective model of research on teaching. Harvard Educational Review, 53(3), 294-308. 
Bolte, E., \& Diehl, J. (2013). Measurement tools and target symptoms/skills used to assess treatment response for individuals with autism spectrum disorder. Journal of Autism and Developmental Disorders, 43(11), 2491-2501.

Bronfenbrenner, U., \& Evans, G. W. (2000). Developmental science in the 21st century: Emerging questions, theoretical models, research designs and empirical findings. Social Development, 9(1), 115-125.

Bullock, D. H. (1982). Behaviorism and NSPI: The erratically applied discipline. Performance and Instruction, 21(3), 4-8.

Center for Autism Research. (2014). Social Responsiveness Scale. The Children's Hospital of Philadelphia, PA. Retrieved from https://www.carautismroadmap.org/social-responsiveness-scale/?print=pdf Center for Disease Control and Prevention. (2012). Prevalence of autism spectrum disorders-Autism and Developmental Disabilities Monitoring Network, 14 sites, United States, 2008. Morbidity and Mortality Weekly Report, 61, 1-19.

Charman, T., \& Gotham, K. (2013). Measurement issues: Screening and diagnostic instruments for autism spectrum disorders-lessons from research and practice. Child and Adolescent Mental Health, 18(1), 52-63.

Charlop, M. H., Schreibman, L., \& Tryon, A. S. (1983). Learning through observation: The effects of peer modeling on acquisition and generalization in autistic children. Journal of Abnormal Child Psychology, 11(3), 355-366. 
Cicchetti, D. V. (1994). Guidelines, criteria, and rules of thumb for evaluating normed and standardized assessment instruments in psychology. Psychological Assessment, 6(4), 284.

Constantino J. N., \& Gruber C. P. (2005). Social Responsiveness Scale (SRS). Los Angeles, CA: Western Psychological Services.

Creswell, J. W. (2012). Qualitative inquiry and research design: Choosing among five approaches. Los Angeles, CA: Sage.

Cunningham, S. (2012). Examining the validity of the autism spectrum rating scales with a preschool population referred for special education evaluation. (Dissertation). Available from ProQuest Dissertations and Theses database. (Order No. $3522302)$.

Dawson, G., \& Bernier, R. (2013). A quarter century of progress on the early detection and treatment of autism spectrum disorder. Development and Psychopathology, 25(42), 1455-1472.

Dey, I. (1993). Qualitative data analysis: A user friendly guide for social scientists. London, England: Routledge.

Dollard, J., \& Miller, N. E. (1950). Personality and psychotherapy, New York, NY: McGraw-Hill.

Drasgow, E., Yell, M. L., \& Robinson, T. R. (2001). Developing legally correct and educationally appropriate IEPs. Remedial and Special Education, 22(6), 359-373. 
Dunn, K. E., Airola, D. T., Lo, W. J., \& Garrison, M. (2013). Becoming data driven: The influence of teachers' sense of efficacy on concerns related to data-driven decision making. The Journal of Experimental Education, 81(2), 222-241.

Falkmer, T., Anderson, K., Falkmer, M., \& Horlin, C. (2013). Diagnostic procedures in autism spectrum disorders: A systematic literature review. European Child and Adolescent Psychiatry, 22(6), 329-340.

Feng, L., \& Sass, T. R. (2013). What makes special-education teachers special? Teacher training and achievement of students with disabilities. Economics of Education Review, 36, 122-134.

Filipek, P. A., Accardo, P. J., Baranek, G. T., Cook Jr, E. H., Dawson, G., Gordon, B., ... \& Volkmar, F. R. (1999). The screening and diagnosis of autistic spectrum disorders. Journal of Autism and Developmental Disorders, 29(6), 439-484.

Filipek, P. A., Accardo, P. J., Baranek, G. T., Cook, E. H., Jr., Dawson, G., Gordon, B., . .. \& Fombonne, E. (2005). The changing epidemiology of Autism. Journal of Applied Research in Intellectual Disabilities, 18(4), 281-294.

Fish, W. W. (2008). The IEP meeting: Perceptions of parents of students who receive special education services. Preventing School Failure: Alternative Education for Children and Youth, 53(1), 8-14.

Fisher, M., \& Meyer, L. H. (2002). Development and social competence after two years for students enrolled in inclusive and self-contained educational programs. Research and Practice for Persons with Severe Disabilities, 27(3), 165174. 
Fombonne, E. (2005). The changing epidemiology of autism. Journal of Applied Research in Intellectual Disabilities, 18, 281-294.

Fombonne, E., Sherman, K., \& Ganzler, S., (2015). Preliminary validity study of the Continuum of Autism Spectrum Traits (COAST). A parent survey of autistic Behaviors. Portland, OR: Oregon Health and Sciences University.

Fowler, F. J. (2009). Survey research methods (4 ${ }^{\text {th }}$ ed. $)$. Thousand Oaks, CA: Sage. Ganzler, S. (2014). Proceedings from Grand Rounds: The Evolution of Autism Spectrum Disorder Diagnosis. Chico, CA: Enloe Medical Center.

Gilliam, J. E. (2006). GARS-2: Gilliam Autism Rating Scale. Austin, TX, Pro-ed.

Glaser, B.G., \& Strauss, A.L. (1967). The discovery of grounded theory: Strategies for qualitative research. New York, NY: Aldine De Gruyter.

Goldstein, S., \& DeVries, M. (2013). Autism spectrum disorder enters the age of multidisciplinary treatment. In S. Goldstein \& J. A. Naglieri (Eds.), Interventions for autism spectrum disorders (pp. 3-18). New York, NY: Springer.

Goldstein, S., \& Naglieri, J. A. (2009). Autism Spectrum Rating Scales (ASRS) technical manual. Tonawanda, NY: Multi-Health Systems.

Ho, H. S., Yi, H., Griffiths, S., Chan, D. F., \& Murray, S., (2013). Lay abstracts. Autism, 18(7), 832-844.

Humphrey, N., \& Symes, W. (2013). Inclusive education for pupils with autistic spectrum disorders in secondary mainstream schools: teacher attitudes, experience and knowledge. International Journal of Inclusive Education, 17(1), 32-46.

Individuals with Disabilities Education Act Regulations (2006), 71 FR 46540-46844. 34 
C.F.R. $\S 300.1$ et seq. (2008).

Ingvarson, L., Meiers, M., \& Beavis, A. (2005). Factors affecting the impact of professional development programs on teachers' knowledge, practice, student outcomes \& efficacy. Retrieved from http://research.acer.edu.au/professional_dev/1

Joy, S. M. (2008). The impact of legislation and litigation on the education of students with autism spectrum disorders. (Dissertation). Available from ProQuest Dissertations \& Theses Full Text. (Order No. 3318938).

Kanner, L. (1943). Autistic disturbances of affective contact. Nervous Child, 2, 217-250.

Karim, K., Cook, L., \& O'Reilly, M. (2014). Diagnosing autistic spectrum disorder in the age of austerity. Child: Care, Health and Development, 40(1), 115-123.

Keenan, M., Dillenburger, K., Doherty, A., Byrne, T., \& Gallagher, S. (2010). The experiences of parents during diagnosis and forward planning for children with autism spectrum disorder. Journal of Applied Research in Intellectual Disabilities, 23, 390-397.

Krathwohl, D.R., (2009). Methods of educational and social science research. Long Grove, IL: Waveland Press.

Krug, D., Arick, J., \& Almond, P., (2008). Autism screening instrument for educational planning ( $2^{\text {nd }}$ ed.). Austin, TX: Pro-Ed.

Kulage, K. M., Smaldone, A. M., \& Cohn, E. G. (2014). How will DSM-5 affect autism diagnosis? A systematic literature review and meta-analysis. Journal of Autism and Developmental Disorders, 44(8) 1918-1932. 
Kurth, J., \& Mastergeorge, A. M. (2010). Individual education plan goals and services for adolescents with autism: Impact of age and educational setting. The Journal of Special Education, 44(3), 146-160.

Landa, R., (2008). Diagnosis of autism spectrum disorders in the first 3 years of life. Natural Clinical Practice Neurology, 4, 138-147.

Landa, R. J., Gross, A. L., Stuart, E. A., \& Faherty, A. (2013). Developmental trajectories in children with and without autism spectrum disorders: The first 3 years. Child Development, 84(2), 429-442.

Lavelle, T. A., Weinstein, M. C., Newhouse, J. P., Munir, K., Kuhlthau, K. A., \& Prosser, L. A. (2014). Economic burden of childhood autism spectrum disorders. Pediatrics, 133(3), e520-e529.

Leaf, J. B., Leaf, R., McEachin, J., Taubman, M., Ala'i-Rosales, S., Ross, R. K., ... \& Weiss, M. J. (2016). Applied behavior analysis is a science and, therefore, progressive. Journal of autism and developmental disorders, 46(2), 720-731.

Lebeer, J., Birta-Székely, N., Demeter, K., Bohács, K., Candeias, A. A., Sønnesyn, G.,... \& Dawson, L. (2012). Re-assessing the current assessment practice of children with special education needs in Europe. School Psychology International, 33(1), 69-92.

Lincoln, Y. S., \& Guba, E. G. (1985). Naturalistic inquiry. Newbury Park, CA: Sage. Liu, X., Zhou, X., \& Lackaff, J. (2013). Incremental validity in the clinical assessment of early childhood development. Journal of Psychoeducational Assessment, 31(5), 506-515. 
Lord, C., Rutter, M., DiLavore, P. C., Risi, S., Gotham, K., \& Bishop, S. (2012). Autism diagnostic observation schedule: ADOS-2. Torrance, CA: Western Psychological Services.

Lord, C., \& Jones, R. M. (2012). Annual research review: Re-thinking the classification of Autism Spectrum Disorders. Journal of Child Psychology and Psychiatry, $53,490-509$.

Matson, J. L., Rieske, R. D., \& Tureck, K. (2011). Additional considerations for the early detection and diagnosis of autism: Review of available instruments. Research in Autism Spectrum Disorders, 5(4), 1319-1326.

Matson, J. L., Wilkins, J., Sharp, B., Knight, C., Sevin, J. A., \& Boisjoli, J. A. (2009). Sensitivity and specificity of the Baby and Infant Screen for Children with Autism Traits (BISCUIT): Validity and cutoff scores for autism and PDD-NOS in toddlers. Research in Autism Spectrum Disorders, 3(4), 924-930.

Maxwell, J. A. (2012). Qualitative research design: An interactive approach. Los Angeles, CA: Sage.

Miles, M. B., \& Huberman, A. M. (1994). Qualitative data analysis: An expanded sourcebook. Thousand Oaks, CA: Sage.

More, C. M., \& Hart Barnett, J. E. (2014). Developing individualized IEP goals in the age of technology: Quality challenges and solutions. Preventing School Failure: Alternative Education for Children and Youth, 58(2), 103-109. 
National Association of School Psychologists. (2015). Who are school psychologists? Retrieved from https://www.nasponline.org/about-school-psychology/who-areschool-psychologists.

National Professional Development Center on Autism Spectrum Disorders. (2011).

Recommended instruments for diagnostic evaluation. Multi-University Center: University of North Carolina at Chapel Hill, University of California at Davis Medical School, and University of Wisconsin at Madison. Retrieved from http://autismpdc.fpg.unc.edu/content/ei-module-resources

National Research Council. (2001). Educating children with autism. Washington, DC: National Academy Press.

No Child Left Behind (NCLB) Act of 2001, Pub. L. No. 107-110, § 115, Stat. 1425 (2002).

Ozonoff, S., Goodlin-Jones, B. L., \& Solomon, M. (2005). Evidence-based assessment of autism spectrum disorders in children and adolescents. Journal of Clinical Child and Adolescent Psychology, 34(3), 523-540.

Parsons, S., Charman, T., Faulkner, R., Ragan, J., Wallace, S., \& Wittemeyer, K. (2013). Commentary-bridging the research and practice gap in autism: The importance of creating research partnerships with schools. Autism, 17(3), 268-280.

Pazey, B. L., \& Cole, H. A. (2013). The role of special education training in the development of socially just leaders building an equity consciousness in educational leadership programs. Educational Administration Quarterly, 49(2), $243-271$. 
Pettygrove, S., Pinborough-Zimmerman, J., Meaney, F. J., Braun, K. V. N., Nicholas, J., Miller, L., ... \& Rice, C. (2013). Predictors of ascertainment of autism spectrum disorders across nine US communities. Journal of Autism and Developmental Disorders, 43(8), 1867-1879.

Plano Clark, V., \& Creswell, J.W., (2010). Understanding research, a consumer's guide. Upper Saddle River, NJ: Pearson.

Prelock, P. A., Beatson, J., Bitner, B., Broder, C., \& Ducker, A. (2003). Interdisciplinary assessment of young children with autism spectrum disorder. Language, Speech \& Hearing Services in Schools, 34(3), 194-202.

Pretti-Frontczak, K., \& Bricker, D. (2000). Enhancing the quality of individualized education plan (IEP) goals and objectives. Journal of Early Intervention, 23(2), 92-105.

Qualtrics (2014). Qualtrics survey software. 59780 0.999s (0.201, 0.157, 0.076, 0.060, 0.009) Provo, UT.

Reed, P., \& Osborne, L. A. (2013). The role of parenting stress in discrepancies between parent and teacher ratings of behavior problems in young children with autism spectrum disorder. Journal of Autism and Developmental Disorders, 43(2), 471477.

Rehabilitation Act of 1973, Pub. L. No. 93-112, 87 Stat. 355 (1973).

Rimland, B. (1971). The differentiation of childhood psychoses: An analysis of checklists for 2,218 psychotic children. Journal of Autism and Childhood Schizophrenia, 1(2), 161-174. 
Rosenberg, R. E., Landa, R., Law, J. K., Stuart, E. A., \& Law, P. A. (2011). Factors affecting age at initial autism spectrum disorder diagnosis in a national survey. Autism Research and Treatment, 41, 110-121.

Ruble, L., \& McGrew, J. H. (2013). Teacher and child predictors of achieving IEP goals of children with autism. Journal of Autism and Developmental Disorders, 43(12), 2748-2763.

Ruble, L. A., McGrew, J., Dalrymple, N., \& Jung, L. A. (2010). Examining the quality of IEPs for young children with autism. Journal of Autism and Developmental Disorders, 40(12), 1459-1470.

Ruble, L. A., Usher, E.L., \& McGrew, J. H., (2011) Preliminary investigation of the sources of self-efficacy among teachers of students with autism. Focus on Autism and Other Developmental Disabilities, 26(2), 67-74.

Schopler, E., Van Bourgondien, M. E., Wellman, G. J., \& Love, S. R. (2010). The Childhood Autism Rating Scale ( $2^{\text {nd }}$ ed.). Los Angeles, CA: Western Psychological Services.

Shattuck, P. T. (2006). The contribution of diagnostic substitution to the growing administrative prevalence of autism in US special education. Pediatrics, 117(4), 1028-1037.

Shelton, T. H., (2013). Exploring pre-service early childhood educators' self-efficacy beliefs and preparedness to teach students with autism spectrum disorder in inclusive classrooms. (UMI No. 3602860). ProQuest Dissertations and Theses, Ann Arbor, MI. 
Sikora, D. M., Hall, T. A., Hartley, S. L., Gerrard-Morris, A. E., \& Cagle, S. (2008). Does parent report of behavior differ across ADOS-G classifications: Analysis of scores from the CBCL and GARS. Journal of Autism and Developmental Disorders, 38(3), 440-448.

Simonoff, E., Pickles, A., Charman, T., Chandler, S., Loucas, T., \& Baird, G. (2008). Psychiatric disorders in children with autism spectrum disorders: Prevalence, comorbidity, and associated factors in a population-derived sample. Journal of the American Academy of Child \& Adolescent Psychiatry, 47(8), 921-929.

Simpson, R. L., Mundschenk, N. A., \& Heflin, L. J. (2011). Issues, policies, and recommendations for improving the education of learners with autism spectrum disorders. Journal of Disability Policy Studies, 22(1), 3-17.

Skinner, B.F. (1945). The operational analysis of psychological terms. Psychology Review, 52(5), 270.

Skinner, B. F. (1953). Science and human behavior. New York, NY: Macmillan.

Smith, D. D., Robb, S. M., West, J., \& Tyler, N. C. (2010). The changing education landscape: How special education leadership preparation can make a difference for teachers and their students with disabilities. Teacher Education and Special Education: The Journal of the Teacher Education Division of the Council for Exceptional Children, 33(1), 25-43.

Stahmer, A. C., Schreibman, L., \& Cunningham, A. B. (2011). Toward a technology of treatment individualization for young children with autism spectrum disorders. Brain Research, 1380, 229-239. 
Sulik, R. L. (2013) Proceedings from Differential Diagnosis and Autism Spectrum Disorder. Fargo, ND: Sanford Behavioral Health Services.

Taber-Doughty, T., \& Jasper, A. D. (2012). Does latency in recording data make a difference? Confirming the accuracy of teachers' data. Focus on Autism and Other Developmental Disabilities, 27(3), 168-176.

U.S. Department of Education. (2014).36th Annual report to Congress on the implementation of the Individuals with Disabilities Education Act, 2014. Washington, DC: , Office of Special Education and Rehabilitative Services, Office of Special Education Programs.

U.S. Department of Education. (2014). Teacher shortage areas nationwide listing 199091 thru 2013-2014: March 2014 [OMB No. 1840-0595]. Washington DC: Office of Postsecondary Education Policy and Budget Development Staff.

Unites States Government Accountability Office. (2005). Special education: Children with autism (Report to the chairman and ranking minority member, subcommittee on human rights and wellness, committee on government reform, house of representatives). No. GAO-05-220 (p. 1-40). United States House of Representatives. Retrieved from http://www.gao.gov/new.items/d05220.pdf United States Government Accountability Office. (2014). Annual report: Additional opportunities to reduce fragmentation, overlap, and duplication and achieve other financial benefits. No. GAO-14-343SP (p. 1-218). Retrieved from http://www.gao.gov/assets/670/662327.pdf 
United States Government, Public Health and Welfare Chapter 6 U.S.C. § 280i-1 (2011) - Public Health Service Subchapter II - General Powers and Duties Part R Programs Relating to Autism Code, Pub. L. No. 112-32, U.S.C. § $280 \mathrm{i}-1$.

Vogt, W. P., Vogt, E. R., Gardner, D. C., \& Haeffele, L. M. (2014). Selecting the right analyses for your data: Quantitative, qualitative, and mixed methods. New York, NY. Guilford.

Volkmar, F., Cook Jr., E., Pomeroy, J., Realmuto, G., \& Tanguay, P. (1999). Summary of the practice parameters for the assessment and treatment of children, adolescents, and adults with autism and other pervasive developmental disorders. Journal of the American Academy of Child and Adolescent Psychiatry, 38(12), 1611-1616.

Volkmar, F., Siegel, M., Woodbury-Smith, M., King, B., McCracken, J., \& State, M. (2014). Practice parameter for the assessment and treatment of children and adolescents with autism spectrum disorder. Journal of the American Academy of Child and Adolescent Psychiatry, 53(2), 237-257.

Watson, J. B. (1924). Behaviorism. New York, NY: The People's Institute.

Whittemore, R., Chase, S. K., \& Mandle, C. L. (2001). Validity in qualitative research. Qualitative Health Research, 11(4), 522-537.

Wilson, C. E., Gillan, N., Spain, D., Robertson, D., Roberts, G., Murphy, C. M., ... \& Murphy, D. G. (2013). Comparison of ICD-10R, DSM-IV-TR and DSM-5 in an Adult Autism Spectrum Disorder Diagnostic Clinic. Journal of Autism and Developmental Disorders, 43(11), 2515-2525. 
Wolff, S. (2004). The history of autism. European Child \& Adolescent Psychiatry, 13(4), 201-208.

Wong, C., Odom, S. L., Hume, K. Cox, A. W., Fettig, A., Kucharczyk, S., ... Schultz, T. R.(2013). Evidence-based practices for children, youth, and young adults with autism spectrum disorder. Chapel Hill, NC: The University of North Carolina, Frank Porter Graham Child Development Institute, Autism Evidence-Based Practice Review Group.

Zeitlin, V. M., \& Curcic, S. (2014). Parental voices on individualized education programs: 'Oh, IEP meeting tomorrow? Rum tonight!' Disability \& Society, 29(3), 373-387. 
Appendix A

\section{Script of introduction to clinician's offices}

Hello, my name is Kate and I am a doctoral student in the Educational Leadership Program at Portland State University. I am conducting research about autism evaluations and would like to give (name of clinician), the opportunity to participate in the study.

Participation requires reviewing a brief example of an autism evaluation and answering a 10-minute anonymous online survey. Would it be possible to email the information to you for forwarding to (Clinician's name)?

There will be no follow up or further action on your part required.

Yes - Thank you, I appreciate your help with this matter. No - Thank you for your time.

\section{Brief introduction email to clinician office staff.}

Re: Forward Study Information

Dear (office staff name, title)

This email contains information about an autism research study you agreed to forward to (Clinician's name). Thank you for assistance in this matter.

Sincerely, Kate Panaccione

Dear _ (Clinician's name)

I am a doctoral candidate at Portland State University and I am conducting a study about autism behavior rating scales. I am seeking your participation by reading a brief example of a context-specific autism behavior rating scale for teachers and then answer 10 questions related to the scale. It should not take more than 10 minutes of your time. You can access more information, consent to participate, and the survey by clicking on the following link: (link to Qualtrics Survey

Software). You will be re-directed to Qualtrics Survey Software and your responses will be anonymous.

Thank you for your consideration on this matter.

Kate Panaccione

Kpan2@pdx.edu 503-477-0369 
Appendix B

\section{Educator Flyer}

The flyer was a full page with a green colored background with the following text:

Are you a licensed educator in Oregon?

Your help is needed to further knowledge of autism evaluations. The study requires Internet access for a brief 20-minute survey.

For more information and to access the survey go to:

(insert Qualtrics Link and Quick Reader)

For more information, contact: Kate Panaccione, M.Ed. CAGS, ASD

Doctoral Student Department of Education, Portland State University

Kpan2@pdx.edu 


\section{Appendix C}

\section{Parent Flyer}

The flyer was a full page and had a green colored background with the following text: Autism Study

Do you have a child that is diagnosed with Autism/Asperger's, or receives special education services for Autism?

Your help is needed to further knowledge of autism evaluations. The study requires Internet access for a brief 20-minute survey.

For more information and to access the

Survey go to:

(insert Qualtrics Link and Reader Square)

For more information or for a paper copy of the materials contact: Micki Caskey, caskeym@pdx.edu, or 503-725-4749 


\section{Appendix D}

\section{Consent for Clinicians}

\section{Introduction}

You are being asked to participate in a research study that is being done by Kate Panaccione, who is the Principal Investigator from the Department of Education, at Portland State University in Portland, Oregon. This is a study about autism behavior rating scales. As a practitioner licensed to diagnose and treat mental disorders in the state of Oregon, your input is needed to advance the knowledge in this field.

School districts and clinicians often rely on autism behavior-rating scales for diagnosis and special education identification. Current autism behavior rating scales use the same behavior descriptors for parents and educators regardless of the setting in which behaviors occur, and they rely on reflective data collection methods. I would like your feedback about the efficacy and feasibility of a behavior rating scale designed specifically for the educational environment that uses real time data collection methods.

\section{Procedures}

You will be shown an example of a context-specific autism behavior rating scale for teachers and asked to complete a short questionnaire about the scale. The questionnaire consists of 10 questions and will take approximately 10 minutes or less. This questionnaire will be conducted with an on-line Qualtrics-created survey.

\section{Risks/Discomforts}

Risks are minimal for involvement in this study. However, you may use your time for an endeavor that ultimately may not influence current practice.

\section{Benefits}

There are no direct benefits for participants. However, it is hoped that through your participation, researchers will learn more about the efficacy and feasibility of an autism behavior rating scales for an educational environment.

\section{Confidentiality}

All data obtained from participants will be kept confidential and anonymous. Data will only be reported in an aggregate format (by reporting only combined results and never reporting individual ones). All questionnaires will be concealed, anonymous, and no one other than the primary investigator and Portland State University will have access to 
them. The data collected will be stored in the HIPPA-compliant, Qualtrics-secure database until the primary investigator has deleted it. The Portland State University Institutional Review Board (IRB) that oversees human subject research and/or other entities may be permitted to access your records, and there may be times when we are required by law to share your information. It is the investigator's legal obligation to report child abuse, child neglect, elder abuse, harm to self or others or any lifethreatening situation to the appropriate authorities, and; therefore, your confidentiality will not be maintained.

\section{Compensation}

There is no direct compensation; however, the researcher appreciates your participation.

\section{Participation}

Participation in this research study is completely voluntary. You have the right to withdraw at anytime or refuse to participate entirely without jeopardy to your employment or academic standing. If you desire to withdraw, please close your Internet browser before submitting your responses.

\section{Questions about the Research}

If you have questions regarding this study, you may contact Kate Panaccione (principal investigator), at 503-477-0369, or Kpan2@pdx.edu

\section{Questions about your Rights as Research Participants}

If you have questions regarding your rights as a research participant, you may call the PSU Office for Research Integrity at (503) 725-2227 or 1(877) 480-4400. The ORI is the office that supports the PSU Institutional Review Board (IRB). The IRB is a group of people from PSU and the community who provide independent oversight of safety and ethical issues related to research involving human participants. For more information, you may also access the IRB website at https://sites.google.com/a/pdx.edu/research/integrity. 
Appendix E

\section{Consent for Teachers}

\section{Introduction}

You are being asked to participate in a research study that is being done by Kate Panaccione, who is the Principal Investigator from the Department of Education, at Portland State University in Portland, Oregon. This is a study about autism behavior rating scales. As a licensed educator in the state of Oregon, your input is needed to advance the knowledge in this field.

Current autism behavior rating scales use the same behavior descriptors for parents and educators regardless of the setting in which behaviors occur, and they rely on reflective data collection methods. I would like your feedback about the efficacy and feasibility of a behavior rating scale designed specifically for the educational environment that uses real time data collection methods.

\section{Procedures}

You will be shown a brief example of a context-specific autism behavior rating scale for teachers and asked to complete a short survey about the scale. The survey will take approximately 10 minutes or less and will be conducted with an on-line Qualtrics-created survey.

\section{Risks/Discomforts}

Risks are minimal for involvement in this study. However, you may use your time for an endeavor that ultimately may not influence current practice.

\section{Benefits}

There are no direct benefits for participants. However, it is hoped that through your participation, researchers will learn more about the efficacy and feasibility of an autism behavior rating scales for an educational environment.

\section{Confidentiality}

All data obtained from participants will be kept confidential and will only be reported in an aggregate format (by reporting only combined results and never reporting individual ones). All questionnaires will be concealed, and no one other than the primary investigator and Portland State University will have access to them. The data collected will be stored in the HIPPA-compliant, Qualtrics-secure database until the primary investigator has deleted it. The Portland State University Institutional Review Board (IRB) that oversees human subject research and/or other entities may be permitted to 
access your records, and there may be times when we are required by law to share your information. It is the investigator's legal obligation to report child abuse, child neglect, elder abuse, harm to self or others or any life-threatening situation to the appropriate authorities, and; therefore, your confidentiality will not be maintained.

\section{Compensation}

There is no direct compensation; however, the researcher appreciates your participation.

\section{Participation}

Participation in this research study is completely voluntary. You have the right to withdraw at any time or refuse to participate entirely without jeopardy to your employment or academic standing. If you desire to withdraw, please close your Internet browser before submitting your responses.

\section{Questions about the Research}

If you have questions regarding this study, you may contact Kate Panaccione (principal investigator), at 503-477-0369, or Kpan2@pdx.edu

\section{Questions about your Rights as Research Participants}

If you have questions regarding your rights as a research participant, you may call the PSU Office for Research Integrity at (503) 725-2227 or 1(877) 480-4400. The ORI is the office that supports the PSU Institutional Review Board (IRB). The IRB is a group of people from PSU and the community who provide independent oversight of safety and ethical issues related to research involving human participants. For more information, you may also access the IRB website at https://sites.google.com/a/pdx.edu/research/integrity. 
Appendix F

\section{Consent for Parents}

\section{Introduction}

You are being asked to participate in a research study that is being done by Kate Panaccione, who is the Principal Investigator from the Department of Education, at Portland State University in Portland, Oregon. This is a study about autism behavior rating scales. As a parent with a child that either has a diagnosis or a special education identification of autism, your input is needed to advance the knowledge in this field.

Current autism behavior rating scales use the same behavior descriptors for parents and educators regardless of the setting in which behaviors occur, and they rely on reflective data collection methods. I would like your feedback about the efficacy and feasibility of a behavior rating scale designed specifically for the educational environment that uses real time data collection methods.

\section{Procedures}

You will be shown an example of a context-specific autism behavior rating scale for teachers and asked to complete a short questionnaire about the scale. The questionnaire consists of 10 questions and will take approximately 10 minutes or less. This questionnaire will be conducted with an online Qualtrics-created survey.

\section{Risks/Discomforts}

Risks are minimal for involvement in this study. However, you may use your time for an endeavor that ultimately may not influence current practice. Although we do not expect any harm to come upon any participants due to electronic malfunction of the computer, it is possible though extremely rare and uncommon.

\section{Benefits}

There are no direct benefits for participants. However, it is hoped that through your participation, researchers will learn more about the efficacy and feasibility of an autism behavior rating scales for an educational environment.

\section{Confidentiality}

All data obtained from participants will be kept confidential and will only be reported in an aggregate format (by reporting only combined results and never reporting individual ones). All questionnaires will be concealed, and no one other than the primary investigator and Portland State University will have access to them. The data collected will be stored in the HIPPA-compliant, Qualtrics-secure database until the primary investigator has deleted it. The Portland State University Institutional Review Board (IRB) that oversees human subject research and/or other entities may be permitted to access your records, and there may be times when we are required by law to share your information. It is the investigator's legal obligation to report child abuse, child neglect, 
elder abuse, harm to self or others or any life-threatening situation to the appropriate authorities, and; therefore, your confidentiality will not be maintained.

\section{Compensation}

There is no direct compensation; however, the researcher appreciates your participation.

\section{Participation}

Participation in this research study is completely voluntary. You have the right to withdraw at any time or refuse to participate entirely without jeopardy to your employment or academic standing. If you desire to withdraw, please close your internet browser before submitting your responses.

\section{Questions about the Research}

If you have questions regarding this study, you may contact Kate Panaccione (principal investigator), at 503-477-0369, or Kpan2@pdx.edu

\section{Questions about your Rights as Research Participants}

If you have questions regarding your rights as a research participant, you may call the PSU Office for Research Integrity at (503) 725-2227 or 1(877) 480-4400. The ORI is the office that supports the PSU Institutional Review Board (IRB). The IRB is a group of people from PSU and the community who provide independent oversight of safety and ethical issues related to research involving human participants. For more information, you may also access the IRB website at https://sites.google.com/a/pdx.edu/research/integrity. 


\section{Appendix G}

\section{Example Teacher Rating Scale}

The following is a brief example of a context-specific autism behavior rating scale for teachers. The full scale includes 12 Domains describing the hallmark skill deficits of autism spectrum disorder. This brief example is of domains $1,3,6$, and 8 . The scale includes a data collection sheet for present levels of student performance. The materials in this survey cover school age students in kindergarten through transition. For each Domain, please read the descriptions of the various behaviors that are contained in each level. Then, select the one level in the domain that best describes the student's behaviors. If you feel the student's behaviors are between two levels, please mark accordingly. Please describe behaviors that are currently observed in the school setting. 


\section{Domain 1 \\ This domain covers the ways in which the student interacts with others, as well as how important other peers are to him/her.}

\section{○ Level 1.0}

The student looks for friendships, and interactions appear typical compared to peers.

The student participates in classroom and small group activities similar to classmates. S/he understands her/his role and the roles of others during cooperative learning tasks and during unstructured activities.

The student seems to identify with being part of the class and associates with same age peers.

Level 2.0

The student is interested in friendships with classmates and attempts to join peers in unstructured activities. While sometimes successful, the overtures might be slightly unusual or awkward.

The student does not identify peers facial gestures or tone of voice correctly. S/he may appear shy, or overly eager with classmates. The interactions may appear more forced and ridged than typical. Her/his greetings are unusual and s/he may begin speaking as if in the middle of a conversation or ignore conventional conversation endings.

The student may be included in activities by peers, but might be viewed as someone whose behaviors must be tolerated when participating in playtime or group activities. The student may interrupt often in class or question directions that others have no difficulty understanding.

○

Level 2.5 Between 2.0 and 3.0

ㄴ Level 3.0

The student makes attempts at friendships with classmates, but typically s/he isn't successful. S/he may have more success with students who are younger or with communications with adults. There may be one or two children that $\mathrm{s} /$ he is able to connect with, especially if the friend has a similar manner or exceptional understanding, and is accepting and flexible. S/he doesn't talk about getting together with friends after school or participating in after-school activities. If asked, the student may identify classmates as friends; yet not spend time with them other than in structured class activities.

The student may talk at others rather than engage in back and forth conversation. During unstructured times like recess, P.E., or lunch s/he may attempt to direct the actions and conversation of others, resulting in her/him being excluded from the group play.

The student may feel bullied or complain of unfairness. S/he may argue with others when pointing out what s/he feels is an injustice. S/he has difficulty understanding how others perceive the situation. S/he may react in a way that seems excessive for the

situation. At times it may seem as if the student isn't attending to the lesson and may appear bored or disrespectful by closing her/his eyes or seeming to be focused on something else, yet s/he can answer questions related to what is discussed.

Some interventions or classroom accommodations may include breaking assignments down into smaller steps, giving the student a time frame to ask questions, having the student write questions on paper to give to teacher, structuring small group lessons to include defined roles for each student, visual supports for when a student is allowed to comment and when s/he needs to remain quiet, and concrete step by step directives for assignments. 
- Level 4.0

The student doesn't typically interact with others unless required. S/he may have fleeting eye contact and may not direct responses at people, but rather toward the floor or away from her/his conversation partner. Responses are likely to be brief and direct without elaboration.

The student may interact with others during structured activities like working in pairs or answering direct questions in class; however, during unstructured times s/he prefers to be alone. At recess, study hall, or lunch $\mathrm{s} /$ he is likely to be sitting alone not interacting with peers. The student may have an individual activity s/he engage in during unstructured times like looking at a book, playing a video game, or walking alone. If the student initiates interaction it is likely with adults rather than with peers, because adults are more tolerant of the student's communication deficits.

Classmates are likely to view the student as part of the class, but not know a great deal about her/his personal life. Peers may comment that he/she likes to be left alone or that he/she is really shy or a awkward. The student may show signs of anxiety when faced with times that interactions with peers are inevitable (i.e. small group work, locker time, hall passing time, lunch).

The student may not demonstrate a clear understanding of reciprocal conversation and continues talking even when others walk away or have stopped listening. The student may also talk to himself/herself, scripting movie lines or speaking out loud about a topic that interests them.

○

Level 4.5 Between 4.0 and 5.0

\section{○ Level 5.0}

The student typically avoids interaction with others. S/he may demonstrate an awareness of others by sitting next to peers or handing them something, but it is typically done without eye contact. S/he may share enjoyment in a movie or music and laugh when others laugh (even though s/he may not seem to have an understanding of the humor). S/he may initiate brief exchanges, typically to gain access to a desired object or task.

The student may react negatively when pressed to interact with others, demonstrating signs of anxiety or anger. $\mathrm{S} /$ he uses greetings infrequently or only when prompted by others. The student may give high fives or use a routine greeting with certain school staff or preferred peers. Occasionally the student may attempt to hug staff or peers regardless of the social norm to do so or the relationship.

The student may have one or two people that s/he appears more relaxed working with, but s/he does not have friendships that involve common interests. Her/his response to others is more related to who is in close proximity than whom s/he seeks out. S/he may occasionally reach out for physical contact, but it seems to be more for self-soothing than to demonstrate affection.

When the student is given a task s/he may appear to ignore the request or be delayed in response. The student prefers a predictable environment and does not typically enjoy activities outside of the classroom or typical schedule (Ex: assemblies, recess, class parties).

\section{Level 5.5 Between 5.0 and 6.0}

○ Level 6.0

The student does not seek out interaction with others and attempts to avoid interaction when approached. S/he may follow classroom routines such as lining up and independently getting and having lunch. S/he does not seem aware of social conventions and does not initiate greetings or respond to greetings without prompting.

The student requires a high level of supports to function in the school environment. S/he may demonstrate an awareness of new staff or students in close proximity, but does not tend to have preferences. S/he doesn't acknowledge the presence of unfamiliar people when they enter the room. S/he will follow routine directives regardless of who issues them.

If the student were left to her/his own preferences s/he would be likely to engage in self-stimulating behaviors such as video games, watching videos, or categorizing objects rather than seeking the company of others. 
The student does not engage in reciprocal communication other than to get needs met and s/he likely needs prompting to engage with others. S/he may react to repeated bids for attention with anger or dismissal.

○

Level 6.5 Between 6.0 and 7.0

- Level 7.0

The student requires a high level of support in the school setting. The student is completely withdrawn and resistant to social interaction, even to staff and students known to the student. S/he refuses bids for interaction expressing these refusals by, walking away, turning her/his head away from those attempting interaction, or by not reacting in any way (as if s/he can't hear). There may be other forms of refusal.

The student does not engage in activities to share social pleasure. Activities that appear pleasurable to the student are solitary activities. The student may not be able to transition from place to place in the school without assistance. While s/he may demonstrate some pleasure to peer buddies it seems to be the direct attention for a preferred activity rather than the relationship with the peer.

○ Option D - Does Not Apply

The behavioral and mental characteristics that are presented do not accurately match the student.

\begin{tabular}{|l|}
\hline Notes: \\
\hline \\
\hline \\
\hline \\
\hline \\
\hline \\
\hline \\
\hline \\
\hline \\
\hline \\
\hline \\
\hline \\
\hline
\end{tabular}

Domain 3

Types of Interests - this Domain covers the child's interests and activities, her/his scope and the extent to which he/she invites others to participate in them.

○ Level 1.0 Typical Development

The student learns new material in the usual way it is presented to the class as a whole, and at the same rate as her/his peers. S/he enjoys similar experiences and participates in a variety of classroom and free time activities. The student is able to build on prior learning to understand how new concepts relate to those previously learned. The student is able to apply mastered materials in a variety of settings and under new circumstances.

The student seems to take pride and satisfaction in mastering new skills and can share knowledge and instruct others in areas of mastery. The student seems motivated by praise and pride in her/his work.

\section{$\circ \quad$ Level 1.5 Between 1.0 and 2.0}

L Level 2.0

The student has slightly limited areas of interest and s/he frequently redirects conversation to her/his topic of choice. Conversation may be awkward as s/he doesn't read the subtle social cues that demonstrate others are 
losing interest. In unstructured settings s/he may prefer a routine activity (Ex: swings at recess, game during free study time, visiting the library after eating lunch).

The student may have difficulty accepting viewpoints that differ from her/his own, arguing when presented with information that is contrary to her/his beliefs. S/he may interrupt instruction and speak out in class more often than peers. S/he likely feels that $\mathrm{s} /$ he is an expert in areas that interest her/him, regardless of any evidence to the contrary. While the student may be redirected, s/he requires more attention than her/his peers to stay on topic. S/he likely has the ability to cite many facts about some topics but have difficulty understanding how to extend the topics.

The student may seem slightly rigid in her/his behaviors and routines and express dissatisfaction with unexpected changes.

○

Level 2.5 Between 2.0 and 3.0

- Level 3.0

The student has definite interests and may have a great deal of knowledge in specific areas. The interests may change over time and may not seem age appropriate or functional (Ex: gemstones, dates/places, paleontology, electric appliances). The student is typically able to maintain an extended focus for topics s/he has both a special interest and more knowledge than usual. S/he attempts to share her/his knowledge with peers who may listen for a brief time, but quickly lose interest or understanding of the topic. Adults may be more tolerant of the student's interests and allow the student to tell them the "facts" s/he know about the topic.

The student may have difficulty in subjects that require engagement with others, such as P.E. or small group work. S/he may be more successful working individually than with peers. Sometimes the student may find a peer (or peers) who share her/his interest and converse at length about the topic. However, s/he does not engage socially with them outside of the interest area.

The student may be encouraged to produce more work in other subject areas if the interest is somehow incorporated into the assignments. For example, if the student's interest is in film, writing assignments put on filmstrip paper or worked into screenplays is likely to produce more results.

The student requires concrete examples and often asks for clarification, repeatedly questioning the directions of assignments. If $\mathrm{s} / \mathrm{he}$ is unable to finish assignments, $\mathrm{s} /$ he may express feelings of unfairness, ask for concessions, or attempt to bargain how or when the work is completed. S/he is more likely to complete assignments that are related to her/his areas of interest.

Some classroom supports and accommodations may have included pre-warning before changes and transitions, graphic organizers, scheduled times to talk about her/his interests, positive behavior supports with the student's interest area for rewards (i.e., stickers, time on Ipad, books about topics of choice, etc.).

\section{○ Level 3.5 Between 3.0 and 4.0}

\section{○ Level 4.0}

The student has interest in a limited number of topics/activities, choosing these above engagement with peers or others. The topics/activities may be used as an incentive or reward for engagement in other areas. The student may seem perturbed if prompted to share her/his interest with others or if s/he is interrupted when engaged in the activity of choice. The student seems to enjoy the topic/activity in a routine way, using it the same way over and over again rather than expanding knowledge of the topic/activity. The topic may or may not have functional value to the student's self-care skills or independent functioning.

The student may ask questions about time/schedule repeatedly. S/he may respond to timers set for length of engagement in a particular activity, and more easily transition away from preferred activities with set time frames and pre-warning.

The student may need supervision for both structured and unstructured times of the school day. 
○

○
Level 4.5 Between 4.0 and 5.0

Level 5.0

The student has very narrow interests preferring to repeat the same activities over and over rather than explore new things. The interests are typically not functional in themselves, however interests may be incorporated into activities to become more functional. For example, if the student enjoys water play s/he may be taught measuring and cooking/cleaning tasks that involve water. The student requires a high level of supports to master routines and then must be explicitly taught the next steps so that routines become a series of functional events. Generalization must be taught, as the student does not automatically apply learning to new situations or events.

The student may tolerate close proximity to others but will not engage unless prompted to do so or by desire for an item someone else has. S/he may become agitated if $\mathrm{s} /$ he is not allowed access to desired items, $\mathrm{s} / \mathrm{he}$ is seemingly unaware of sharing. Back and forth turn taking happens only during structured activities.

The student may notice changes in surroundings and become upset when things are not found where expected. $\mathrm{S} /$ he may focus on organizing or putting things where $\mathrm{s} /$ he feels they belong. The student may need hand over hand prompting to complete tasks.

O

\section{Level 5.5 Between 5.0 and 6.0}

는 6.0

The student requires constant or almost constant supervision. Left to themselves s/he would likely engage in a limited number of repetitive routines and activities. S/he needs to be directed to tasks and materials to focus attention where it is needed for learning. S/he may require more supports for some activities over others. For example, s/he may need hand over hand supports for written tasks, yet perform alphabetizing or numbering independently.

The student may require extended repetition to master new tasks or skills. Learning goals likely require a high degree of scaffolding and supports. While the student may engage in back and forth activities s/he does so only when prompted. The student does not generalize skills to novel situations or settings

O

\section{Level 6.5 Between 6.0 and 7.0}

O

Level 7.0

The student has very little interaction with others and the world around them. At times s/he may appear to be scripting or "watching a movie" in her/his mind. S/he does not attend to what others around them are engaged in. S/he is likely to engage in behaviors that are not functional. For example, the student may line up objects (toys, utensils, etc.) rather than use them functionally. The student may not respond to her/his name and likely cannot identify personal information (i.e., parents names, address, phone number, etc.) S/he may have unusual body movements that are repeated during times of excitement or anxiety.

O Option D - Does Not Apply

The behavioral and mental characteristics that are presented do not accurately match the student.

\begin{tabular}{|l|}
\hline Notes: \\
\hline \\
\hline \\
\hline \\
\hline \\
\hline \\
\hline \\
\hline \\
\hline \\
\hline
\end{tabular}




\section{Domain 6 \\ Social Use Language/Pragmatic Language - Pragmatic Language describes the style of language and is related to the child's ability and interest in participating in a balanced, back-and-forth conversation. This domain covers the ways in which the child uses speech and language in conversations and social interactions. It also includes the ways in which he/she changes her/his tone, rate of speech, and voice emphasis in his/her spoken language.}

Level 1 Typical Development

The student uses language in a manner similar to her/his peers. S/he uses a similar expression and gestures when speaking. S/he asks questions of her/his conversation partner and read subtle social communication cues that indicate the end of a conversation.

The student uses a different way of speaking when talking to teachers or adults than when talking to peers in unstructured settings. The student uses similar slang, colloquialisms, and figures of speech as her/his peers.

The student seeks relationships with her/his classmates and demonstrates an interest in her/his peers thoughts and feelings. The student faces her/his conversation partner and directs comments toward the person or persons with whom $\mathrm{s} /$ he is speaking.

○

Level 1.5 Between 1.0 and 2.0

○

Level 2.0

The student may use a slightly awkward tone (formal, little professor, immature) when speaking with others. $\mathrm{S} /$ he may have limited facial expression when speaking. The student likely communicates in the same manner regardless of the conversation partner being an adult or another student.

The student has limited use of physical gesture when speaking (pointing, using hands for emphasis). The rate or cadence of speech may be slightly fast or delayed when compared to peers. The student may have some difficulty adjusting the volume of her/his voice to match the setting. S/he may not speak loudly enough to be heard or speak too loudly for the setting.

S/he likely will ask few questions of her/his conversation partner and may respond in ways that seem abrupt. Eye contact may be fleeting or awkward and the student may not always orient herself/himself toward conversation partners.

○

Level 2.5 Between 2.0 and 3.0

○

Level 3.0

The student has impairments when communicating with others. S/he may cite facts and knowledge to others rather than engaging in reciprocal conversation or asking questions of a conversation partner. The student likely uses limited expression in speech. Excitement may present as speaking faster rather than with more emphasis or expression. S/he may stand too close or far away from her/his conversation partner or not orient her/his body toward her/his conversation partner.

S/he lacks an understanding of how to initiate conversation or interactions with other students. S/he may attempt to engage others by physically hitting or pushing and not understand why s/he shouldn't. The student may start speaking as if in the middle of a conversation and continue speaking even if her/his conversation partner has lost interest or walked away. S/he may speak out as if in conversation when no one is attending. Conversation is likely awkward and one sided as the student lacks the necessary skills to demonstrate interest, tolerate different opinions, read non-verbal social cues, and identify social norms.

The student may make remarks out of the blue, without ensuring someone is attending to her/his comments. $\mathrm{S} /$ he likely makes awkward attempts to bring conversation back to a topic of interest to them.

Some classroom supports and interventions may have included instruction in full body listening (i.e., turning body toward conversation partner, focusing on face of partner, etc.). Social scripts for the student to follow for 
initiating conversations, friendship groups and/or peer supports, question prompts for demonstrating interest, and reciprocal play and communication prompts.

O

Level 3.5 Between 3.0 and 4.0

L Level 4.0

The student struggles with reciprocal communication and doesn't display an interest in maintaining conversations with peers. S/he doesn't ask questions of others or elaborate on what others have said. S/he may appear to not care about what others think or have to say, but are only focused on her/his own interests. The student doesn't engage in games or imaginative play with peers. The focus of interaction with peers is limited to areas of intense interest to the student.

The student may seem uncaring; as s/he does not exhibit a desire to build relationships with her/his classmates. $\mathrm{S} /$ he might have attempted to be included in peer activities, but she/he lacks the skills needed to sustain connections.

The student may speak in short phrases and use scripted language as a means to get her/his needs met. S/he may repeat themselves or directly repeat (echo) what others say. The flow of her/his speech is awkward and peers may be reluctant to engage because $\mathrm{s} /$ he has a hard time understanding her/his intent.

Level 4.5 Between 4.0 and 5.0

○ Level 5.0

The student's interaction with peers is limited by the inability to share social norms. S/he doesn't greet others or acknowledge an interest in communicating for reasons beyond getting her/his needs met. S/he may use vocalizations rather than words to express dissatisfaction. The student might make comments without regard for anyone listening. Class participation is limited to answering direct questions that may require repeated prompting for response.

The student doesn't seek out friendships with peers. S/he is more likely to be concerned with routine and familiarity than who is in her/his class or whom s/he spends her/his time with. The student's interactions are likely parallel rather than cooperative in nature.

At times it may appear as if the student is carrying on a conversation with himself/herself. S/he may appear to be watching a movie in her/his head and/or reciting the lines.

○

Level 5.5 Between 5.0 and 6.0

○

Level 6.0

The student doesn't interact with peers except for structured situations that encourage participation. Turn taking is likely part of instruction to encourage cooperation in completing tasks as well as taking turns in conversation. The student has little interest or tolerance in waiting for a turn to speak or participate. The student may be compliant in waiting, but needs to be encouraged to engage.

Without direction the student would likely engage in a preferred activity or sit for extended periods of time with nothing to engage them. S/he does not seek out companionship.

○

Level 6.5 Between 6.0 and 7.0

- Level 7.0

The student doesn't demonstrate any desire to interact with others. S/he may be compliant when prompted; however s/he does not seem to take any satisfaction in being engaged. Her/his affect may present as very low or highly agitated when asked to engage with others.

Interaction needs to be prompted and supervised for it to be sustained. The student does not willing engage with others for purposes other than to get her/his needs met.

\section{O Option D - Does Not Apply}

The behavioral and mental characteristics that are presented do not accurately match the student 


\begin{tabular}{|l|}
\hline Notes: \\
\hline \\
\hline \\
\hline \\
\hline \\
\hline \\
\hline \\
\hline \\
\hline \\
\hline
\end{tabular}

Domain 8

Flexibility and Transitions - This domain covers the child's interest in new experiences - whether the child prefers a wide range of activities or a constant routine. This domain also covers how comfortable the child can transition from one activity to another.

\section{$\circ \quad$ Level 1 Typical Development}

The student is interested in a wide variety of topics and activities. S/he engages in games, and conversations with peers during unstructured times in the school day. The student has groups of peers that s/he typically associate with, but are able to adjust for successful interactions with those outside of her/his peer group. The student enjoys a variety of activities and expresses excitement or anticipation of new events and situations.

The student can work cooperatively with others and is able to assume the role needed to help the group progress toward a common goal. The student can assume expected routines without difficulty (i.e., lining up, sharing hallway space, attending student assemblies).

The student is able to easily apply mastered skills in multiple situations and environments. S/he recognize when peers may be having difficulty and can adjust her/his behaviors to either be of assistance or distance themselves. If there is a substitute teacher or an unexpected event in the school day, the student is able to adjust expectations to meet the situation.

○

\section{Level 1.5 Between 1.0 and 2.0}

\section{Level 2.0}

The student may be one of the last ones ready when transitioning to a new activity. S/he likely maintains intense focus on the task at hand, and may need more than one prompt to switch to a new activity. S/he may be very organized in some areas and in others lack the skills needed to complete tasks.

During unstructured times the student may prefer activities that s/he are easily understood with clear rules and social norms. S/he likely engages in the same activities until peers guide them in another direction. S/he relies on others to make decisions about new routines and changes.

The student may have difficulty with lessons and topics that are not concrete in nature (ex: reading comprehension, problem solving). Once the student finds a solution to particular problem s/he may attempt to apply the same reasoning to other dissimilar problems rather than seeking a novel solution.

○
Level 2.5 Between 2.0 and 3.0

Level 3.0 
The student struggles with transitioning from one activity to the next. S/he likely needs to be prompted multiple times to switch activities. S/he may often ask what is happening next and schedules are important to them. Unexpected changes can be difficult and it takes longer than her/his peers to adjust (ex: schedule changes, fire drills, substitute staff).

During unstructured times s/he may prefer to be alone engaged in solitary activities. If participating in activities with peers $s /$ he may attempt to dictate the rules to others and become upset if s/he feels her/his understanding of the rules have been deviated from. S/he has difficulty accessing solutions to problems and may seek adult guidance in "enforcing" the rules as s/he sees them. Her/his peers may be reluctant to engage in unstructured activities with them because of inflexibility or bossiness.

The student needs to be taught self-calming strategies as s/he has difficulty regulating her/his emotions during times of stress or excitement. The student likely performs better in a structured environment, as opposed to larger unpredictable venues (i.e., gymnasium, cafeteria, assemblies, outdoors).

The student struggles with problem solving in lessons and needs very concise direct instruction. S/he may repeatedly ask questions about assignments and question events that are unlikely to happen. Her/his peers may express distain for classroom interruptions and apparent off topic or irrelevant comments.

When working in small groups the student may attempt to direct the roles of others in the group. S/he may experience conflict when working with others due to inflexibility and limited creativity when faced with difficulty.

Some classroom supports and interventions may have included pre-warning for change and transitions, timers to indicate transitions, visual schedules, instruction of flexible thinking and problem solving skills, adult monitoring for the size and context of a problem, and repeated reassurances for comfort and self-regulation.

○

\section{Level 3.5 Between level 3.0 and 4.0}

- Level 4.0

The student requires routine and predictability to successfully maneuver through the school day. Transitions to new activities require pre-warning and prompting. Unexpected events are difficult for the student and s/he may need added supports and additional processing time to adjust to changes. Without additional supports the student is likely to express distress, dissatisfaction and/or refusal to participate.

The student may not recognize prior learning if it is presented in a different way or context. Generalizing skills must be taught and practiced. Outside of routine events the student may be unable to participate in a way that encourages learning. Change must be introduced slowly and incrementally to be successful.

The student demonstrates definite preferences for certain routines and activities. These activities can be shaped to assist in functional routines and pre-employment activities.

○

\section{Level 4.5 Between 4.0 and 5.0}

- Level 5.0

The student functions best with structured routine and little change. The student is likely to become upset or agitated if there are changes in the routine or environment. The student prefers little variety and may become overwhelmed with too many choices. S/he lacks the ability to problem-solve even the most basic obstacles. Simple directives paired with visual supports are helpful for transitions from one activity to the next.

Learning is most successful with a high level scaffold and predictable steps. The student may gain some independence for routine events, but requires supervision to transition from one routine activity to the next. $\mathrm{S} /$ he needs direct instruction in performing self-care and daily living skills.

The student's leisure time activities are very limited and solitary events. S/he may prefer non-functional routines and repetitive behaviors that may help with regulating emotions. If the routine or behaviors are interrupted, the student may become agitated. S/he likely has difficulty transitioning from a preferred activity to a less preferred activity, and may require incentives and rewards for completing undesired tasks. 
The student has a very limited range of preferred activities. S/he is likely to have a routine way of performing the activity and become upset if interrupted or asked to make a substitution. S/he does not demonstrate a desire to learn new skills or routines and are resistant to change of any kind.

At times s/he may become very resistant to an activity that was previously done without protest. It is usually difficult to determine the motivation behind what $s /$ he chose to engage in and what s/he refuses. Often teachers try many different methods and rewards to encourage learning and trying new things.

Students are not motivated by praise or acceptance so teachers attempt to attach preferred activities new topics. For example, if the preferred activity is looking at a particular book or video, the teacher may use the characters in the book/video in an attempt to introduce math activities.

The student requires pre-warning for all transitions, even routine. Changes may cause regression in learning and the student may require re-teaching previously mastered skills after breaks, vacations, illness, etc. There is likely communication between home and school on a regular basis to assist in the student's regulation. Factors such as poor sleep, or change in home routines are likely reflected in school behaviors and vise versa.

\section{Level 6.5 Between 6.0 and 7.0}

\section{○ Level 7.0}

The student independently engages in a very limited number of activities, which are not in themselves functional for daily living. When the student is redirected to different activities s/he need repeated prompting, supports, and rewards. There is little motivation for learning other than access to preferred activities. The goal of teaching becomes following directives, and expanding functional life skills.

Without constant supervision the student would likely not be able to attend to basic personal care. Learning requires extended periods of repeated small steps with frequent breaks and rewards. The student likely has a limited range of individuals on whom s/he relies for all care and support. Relationships with the student are based on attaining desired activities and meeting basic needs and functions.

○ Option D - Does Not Apply

The behavioral and mental characteristics that are presented do not accurately match the student

\begin{tabular}{|l|}
\hline Notes: \\
\hline \\
\hline \\
\hline \\
\hline \\
\hline \\
\hline \\
\hline \\
\hline
\end{tabular}




\author{
Appendix $\mathrm{H}$ \\ Data Collection Sheet \\ Present Levels of Student Performance
}

\title{
Domain 1
}

Social Relationships - This domain covers the ways in which the child interacts with others, as well as how important other people are to her/him.

$>$ Does the student initiate interaction with peers for a variety of reasons?

Example: Ask a question about a topic of peer's choice? Does s/he participate in activities of other's choosing without argument or bargaining? Does s/he seek out other children during unstructured times of the day (recess, lunch, study)?

Opportunity 1: Setting: Date:

Initiated interaction? Yes No

Please indicate if interaction is with a peer or an adult. Peer Adult Brief description of interaction:

Opportunity 2: Setting: Date: Initiated interaction? Yes No

Please indicate if interaction is with a peer or an adult. Peer Adult Brief description of interaction:

Opportunity 3: Setting: Date: Yes No 
Please indicate if interaction is with a peer or an adult.

Peer Adult

Brief description of interaction:

\section{Domain 3}

Types of Interests - this Domain covers the student's interests and activities, the scope and the extent to which $s / h e$ invites others to participate in them.

$>$ Does the student have specific or unusual interests that occupy thoughts and conversation with others?

Example: Does the student become hyper-focused on her/his preferred topic or area of interest? Does the student have difficulty shifting thoughts and discussion with the pace of the class? Does the student continue conversing without regard of interest from a conversation partner?

Opportunity 1: Setting:

Date:

Did the student interrupt/blurt comment or question? Yes No

Did the student talk longer than expected on topic? Yes No

When conversation changed did the student shift focus?

Yes No

Brief description of interaction:

Opportunity 2: Setting: Date:

Did the student interrupt/blurt comment or question? Yes No

Did the student talk longer than expected on topic? Yes No

When conversation changed did the student shift focus? Yes No

Brief description of interaction: 
Opportunity 3: Setting: Date:

Did the student interrupt/blurt comment or question? Yes No

Did the student talk longer than expected on topic? Yes No

When conversation changed did the student shift focus? Yes No

Brief description of interaction:

Does the student have any routines/preferences beyond typical peers for particular activities, classroom environment, tools for learning, foods eaten at lunch or brought from home, free time activities, etc.

Please describe:

\section{Domains 6/7}

Social Use Language/Pragmatic Language - Nonverbal Communication -These domains cover the ways in which the student uses speech and language in conversations and social interactions. It also includes the ways in which $\mathrm{s} / \mathrm{he}$ changes her/his tone, rate of speech, and voice emphasis in her/his spoken language, eye contact, facial expression, gestures and, personal space when speaking.

$>$ Does the student converse in a similar manner as peers? For example: Does s/he pair gestures with language? Does s/he use expected voice volume for the environment? Does s/he make eye contact when conversing with others? 
Place an $\mathrm{X}$ in the box for each time the student is observed pairing verbal language with gesture. Ex: Shakes head to indicate yes or no, waves and says, "Hello," shrugs shoulders and says, "I don't know. “

Date:
\begin{tabular}{|l|l|l|l|l|l|l|l|l|l|}
\hline & & & & & & & & & \\
\hline
\end{tabular}

Date: $\quad$ Time observation starts: Time observation stops:

\begin{tabular}{|l|l|l|l|l|l|l|l|l|l|}
\hline & & & & & & & & & \\
\hline
\end{tabular}

Date:

Time observation starts:

Time observation stops:

\begin{tabular}{|l|l|l|l|l|l|l|l|l|l|}
\hline & & & & & & & & & \\
\hline
\end{tabular}

Place an $\mathrm{X}$ in the box for each incidence when the student uses an unexpected voice volume (either too loud or too soft for the environment).

Date:

Time observation starts:

Time observation stops:

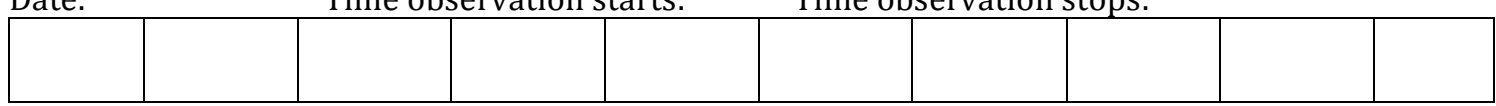

Date:

Time observation starts:

Time observation stops:

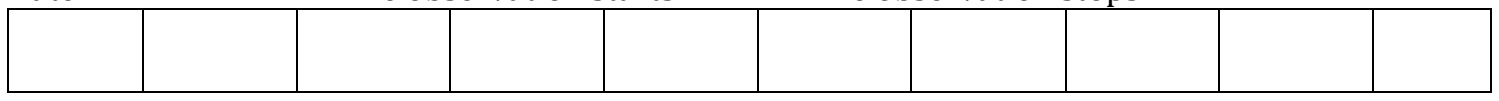

Date:

Time observation starts:

Time observation stops:

\begin{tabular}{|l|l|l|l|l|l|l|l|l|l|}
\hline & & & & & & & & & \\
\hline
\end{tabular}

Place an $\mathrm{X}$ in the box for each time the student is observed raising her/his face toward her/his conversation partner, paired with making eye contact while the partner is speaking (Whole body listening).

Date:

Time observation starts:

Time observation stops:

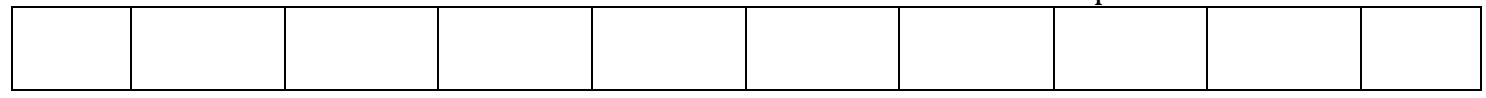

Date:

Time observation starts:

Time observation stops:

\begin{tabular}{|l|l|l|l|l|l|l|l|l|l|}
\hline & & & & & & & & & \\
\hline
\end{tabular}

Date:

Time observation starts:

Time observation stops:

\begin{tabular}{|l|l|l|l|l|l|l|l|l|l|}
\hline & & & & & & & & & \\
\hline
\end{tabular}


Domain 8

Flexibility and Transitions - This domain covers the child's interest in new experiences whether the child prefers a wide range of activities or a constant routine. This domain also covers how comfortable the child can transition from one activity to another.

$>\quad$ Does the student transition from one activity to the next in the same time frame and manner as peers? For example: Does s/he typically take the same amount of time as peers to get prepared for the next activity? Does s/he need additional prompting (verbal or nonverbal) than peers to move to the next activity? Does the student become upset or complain if routines are changed in any way (i.e., schedule, substitute, seating arrangement, etc.)?

Place an $\mathrm{X}$ in the box each time the student is not one of the last three students in the class to transition to the next activity (can be switch in lesson, switch of class, lining up, etc.) Place an 0 in the box each time the student transitions in the same time frame as peers.

Date:

\begin{tabular}{|l|l|l|l|l|l|l|l|l|l|}
\hline & & & & & & & & & \\
\hline
\end{tabular}

Date:

\begin{tabular}{|l|l|l|l|l|l|l|l|l|l|}
\hline & & & & & & & & & \\
\hline
\end{tabular}

Date:

\begin{tabular}{|l|l|l|l|l|l|l|l|l|l|}
\hline & & & & & & & & & \\
\hline
\end{tabular}

Place an $\mathrm{X}$ in the box each time the student requires additional prompting (verbal or nonverbal) to transition to the next activity (can be switch in lesson, switch of class, lining up, etc.) Place an 0 in the box each time the student transitions without requiring additional prompts.

Date:

\begin{tabular}{|l|l|l|l|l|l|l|l|l|l|}
\hline & & & & & & & & & \\
\hline
\end{tabular}

Date:

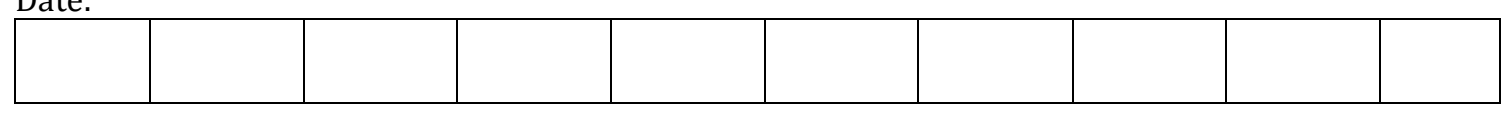

Date:

\begin{tabular}{|l|l|l|l|l|l|l|l|l|l|}
\hline & & & & & & & & & \\
\hline
\end{tabular}


Appendix I

\section{Clinician Survey}

1. How might a context-specific autism behavior rating scale for teachers, with real time data collection methods, be useful for diagnosing autism?

2. Please describe any benefit you could perceive from having real time data from a school setting with same aged peers for diagnosis and differential diagnosis of autism spectrum disorder.

3. How could information collected from a context-specific teacher scale be useful in addition to any evaluations and information you might typically collect as part of the diagnostic process?

4. If a context-specific autism behavior rating scale for teachers were available for use, please indicate the likelihood of your requesting teachers complete such a tool to assist in diagnostic decisions.

\begin{tabular}{|c|c|c|c|c|c|c|c|c|c|c|}
\hline \multicolumn{2}{|c|}{ Not Likely } \\
\hline 0 & 10 & 20 & 30 & 40 & 50 & 60 & 70 & 80 & 90 & 100 \\
\hline & & & & & & & & & & \\
\hline
\end{tabular}

5. Please identify your area of practice. Ex: Pediatrician, Psychologist, etc.

6. In your practice do you diagnose children with autism spectrum disorder?

○ Yes - If Yes, how many children have you diagnosed in the last year?

o No

- In the past but not currently

7. Please identify which autism evaluation tools you are familiar with and would feel comfortable administering. (Check all that apply)

- Childhood Autism Rating Scale - 2 (CARS - 2)

$\circ \quad$ Autism Diagnostic Interview - Revised (ADI-R)

$\circ \quad$ Autism Diagnostic Observation Schedule - 2 (ADOS - 2)

- Gilliam Autism Rating Scale - 2 (GARS - 2)

- Autism Behavior Checklist (ABC)- part of Autism Screening Instrument for Educational Planning - 3 (ASIEP-3) 
O Other

8. How frequently would you say you request educational information to support diagnostic decisions for autism?

$\circ \quad$ Once a year

O Once a month

o Once a week

I I have never requested educational information

9. Please feel free to offer any other thoughts you may have 


\section{Appendix J}

\section{Educator Survey}

1. How do you think that a rating scale designed specifically for a school setting might assist you in understanding the learning needs of children with autism?

2. Please describe any ways a context-specific rating scale for a school setting might help you understand and participate in the Individual Education Planning team?

3. How might the behavior descriptors of a context-specific rating scale serve as a training opportunity for yourself or others about how autism presents in a school environment?

4. Considering data collection can happen over the course of three days (they do not need to be consecutive) and can be completed by teachers, aides, lunch and recess monitors, etc., and a full-length scale might contain 12 behavior descriptors. How feasible would it be to complete this type of scale during the regular school day?

\begin{tabular}{|l|l|l|l|l|l|l|l|l|l|l|}
\hline \multicolumn{2}{|l|}{ Easy } \\
\hline 0 & 10 & 20 & 30 & 40 & 50 & 60 & 70 & 80 & 90 & 100 \\
\hline & & & & & & & & & & \\
\hline
\end{tabular}

5. What grade levels and subjects are you licensed to teach?

6. How many years of teaching experience do you have? Please do not include student teaching.

$0-5$ years

5-10 years

10-15 years

15-20 years

Over 20 years

7. Have you ever had any professional development or continuing education in autism spectrum disorder?

Yes, school based professional development

Yes, coursework at college or university

None 
8. Have you ever been asked to complete an autism behavior rating scale for a student? If so please check all scales you have completed.

Childhood Autism Rating Scale - 2 (CARS - 2)

Gilliam Autism Rating Scale - 2 (GARS - 2)

Autism Behavior Checklist (ABC)- part of Autism Screening Instrument for Educational Planning - 3 (ASIEP-3)

Autism Spectrum Rating Scale - ASRS

10. How often would you say you participate in Individual Education Planning Team meetings (IEP meetings) for students with autism?

Once a year

Once a month

Once a week

I have never participated in an eligibility meeting for a student with autism.

I have completed an autism behavior rating scale, but I'm not sure which one.

I have never completed an autism behavior rating scale for a student.

10. Thank you for your participation. Please feel free to offer any thoughts, comments, or suggestions. 


\section{Appendix K}

\section{Parent Survey}

1. Please describe any ways a context-specific rating scale for a school setting might be helpful for you to understand how your child functions in the school setting?

2. Please describe any ways you might find a context-specific rating scale helpful to understanding your child's Individual Education Plan goals and objectives?

3. Please describe any ways you think behavior descriptors that give your child's current functioning might help you be more informed to participate in the decision making at your child's IEP meeting?

4. Please describe any ways that the process of an autism diagnosis/educational identification of your child could be more understandable for you and other parents.

5. Please indicate how helpful you would find the information contained in a contextspecific teacher rating scale in understanding the educational and learning needs of your child.

\begin{tabular}{|c|c|c|c|c|c|c|c|c|c|c|}
\hline \multicolumn{1}{|c|}{ Not Helpful } \\
\hline 0 & 10 & 20 & 30 & 40 & 50 & 60 & 70 & 80 & 90 & 100 \\
\hline & & & & & & & & & & \\
\hline
\end{tabular}

6. Does your child have a medical diagnosis of Autism Spectrum Disorder?

Yes

No

Diagnosis of Asperger's syndrome

7. Does your child receive special education services under the identification of autism spectrum disorder?

Yes

No

In the past, but not currently

I don't know

8. How old was your child when they were first diagnosed or identified for special education for autism spectrum/ Asperger's disorder?

Birth to 5 years

6 to 12 years 


\section{2 years or}

9. Thank you for your participation. Please feel free to offer any thoughts, comments, or suggestions. 